Research paper

\title{
Antimalarial agents against both sexual and asexual parasites stages: structure-activity relationships and biological studies of the Malaria Box compound 1-[5-(4-bromo-2-chlorophenyl) furan-2-yl]-N-[(piperidin-4-yl)methyl]methanamine (MMV019918) and analogues
}

\author{
Alessandra Vallone ${ }^{\text {a, b, d, } 1}$, Sarah D'Alessandro ${ }^{\text {b, d, e, } 1 \text {, Simone Brogi }}{ }^{\text {a, b, d, }}$

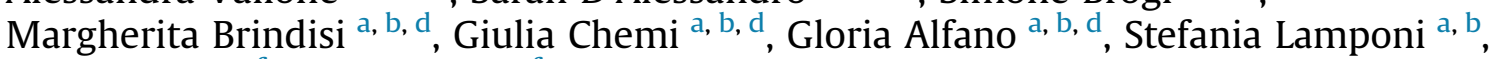 \\ Soon Goo Lee ${ }^{\mathrm{f}}$, Joseph M. Jez ${ }^{\mathrm{f}}$, Karin J.M. Koolen ${ }^{\mathrm{g}}$, Koen J. Dechering ${ }^{\mathrm{g}}$,

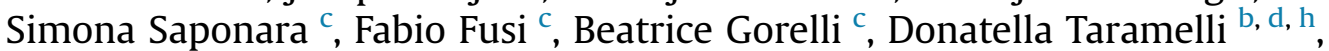 \\ Silvia Parapini b, d, h, Reto Caldelari i , Giuseppe Campiani a, b, d, **, Sandra Gemma a, b, d, *, \\ Stefania Butini ${ }^{\text {a, b, } d}$ \\ ${ }^{a}$ Department of Biotechnology, Chemistry and Pharmacy, Dipartimento di Eccellenza 2018-2022, University of Siena, Via Aldo Moro 2, 53100, Siena, Italy \\ ${ }^{\mathrm{b}}$ European Research Centre for Drug Discovery and Development (NatSynDrugs), University of Siena, Via Aldo Moro 2, 53100, Siena, Italy \\ ${ }^{\mathrm{c}}$ Department of Life Sciences, University of Siena, Via Aldo Moro 2, 53100, Siena, Italy \\ ${ }^{\mathrm{d}}$ Centro Interuniversitario di Ricerche sulla Malaria (CIRM), University of Perugia, Perugia, Italy \\ e Dipartimento di Scienze Biomediche, Chirurgiche e Odontoiatriche, Università di Milano, Via Pascal 36, 20133, Milan, Italy \\ ${ }^{\mathrm{f}}$ Department of Biology, Washington University in St. Louis, St. Louis, MO, 63130, United States \\ ${ }^{g}$ TropIQ Health Sciences, Transistorweg 5-C02, 6534 AT, Nijmegen, The Netherlands \\ h Dipartimento di Scienze Farmacologiche e Biomolecolari, Università di Milano, Via Pascal 36, 20133, Milan, Italy \\ ${ }^{\mathrm{i}}$ Institute of Cell Biology, University of Bern, Baltzerstrasse 4, 3012, Bern, Switzerland
}

\section{A R T I C L E I N F O}

\section{Article history:}

Received 24 July 2017

Received in revised form

6 March 2018

Accepted 8 March 2018

Available online 10 March 2018

\section{Keywords}

Malaria

Gametocytes

Plasmodium falciparum

Inhibition

Structure-activity relationships

\begin{abstract}
A B S T R A C T
Therapies addressing multiple stages of Plasmodium falciparum life cycle are highly desirable for implementing malaria elimination strategies. MMV019918 (1, 1-[5-(4-bromo-2-chlorophenyl)furan-2yl]- $N$-[(piperidin-4-yl)methyl]methanamine) was selected from the MMV Malaria Box for its dual activity against both asexual stages and gametocytes. In-depth structure-activity relationship studies and cytotoxicity evaluation led to the selection of $\mathbf{2 5}$ for further biological investigation. The potential transmission blocking activity of $\mathbf{2 5}$ versus $P$. falciparum was confirmed through the standard membranefeeding assay. Both $\mathbf{1}$ and $\mathbf{2 5}$ significantly prolonged atrioventricular conduction time in Langendorffisolated rat hearts, and showed inhibitory activity of $\mathrm{Ba}^{2+}$ current through $\mathrm{Ca}_{\mathrm{v}} 1.2$ channels. An in silico target-fishing study suggested the enzyme phosphoethanolamine methyltransferase (PfPMT) as a potential target. However, compound activity against PfPMT did not track with the antiplasmodial activity, suggesting the latter activity relies on a different molecular target. Nevertheless, $\mathbf{2 5}$ showed interesting activity against PfPMT, which could be an important starting point for the identification of more potent inhibitors active against both sexual and asexual stages of the parasite.
\end{abstract}

( 2018 Elsevier Masson SAS. All rights reserved.

\footnotetext{
* Corresponding author. Department of Biotechnology, Chemistry and Pharmacy, Siena, Italy

** Corresponding author. Department of Biotechnology, Chemistry and Pharmacy, Siena, Italy.

E-mail addresses: campiani@unisi.it (G. Campiani),gemma@unisi.it (S. Gemma).

1 These authors equally contributed to the present work.
}

\section{Introduction}

Despite recent advances in the field of antimalarial treatment, malaria is still responsible for a high number of infections and related deaths in tropical and sub-tropical regions [1]. The 
antimalarial agenda has currently shifted from malaria control to eradication/elimination strategies. To reach this ambitious goal and to complement appropriate vector-control measures, such as larvicidal compounds and insecticide-treated bed nets, prioritization of new approaches, targeting the transmission stages of Plasmodium falciparum life cycle (i.e. the gametocytes) is necessary [2]. Development of dual acting drugs active against asexual intraerythrocytic parasites, responsible for the clinical symptoms of malaria, and gametocytes, the sexual forms of the parasite responsible for malaria transmission, is a challenging goal but necessary for the implementation of the above-mentioned strategies.

High-throughput screening (HTS) assays have been successfully applied to $P$. falciparum asexual stages for the discovery of novel hits endowed with innovative modes of action [3-14]. Moreover, such approaches have been adapted for the discovery of compounds active as gametocytocidal agents [15-24]. Screening campaigns using these assays allowed a better analysis and characterization of the anti-gametocyte properties of known antimalarials and for the discovery of potential hit compounds useful for the development of transmission-blocking therapies [25]. The implementation of novel methodologies of phenotypic screening for gametocytocidal compounds was recently boosted by the non-profit foundation Medicine for Malaria Venture (MMV), which produced and delivered a collection of 400 commercial compounds divided into 200 druglike and 200 probe-like structures, i.e., the "Open Access Malaria Box" [26]. The structures present in the Malarial Box were selected using results from phenotypic screening of large compound collections against $P$. falciparum $[3,27,28]$. These phenotypic screens identified nearly 20,000 compounds that were active against $P$. falciparum 3D7 and endowed with reasonable toxicity. Selection criteria for compounds included in the Malaria Box were commercial availability, maximization of the structural diversity, and potency.

A cell-based assay with $P$. falciparum gametocytes expressing a potent luciferase and a lactate dehydrogenase (LDH)-based gametocyte assay were used to screen known antimalarial compounds and those of the MMV Malaria Box [23,25,26]. From this initial study, compound MMV019918 (1, Chart 1) [26] demonstrated dual activity against $P$. falciparum asexual and sexual stages with $\mathrm{IC}_{50}<1000 \mathrm{nM}$; an in vitro $\mathrm{IC}_{50}<1000 \mathrm{nM}$ against late stages Plasmodium gametocytes consistently found in different published assays (and also in the structurally related compound $\mathrm{N}$-[(5-(3chloro-4-fluorophenyl)furan-2-yl)methyl]- $N, N^{\prime}$-dimethylpropane1,3-diamine (MMV020505, 2)) [25]; activity on both male and female NF54 gametes; and properties favorable for drug development, including a low molecular weight and a scaffold suitable for optimization of efficacy. Starting from compound $\mathbf{1}$ and combining synthetic and biological efforts, we investigated the structure-

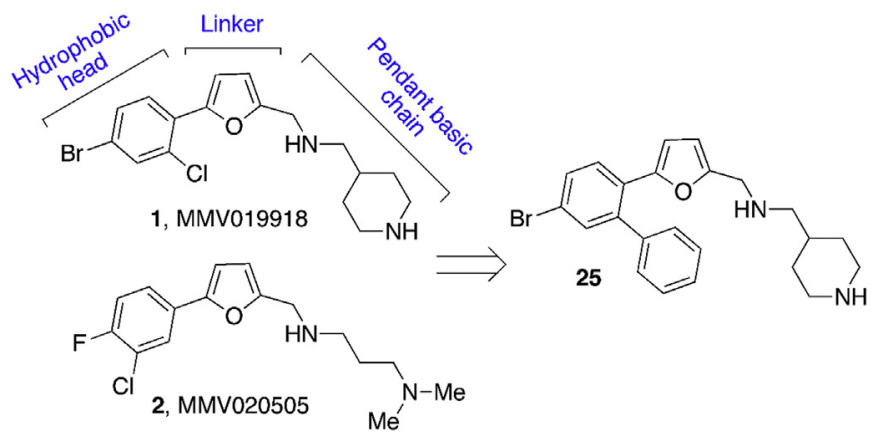

Chart 1. Structure of the reference compounds $\mathbf{1 , 2}$ and of the analogue $\mathbf{2 5 .}$ activity relationships (SAR) of this class of compounds with the aim of understanding the general structural features important for the observed activity. Our goal was also to investigate and possibly improve the toxicity profile of the prepared analogues since the selectivity index (SI) of $\mathbf{1}$ was rather low based on the available information, and a certain degree of $h$ ERG activity (83\% of inhibition at $50 \mu \mathrm{M}$ ) was also known for this compound [25].

The SAR investigation of $\mathbf{1}$ was based on the possibility of disconnecting its scaffold into three modules: a hydrophobic head, a heterocyclic linker, and a pendant basic chain (Chart 1). We introduced different substituents, at the hydrophobic head to explore the role of the two halogen substituents, replaced the central linker with different heterocyclic scaffolds, and replaced the cyclic piperidine moiety with linear lateral chains. Compound 25, showing comparable potency with respect to $\mathbf{1}$, characterized by the presence of and extra aromatic ring at the hydrophobic head and endowed with reasonable $\mathrm{TC}_{50}$, was then selected for further biological studies.

\section{Results and discussion}

\subsection{Chemistry}

We identified a synthetic strategy for the preparation of the hit compound 1 that was also suitable for the preparation of a broad series of analogues bearing different substitution patterns at the phenyl ring.

As displayed in Scheme 1, the first step to the synthesis of $\mathbf{1}$ and analogues 8-12 was a Suzuki-Miyaura coupling between aryliodides 3a-f and the organoboronic acid 4 [29] to afford aldehydes $\mathbf{5 a - f}$. In the case of derivatives $\mathbf{5 a , c , d}$, this palladium-catalyzed cross coupling reaction turned out to be exquisitely regioselective for the formation of reaction products arising from attack at the most reactive iodine with respect to other halides. In the subsequent steps of the synthesis, aldehydes $\mathbf{5 a - f}$ and $\mathbf{6}$ (in turn obtained from $\mathbf{5 f}$ by deprotection) were reacted with the primary amine $\mathbf{7}$ and the resulting imine intermediates were reduced using sodium cyanoborohydride. Final removal of the piperidine protecting group upon exposure to acidic conditions led to the final compounds $\mathbf{1}$ and 8-12.

Amine 7 was prepared starting from $\mathrm{N}$-Boc-piperidone 13, which was subjected to a Wittig reaction using (methoxymethyl) triphenylphosphonium chloride and sodium bis(trimethylsilyl) amide [30] resulting in an intermediate vinylmethyl ether that was hydrolyzed using cerium chloride and sodium iodide [31] to afford aldehyde 14. This latter compound was reduced to the corresponding alcohol, which was converted into methanesulfonate and reacted with sodium azide to furnish $\mathbf{1 5}$. The final catalytic hydrogenation, using palladium on carbon, led to the formation of the desired piperidinyl-methanamine $\mathbf{7}$ in satisfactory yield.

Because of the unavailability of the starting aryliodides, a second set of compounds, modified at the hydrophobic head, was synthesized using a different chemical route (Scheme 2). For the synthesis of aldehydes $\mathbf{5 a}$ and $\mathbf{1 8 b}-\mathbf{e}$, the Meerwein arylation protocol [32], consisting in a copper-catalyzed arylation of furan derivatives with arenediazonium salts, was conveniently used. According to this procedure, anilines 16a-e were converted into the corresponding diazonium salts, and these latter intermediates were coupled in situ with furan-carboxaldehyde 17. Intermediates 5a and 18b were also submitted to a Suzuki coupling to afford the biphenyl derivatives 19a,b, respectively. Aldehydes 5a,18b-e, and 19a,b were finally converted into final compounds $\mathbf{2 1 - 2 6}$ using the protocol previously described for the introduction of the pendant basic chain.

Starting from 16a,b, the Meerwein arylation protocol was also 

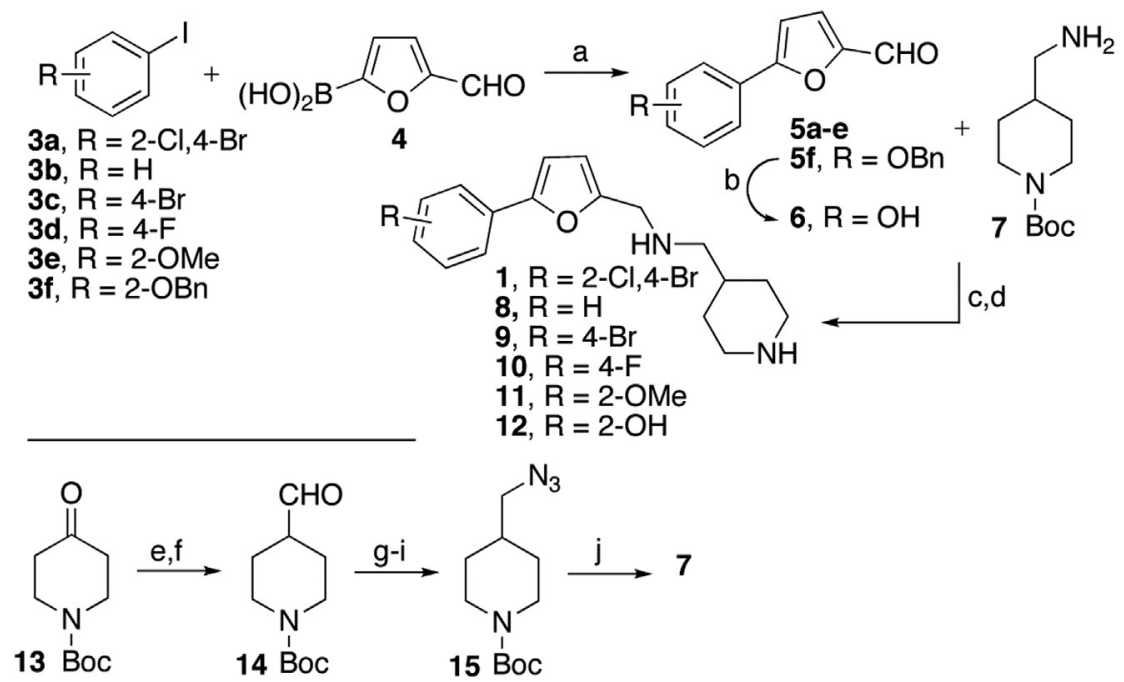

Scheme 1. General synthesis of compounds 1, 8-12. ${ }^{a}$

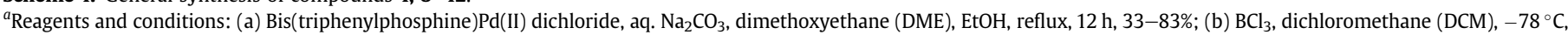

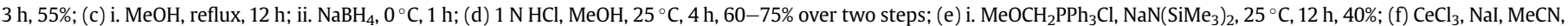

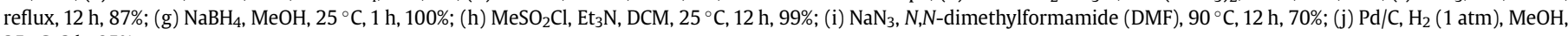
$25^{\circ} \mathrm{C}, 3 \mathrm{~h}, 95 \%$.

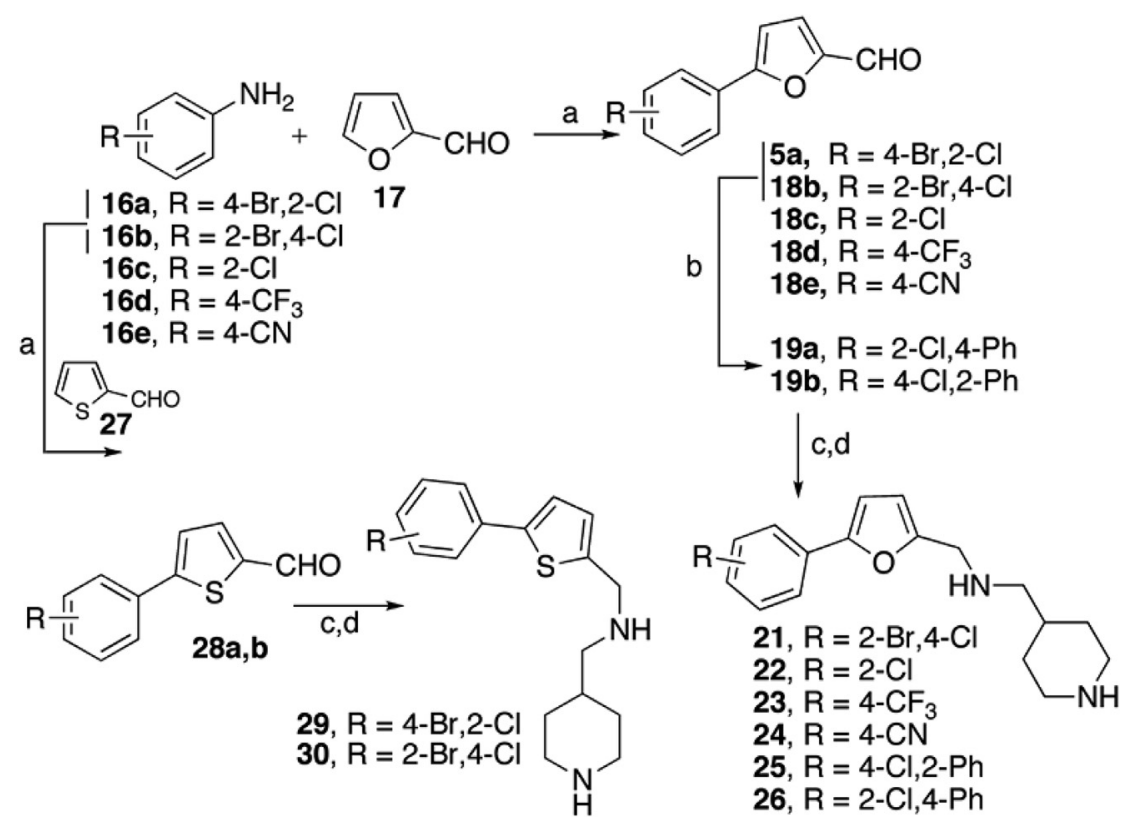

Scheme 2. Synthesis of analogues 21-26 and 29,30. ${ }^{a}$

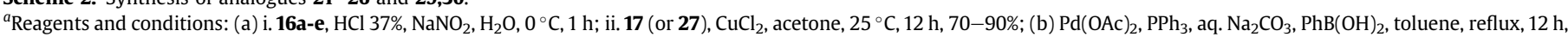
63-85\%; (c) i. 7, $\mathrm{MeOH}$, reflux, $12 \mathrm{~h}$; ii. $\mathrm{NaBH}_{4}, 0^{\circ} \mathrm{C}, 1 \mathrm{~h}$; (d) $1 \mathrm{~N} \mathrm{HCl}, \mathrm{MeOH}, 25^{\circ} \mathrm{C}, 4 \mathrm{~h}, 51-80 \%$ over two steps.

applied to the thiophen-carboxaldehyde $\mathbf{2 7}$ to obtain intermediates 28a,b. These latter compounds were then converted to the final compounds $\mathbf{2 9 , 3 0}$, representing a first set of analogues of the hit compound 1 bearing modification of the heterocyclic linker.

For the synthesis of the benzothiophene derivative $\mathbf{3 2}$ (Scheme 3 ), aldehyde $31[33,34]$ was submitted to the reductive amination reaction, which upon acidic Boc deprotection, led to the preparation of the desired final compound 32. Compounds bearing fivemembered heterocycles $\mathbf{3 7}$ and $\mathbf{3 8}$ were prepared starting from arylhydrazide $\mathbf{3 3}$. Cyclization of $\mathbf{3 3}$ was performed through a Pellizzari-like reaction, consisting in the condensation between acyl hydrazine 33 with benzyl amine [35]. Only the dehalogenated product $\mathbf{3 4}$ was obtained from this reaction. The alcoholic function of 35, introduced by a Prince electrophilic addition using formaldehyde, was activated to the corresponding chloride 36a which was alkylated with amine 7. Oxidative $N$-debenzylation [36] followed by acid-mediated deprotection of the Boc-group furnished the triazole 37. For the synthesis of oxadiazole 38, the chloromethyl intermediate $\mathbf{3 6 b}$ was obtained by cyclization of $\mathbf{3 3}$ in the presence of chloroacetic acid and $\mathrm{POCl}_{3}$ [37].

Another substitution of the central linker is represented by the pyridine derivative $\mathbf{4 3}$ (Scheme 4). A C2 selective Suzuki-Miyaura arylation was applied starting from the commercially available 2bromo-6-methylpyridine 39 and 4-trifluoromethylphenylboronic 
<smiles>O=Cc1cc2ccc(Br)cc2s1</smiles><smiles>[BH3-][13CH3]</smiles>
$\mathrm{Br}$ 32<smiles>[CH]1CCCCC1</smiles><smiles>CC1CCNCC1</smiles><smiles>NNC(=O)c1ccc(Cl)cc1Br</smiles><smiles>CCc1nnc(-c2ccc(Cl)cc2)n1-c1nnc(CO)[nH]1</smiles>
e<smiles>ClCc1nnc(-c2ccc(Cl)cc2Br)o1</smiles>

$36 b$<smiles></smiles>

Scheme 3. Synthesis of central linker analogues $\mathbf{3 2}, \mathbf{3 7}, \mathbf{3 8}{ }^{a}$

${ }^{a}$ Reagents and conditions: (a) i. 7, MeOH, reflux, $12 \mathrm{~h}$; ii. $\mathrm{NaBH}_{4}, 0^{\circ} \mathrm{C}, 1 \mathrm{~h}$; (b) $1 \mathrm{~N} \mathrm{HCl}$ $\mathrm{MeOH}, 25^{\circ} \mathrm{C}, 4 \mathrm{~h}$; (c) $\mathrm{N}, \mathrm{N}$-dimethylformamide dimethyl acetal (DMF-DMA), MeCN, $50{ }^{\circ} \mathrm{C}, 1 \mathrm{~h}$, then $\mathrm{BnNH}_{2}, \mathrm{AcOH}, 120^{\circ} \mathrm{C}, 12 \mathrm{~h}, 60 \%$; (d) aq. $\mathrm{CH}_{2} \mathrm{O}$, reflux, $12 \mathrm{~h}$; (e) pyridine SOCl 2 , DCM, $0{ }^{\circ} \mathrm{C}, 3 \mathrm{~h}, 50 \%$; (f) $\mathrm{POCl}_{3}, \mathrm{ClCH}_{2} \mathrm{CO}_{2} \mathrm{H}$, reflux, $12 \mathrm{~h}, 20 \%$; (g) $7, \mathrm{~K}_{2} \mathrm{CO}_{3}$, $\mathrm{KI}$ (cat.), MeCN, reflux, $1 \mathrm{~h}, 72 \%$; (h) $t \mathrm{BuOK}$, DMSO, THF, $\mathrm{O}_{2}, 25^{\circ} \mathrm{C}, 2 \mathrm{~h}, 87 \%$.<smiles>Cc1cccc(-c2ccc(C(F)(F)F)cc2)n1</smiles>

Scheme 4. Synthesis of pyridine derivative $43 .^{a}$

${ }^{a}$ Reagents and conditions: (a) $\mathrm{Pd}(\mathrm{OAc})_{2}, \mathrm{PPh}_{3}, \mathrm{~K}_{2} \mathrm{CO}_{3}, 7: 3 \mathrm{DMF} / \mathrm{H}_{2} \mathrm{O}$, reflux, $12 \mathrm{~h}, 81 \%$; (b) NBS, AIBN (cat.), $\mathrm{CCl}_{4}$, reflux, $12 \mathrm{~h}, 30 \%$; (c) 7, $\mathrm{K}_{2} \mathrm{CO}_{3}, \mathrm{MeCN}$, reflux, $12 \mathrm{~h}, 20 \%$; (d) $1 \mathrm{~N}$ $\mathrm{HCl}, \mathrm{MeOH}, 25^{\circ} \mathrm{C}, 4 \mathrm{~h}, 98 \%$.

acid 40. The methyl group at $\mathrm{C} 6$ of the pyridine ring was then subjected to a bromination reaction using $N$-bromosuccinimide (NBS) and azobisisobutyronitrile (AIBN). The brominated intermediate $\mathbf{4 2}$ was used to alkylate amine 7. The final Boc deprotection gave in high yield the final derivative $\mathbf{4 3}$.

The open-chain analogue $\mathbf{4 5}$ was synthesized as described in Scheme 5 starting from intermediate $\mathbf{5 a}$ and the commercially available $N, N^{\prime}$-dimethyl-1,3-propanediamine $\mathbf{4 4}$. Starting from $\mathbf{1 8 b}$, reductive amination with $\mathbf{4 4}$ followed by protection of the

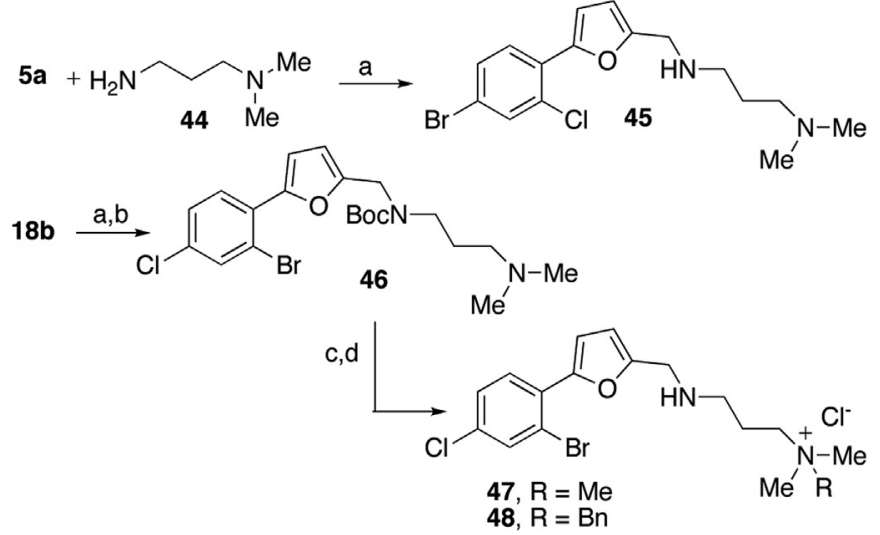

Scheme 5. Synthesis of analogues modified at the protonatable side chain. ${ }^{a}$ ${ }^{a}$ Reagents and conditions: (a) i. $\mathrm{NH}_{2}\left(\mathrm{CH}_{2}\right)_{3} \mathrm{NMe}_{2}, \mathrm{DCM}, 25^{\circ} \mathrm{C}, 1$ h; ii. $\mathrm{NaBH}(\mathrm{OAc})_{3}, 25^{\circ} \mathrm{C}$, $24 \mathrm{~h}, 85 \%$; (b) (Boc) $)_{2} \mathrm{O}, \mathrm{Et}_{3} \mathrm{~N}, \mathrm{MeOH}, 25^{\circ} \mathrm{C}, 4 \mathrm{~h}, 43 \%$ over two steps; (c) MeI (for 47 ) or $\mathrm{BnBr}$ (for 48), acetone, reflux, $72 \mathrm{~h}, 58-60 \%$; (d) $1 \mathrm{~N} \mathrm{HCl}, \mathrm{MeOH}, 25^{\circ} \mathrm{C}, 4 \mathrm{~h}, 94-95 \%$.

secondary amine as Boc-derivative led to intermediate 46. The tertiary amine was subsequently converted to a quaternary ammonium salt using benzyl bromide and iodomethane, respectively. The final Boc-deprotection using acetyl chloride and methanol gave the two final derivatives $\mathbf{4 7}$ and $\mathbf{4 8}$ in satisfactory yields.

\subsection{Antiplasmodial and gametocytocidal activities and structure- activity relationships}

The antiplasmodial activity of the newly synthesized compounds was tested against two laboratory $P$. falciparum strains, the chloroquine-sensitive (CQ-S) D10 and the chloroquine-resistant (CQ-R) W2, according to the described procedures [38,39]. Activity against gametocytes (GCT) was assessed using a luciferase-based assay, as previously described [23].

Selected compounds were also tested against $P$. falciparum strain NF54 asexual blood stage parasites using a Sybrgreen DNA replication assay. NF54 gametocyte assays were performed using reporter strain NF54-HGL [40]. The results of the biological assays are reported in Tables $1-3$.

\subsubsection{Hydrophobic head}

In order to understand if the antiplasmodial and antigametocytocidal activities depended upon the substitution pattern of the aromatic head, we removed one or both alogens of $\mathbf{1}$ (compounds 9, 22 and 8, respectively). Moreover, we inverted the position of the $\mathrm{Cl}$ or $\mathrm{Br}$ substituent obtaining the regioisomeric derivative 21, and introduced different electron-withdrawing groups at the $p$-position such as $-\mathrm{F}(\mathbf{1 0}),-\mathrm{CN}(\mathbf{2 4})$, and $-\mathrm{CF}_{3}$ (23). We also placed electrondonating and $\mathrm{H}$-bond donor/acceptor groups such as -OMe and $-\mathrm{OH}$ ( $\mathbf{1 1}$ and $\mathbf{1 2}$, respectively). A second aromatic ring, giving rise to regioisomers $\mathbf{2 5}$ and $\mathbf{2 6}$ was placed along the halogen present in the original structure in order to explore the tolerance of the system to bulky substituents. From this study we derived interesting SARs: as shown in Table 1, the substituents at the hydrophobic head seems to play a key role for in vitro activity against both asexual and sexual parasite stages. In particular, the presence of both halogens is important for activity since the unsubstituted analogue $\mathbf{8}$, as well as the mono-halogenated derivatives $\mathbf{9 , 1 0}$ and $\mathbf{2 2}$ are less potent antiplasmodial and gametocytocidal agents than the hit compound $\mathbf{1}$. Inversion of chlorine and bromine seems not to have a significant effect on potency as demonstrated by the regioisomeric derivative 21 . 
Table 1

Asexual and sexual stages activity $\left(\mathrm{IC}_{50}, \mu \mathrm{M}\right)$ of compounds modified at the hydrophobic head.

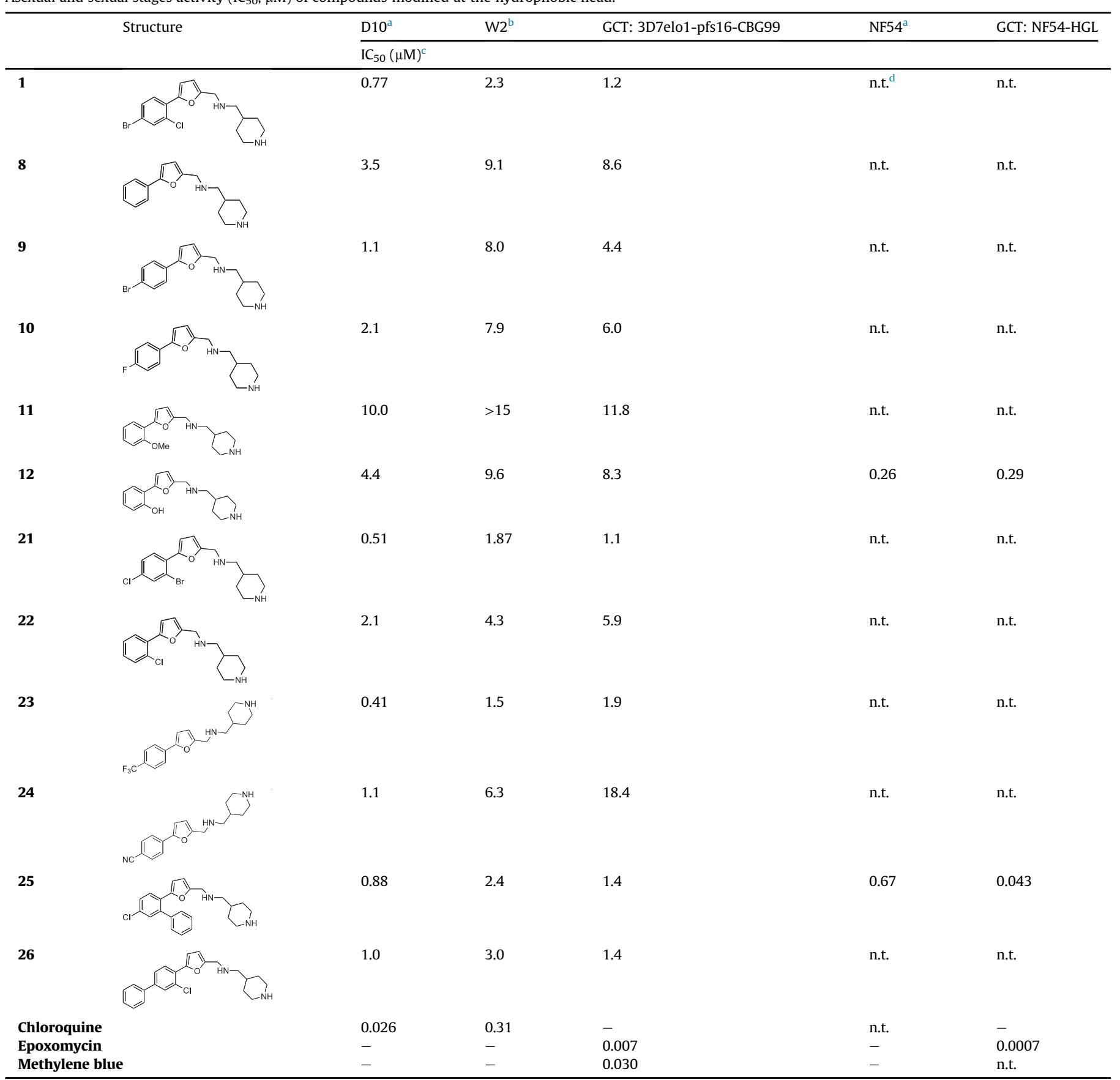

a CQ-S strain.

b CQ-R strain.

${ }^{c} \mathrm{IC}_{50}$ values are the mean of at least three experiments in duplicate; differences in the experimental conditions, parasite strain/stage, and methods of detection may account for the different $\mathrm{IC}_{50}$ observed in the two gametocyte assays. S. D. were within $20 \%$ of the mean.

d n.t. $=$ not tested.

Among the other electron-withdrawing substituents investigated, the trifluoromethyl derivative $\mathbf{2 3}$ maintained a potency similar to $\mathbf{1}$, while with a cyano group at para position (24) a drop of potency was observed, especially against the gametocytes. Also the introduction of electron-donating substituents such as methoxy (11) or hydroxyl (12) groups resulted in a dramatic drop of potency against gametocytes. Interestingly, introduction of an aromatic ring at either $\mathrm{C} 2$ or $\mathrm{C} 4$, as in compounds $\mathbf{2 5}$ and $\mathbf{2 6}$, respectively, was tolerated and antiplasmodial and gametocytocidal activities comparable to the hit compound $\mathbf{1}$ were observed.

\subsubsection{Heterocyclic linker}

The role of the heterocyclic tether on activity was evaluated through the synthesis of several 5-membered heterocyclic systems 
Table 2

Asexual and sexual stages activity $\left(\mathrm{IC}_{50}, \mu \mathrm{M}\right)$ of compounds modified at the heterocyclic linker.

\begin{tabular}{|c|c|c|c|c|c|c|}
\hline & \multirow[t]{2}{*}{ Structure } & $\mathrm{D} 10^{\mathrm{a}}$ & $\mathrm{W} 2^{\mathrm{b}}$ & \multicolumn{2}{|l|}{ 3D7elo1-pfs16-CBG99 } & $\begin{array}{l}\text { GTC } \\
\text { NF54-HGL }\end{array}$ \\
\hline & & \multicolumn{5}{|c|}{$\mathrm{IC}_{50}(\mu \mathrm{M})^{\mathrm{C}}$} \\
\hline 29 & & 0.73 & 2.2 & 0.85 & 0.28 & 0.020 \\
\hline 30 & & 0.53 & 1.4 & 0.83 & 0.42 & 0.028 \\
\hline 32 & & 1.0 & 1.5 & 1.4 & 0.73 & 0.053 \\
\hline 37 & & $>13$ & $>13$ & $>13$ & n.t. $^{d}$ & n.t. \\
\hline 38 & & $>13$ & 7.9 & $>26$ & n.t. & n.t. \\
\hline 43 & & 0.46 & 3.4 & 4.0 & n.t. & n.t. \\
\hline
\end{tabular}

a CQ-S strain.

b CQ-R strain.

${ }^{\mathrm{c}} \mathrm{IC}_{50}$ values are the mean of at least three experiments in duplicate; differences in the experimental conditions, parasite strain/stage, and methods of detection may account for the different $\mathrm{IC}_{50}$ observed in the two gametocyte assays. S.D. were within $20 \%$ of the mean.

d n.t. $=$ not tested.

Table 3

Asexual and sexual stages activity $\left(\mathrm{IC}_{50}, \mu \mathrm{M}\right)$ of compounds modified at basic side chain.

\begin{tabular}{llll} 
3D7elo1-pfs16-CBG99 \\
\cline { 3 - 5 }
\end{tabular}

as isosteric derivatives of the furan ring such as thiophene- $(\mathbf{2 9}, \mathbf{3 0})$, triazole- (37), and oxadiazole- (38) derivatives (Table 2). The pyridine-derivative $\mathbf{4 3}$ was conceived in order to explore the effect on activity of a 6 -membered ring bearing an heteroatom able to function as $\mathrm{H}$-bond acceptor analogously to the furan oxygen, while the fusion of the pendant phenyl ring with the thiophene of $\mathbf{2 9}$ resulted in the benzothiophene-derivative $\mathbf{3 2}$. The sulfur-based heterocycles were tolerated and in some cases led to a slight improvement of activity. Also the six-membered pyridine-derivative (43) showed reasonable potency, especially against the CQ-S strain, while the other heterocycles investigated led to a dramatic drop of potency.

\subsubsection{Pendant basic chain}

Derivative $\mathbf{4 5}$, bearing the same basic chain as $\mathbf{2}$, showed a potency comparable to $\mathbf{1}$ (Table 3 ). The ammonium quaternary salts $\mathbf{4 7}$ and $\mathbf{4 8}$ were synthesized in an attempt to increase potency since quaternary ammonium salt derivatives were previously displayed as interesting antiplasmodial agents [41]. Both compounds displayed a drop of potency against gametocytes. Interestingly, benzyl derivative $\mathbf{4 8}$ maintained its potency against the asexual forms of the parasite, but not against the gametocytes.

For all compounds synthesized, molecular properties calculated in silico by QikProp (version 4.3; Schrödinger, LLC: New York, 2015) such as lipophilicity, polar and solvent accessible surface areas, solubility and membrane permeability were all in the recommended range values for known drugs (Table S1 in the Supplementary Information file).

\subsection{In vitro cytotoxicity}

After investigation of SAR, we selected a representative set of analogues characterized by various degrees of antiplasmodial and gametocytocidal potency for cytotoxicity assays. Cell viability was evaluated in vitro against NIH3T3 after $24 \mathrm{~h}$ of contact, by Neutral Red Uptake (NRU) test. The cell line has been chosen because is a standard fibroblast cell line.

Results of cytotoxicity tests are reported in Table 4. Compounds 11, 23 and 25 resulted the least toxic of the series. The reasonable 
toxicity of compound $\mathbf{2 5}$, combined to the structure of the inhibitor presenting an extra aromatic ring that could be further decorated, prompted us to select this compound for further biological investigation as detailed in the next paragraphs.

\subsection{Standard membrane-feeding assay}

The evaluation of the ability of compounds to inhibit the development of oocysts in the mosquito and thus reduce the mosquito's ability to transmit malaria parasites can be confidently assessed using the standard membrane-feeding assay (SMFA) which remains the assay of choice for this kind of investigation. The assay consists in feeding cultured $P$. falciparum gametocytes to Anopheles mosquitoes in the presence of the test compound and measuring subsequent mosquito infection. The hit compound $\mathbf{1}$ was recently shown to have an $\mathrm{EC}_{50}$ in the SMFA assay of $0.07 \mu \mathrm{M}$ [21]. Evaluation of compound $\mathbf{2 5}$ in the SMFA assay resulted in an $\mathrm{IC}_{50}$ of $0.21 \mu \mathrm{M}$ on infection intensity, and $0.83 \mu \mathrm{M}$ on infection prevalence at a baseline infection intensity of 30 oocysts/midgut (Fig. 1). These data confirm that the gametocytocidal activity of $\mathbf{2 5}$ as observed in the NF54 gametocyte luciferase assay translates into an inability to infect the mosquito vector. The $\mathrm{IC}_{50}$ on infection intensity is slightly higher than expected on basis of the NF54 gametocyte luciferase assay. This may be explained by the difference in incubation time ( $24 \mathrm{~h}$ in the SMFA $v s 72 \mathrm{~h}$ in the gametocyte assay) and a relatively slow mode of action of the compound.

\subsection{Evaluation of activity of compound $\mathbf{2 5}$ against $P$. berghei liver stages}

We also investigated if compound $\mathbf{2 5}$ could have activity against the liver stages of $P$. berghei parasites. Primary mouse hepatocytes have been infected with mCherry expressing $P$. berghei sporozoites. $2 \mathrm{~h}$ post infection (hpi) the cells were exposed to different concentrations of $\mathbf{2 5}$ for 48 hpi with medium change at 24 hpi. Neither parasite numbers (Fig. 2A) nor parasite sizes (Fig. 2B) were significantly influenced at the concentration tested. Compound $\mathbf{2 5}$ was also used to analyze detached cell formation, which is an in vitro assay for final development (equivalent to merosome formation in vivo). Living parasites were counted at $48 \mathrm{~h}$ and from the same wells detached cells at 65 hpi evaluated. Neither concentration tested significantly inhibited detached cell formation, as indicated by the similar rates of detached cells compared to DMSO-treated control cells at $48 \mathrm{~h}$ (Fig. 2C).

\subsection{Evaluation of cardiac toxicity and calcium antagonist activity of 1 and $\mathbf{2 5}$}

Considering the potential $h$ ERG liability previously highlighted for compound $\mathbf{1}$, we decided to evaluate the cardiotoxic potential of both compounds 1 and 25. Accordingly, their effect on cardiac mechanical function and electrocardiogram (ECG) in Langendorffisolated rat hearts was assessed, as previously described [39,42].

Compounds 1 and 25 reduced left ventricular pressure (LVP) in a concentration-dependent manner (Fig. 3), leaving unaltered coronary perfusion pressure (CPP, data not shown). They significantly

Table 4

Cytotoxic activity against 3T3 cell lines of selected compounds evaluated after $24 \mathrm{~h}$ of incubation by NRU test.

\begin{tabular}{llllllllll}
\hline $\mathrm{Cpd}$ & $\mathbf{1 1}$ & $\mathbf{1 2}$ & $\mathbf{2 1}$ & $\mathbf{2 3}$ & $\mathbf{2 5}$ & $\mathbf{2 6}$ & $\mathbf{2 9}$ & $\mathbf{3 0}$ & $\mathbf{4 5}$ \\
\hline $\mathrm{TC}_{50}(\mu \mathrm{M})^{\mathrm{a}}$ & 53 & 7 & $<5$ & 50 & 20 & 5 & $<5$ & $<5$ & 5
\end{tabular}

${ }^{\text {a }}$ Data are expressed as mean of three experiments repeated in six replicate. $\mathrm{S}$. D.are within $5 \%$ of the mean. prolonged atrioventricular conduction time (PQ) and intraventricular conduction time (QRS) in ECG at the maximum concentration tested $(10 \mu \mathrm{M}$; Table 5$)$. However, QTc values did not vary over the drug range tested (Table 5). Compound 1 significantly decreased heart rate (HR), increased cycle length (RR) interval (Table 5) and caused a sinus arrhythmia in 3 out of 4 hearts.

Since channel blockers, by inhibiting the $\mathrm{Ca}_{\mathrm{v}} 1.2$ channel currents, may prolong conduction and refractoriness in the atrioventricular node [43], the increased PQ interval obtained in presence of both compounds prompted us to investigate the effects of $\mathbf{1}$ and $\mathbf{2 5}$ on $\mathrm{Ca}_{\mathrm{v}} 1.2$ channel currents. Compound $\mathbf{1}$ inhibited $\mathrm{I}_{\mathrm{Ba} 1.2}\left(\mathrm{Ba}^{2+}\right.$ current through $\mathrm{Ca}_{\mathrm{v}} 1.2$ channels), measured at $0 \mathrm{mV}$ from a holding potential $\left(\mathrm{V}_{\mathrm{h}}\right)$ of $-50 \mathrm{mV}$, in a concentration-dependent manner (Fig. 4). At $10 \mu \mathrm{M}$ concentration, inhibition amounted to $57 \%$. Compound 25 blocked the current at $30 \mu \mathrm{M}$ concentration and showed an $\mathrm{IC}_{50}$ value of $3.3 \pm 0.5 \mu \mathrm{M}(\mathrm{n}=5)$.

\subsection{In silico approach for target identification of compounds $\mathbf{1}$ and} 25

Despite recent advances in the field, target identification remains a challenging task that could be approached through several methodologies such as direct biochemical methods, genetic interactions, computational approaches, or a combination of methods. We performed a preliminary computational investigation aimed at identifying a potential target of compounds $\mathbf{1}$ and $\mathbf{2 5}$ from structures in the Protein Data Bank (PDB). As a part of a broad investigation aimed at repurposing FDA-approved drugs against malaria, we prepared all the $P$. falciparum X-ray crystal structures present in PDB at May 2016, to be used in a high-throughput docking (HTD) procedure for identifying potential antimalarial drug-targets targeted by known drugs. Employing a reverse-docking procedure (also known as reverse virtual screening or target fishing) [44], we retrieved from the PDB database (and prepared by Protein Preparation Wizard as previously reported [42,45]) all enzymes and proteins relevant for the plasmodium biology, some of which are established drug targets. Compounds $\mathbf{1}$ and $\mathbf{2 5}$ were then used to "fish" for potential targets by using Glide software [46-48]. The results of our in silico study for these compounds indicated a very limited number of potential targets with low docking scores among the examined docking complexes. Surprisingly, for one protein ( $P$. falciparum phosphoethanolamine methyltransferase; PfPMT) we observed for both compounds significant docking scores and calculated ligand-binding energies, as found by Glide and Prime (see Experimental part for further details) [46,49-51]. In fact, for $\mathbf{1}$ and $\mathbf{2 5}$ we found computational scores (1, Glide XP score $=-10.52 \mathrm{kcal} / \mathrm{mol}, \Delta \mathrm{G}_{\text {bind }}=-57.38 \mathrm{kcal} / \mathrm{mol} ; 25$, Glide XP score $=-11.28 \mathrm{kcal} / \mathrm{mol}, \Delta \mathrm{G}_{\text {bind }}=-67.54 \mathrm{kcal} / \mathrm{mol}$ ) comparable to those found for sinefungin (Glide XP score $=-13.16 \mathrm{kcal} / \mathrm{mol}$, $\Delta \mathrm{G}_{\text {bind }}=-84.77 \mathrm{kcal} / \mathrm{mol}$ ) and $S$-adenosylmethionine (SAM) (Glide $\mathrm{XP}$ score $\left.=-10.57 \mathrm{kcal} / \mathrm{mol}, \Delta \mathrm{G}_{\mathrm{bind}}=-82.42 \mathrm{kcal} / \mathrm{mol}\right)$, especially for the docking scores. The most relevant differences were related to the $\Delta G_{\text {bind }}$, for which we observed less negative values of $\mathbf{1}$ and $\mathbf{2 5}$ with respect to the reference ligands. So, given the satisfactory in silico scores, we decided to test them against PfPMT along with two related derivatives $\mathbf{2 4}$ and $\mathbf{4 8}$.

\subsubsection{Evaluation of 1, 25 and analogues as inhibitors of PfPMT}

Compounds 1, 24, 25 and $\mathbf{4 8}$ were tested as potential inhibitors of PfPMT using a radiochemical assay performed with purified recombinant protein, which was expressed and purified as previously reported (Fig. 5A) [52,53]. Compounds $\mathbf{1 , 2 4}$, and $\mathbf{4 8}$ showed weak activity against PfPMT, while compound $\mathbf{2 5}$ displayed an inhibitory effect against PfPMT with an $\mathrm{IC}_{50}=44.3 \pm 5.4 \mu \mathrm{M}$ (Fig. 5B). The experimental data is in good agreement with the computational 
A

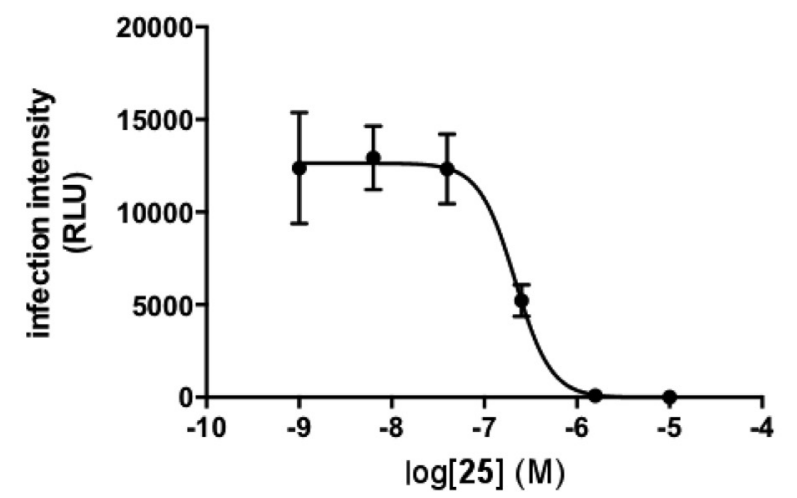

B

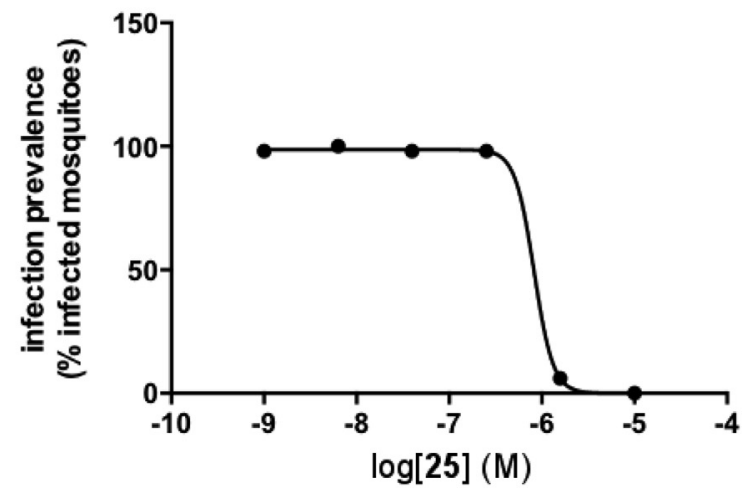

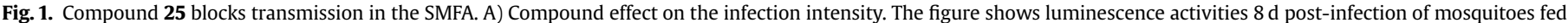

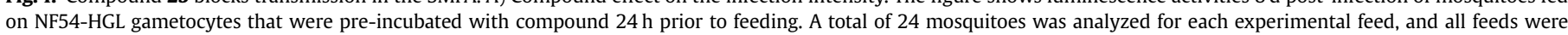

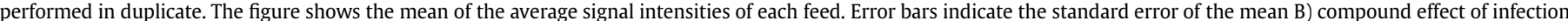

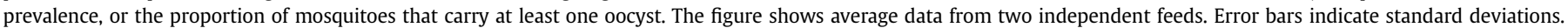
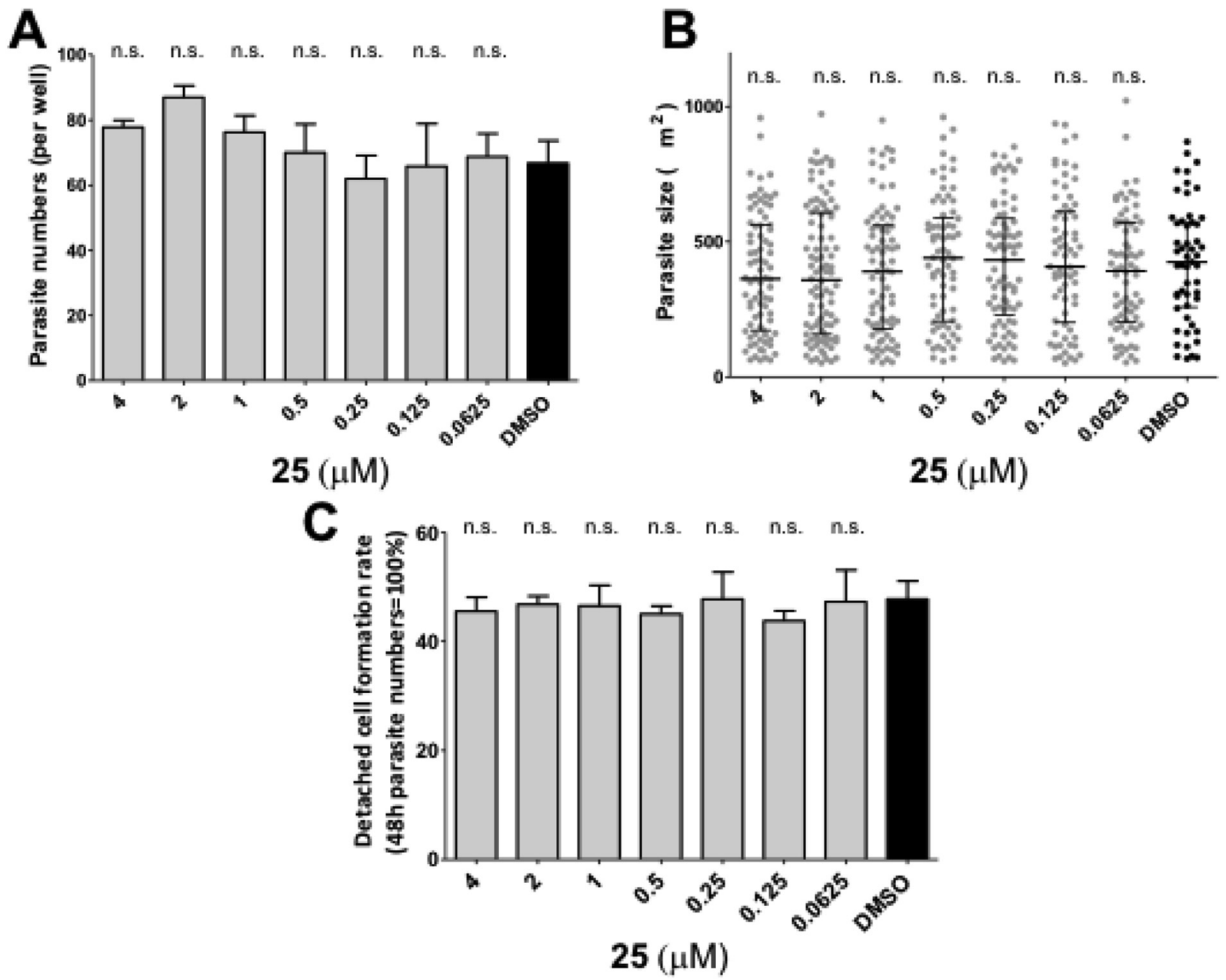

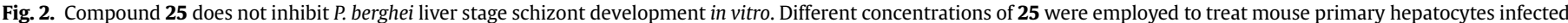

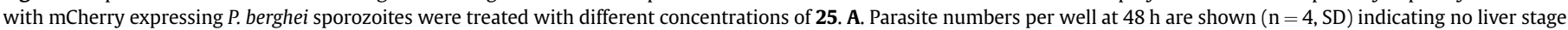

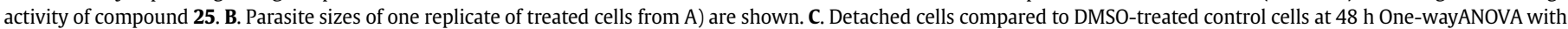
Dunnet's Multiple Comparisons $\left({ }^{*} \mathrm{p} \leq 0.05,{ }^{* *} \mathrm{p} \leq 0.01{ }^{* * *} \mathrm{p} \leq 0.001\right.$, ns/not significant $>0.05$ ) showed no significant difference compared to the control treated cultures.

output. This latter indicates compound $\mathbf{2 5}$ as the best performing compound among the tested molecules, although with slight reduced activity with respect to the reference compounds [53].
Considering that at the moment only few PfPMT inhibitors have been described, mainly related to the natural substrate SAM, compound $\mathbf{2 5}$ could be used as a starting point to develop PfPMT 


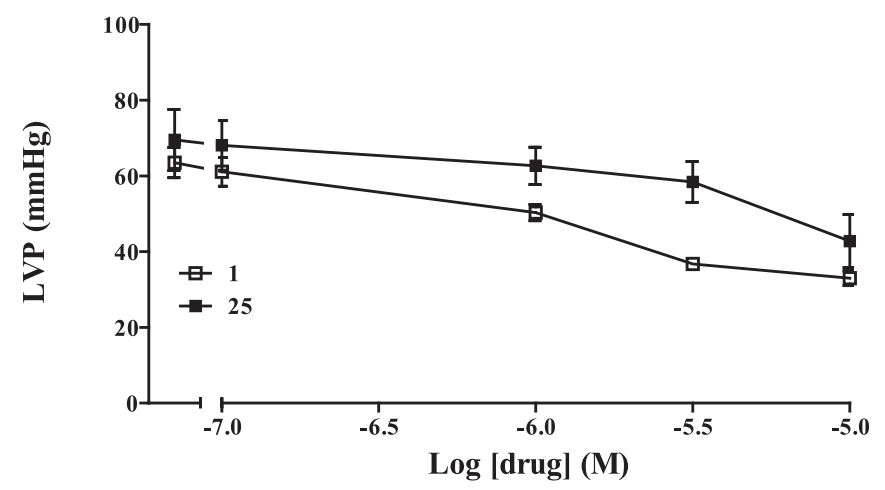

Fig. 3. Effects of $\mathbf{1}$ and $\mathbf{2 5}$ on left ventricular pressure in Langendorff perfused rat hearts. Concentration-effect relationship of $\mathbf{1}$ and $\mathbf{2 5}$ on LVP. On the ordinate scale, response is reported as $\mathrm{mmHg}$. Each value represents mean \pm SEM ( $n=4$ hearts).

inhibitors as potential antimalarials. Fig. 6 depicts the docking output found by Glide software of $\mathbf{2 5}$ into the PfPMT active site. In particular, the amino-groups of the compound may form hydrogen bonds with D85 and R127 with the biaryl system fitting into in a hydrophobic sub-pocket and the furan group stacking with H132. Notably, these interactions are part of the main contacts found for the above-mentioned reference compounds [53].

Despite the interesting findings, the inhibition of PfPMT experimentally observed did not correlated with the antiplasmodial and gametocytocidal activity of the compound and from these data we can rule out PfPMT as the target (or at least the main target) of this series of compounds. Our results are in line with a study recently published [25] in which PfPMT has been excluded as the target of 1 in an indirect yeast-mediated assay.

\section{Conclusions}

Here we described a detailed SAR analysis of hit compound $\mathbf{1}$ and its analogue $\mathbf{2 5}$ for their activity against asexual and sexual life cycle stages of $P$. falciparum. From our SAR studies, the electron withdrawing substituents at the hydrophobic head were identified as important for activity. Moreover, the presence of nitrogen-based heterocyclic linkers resulted detrimental for activity being the thiophene and the furan rings the best performing linkers. A small set of side-chain analogues was explored highlighting that the open-chain analogue retained antiplasmodial potency, while it was interesting to note that among the two quaternary ammonium salts prepared, the benzyl-derivate was active against the asexual life cycle stage. Among the set of compounds synthesized, analogue $\mathbf{2 5}$ was selected for a more in depth biological investigation, due to its antiplasmodial potency in the low micromolar range, reasonable cytotoxicity and the presence of an extra aromatic ring that could offer a handle for further scaffold decoration. In particular, compound 25 was active in the SMFA assay with potency comparable to 1. On the other hand, $\mathbf{2 5}$ did not show activity against $P$. berghei hepatocytic life-cycle stage at the concentration tested, even though this could be a species specific effect. Unfortunately, cardiac toxicity was observed for both $\mathbf{1}$ and $\mathbf{2 5}$. Even though the biological activity of $\mathbf{1}$ and $\mathbf{2 5}$ against gametocytes and asexuals P. falciparum stages remains interesting and worth of further investigation, exploitation of this scaffold will only be possible by identifying its target at the molecular level. This is a necessary pre-requisite for investigating if dissociation of in vitro toxicity from the specific gametocytocidal and schizontocidal activities is a feasible task. Accordingly, we reported herein our preliminary in silico study devoted at identifying the target for this series of compounds.
Driven from this study we subsequently found that analogue $\mathbf{2 5}$ has an interesting in vitro inhibitory activity against PfPMT, a key enzyme for phospholipid biosynthesis in P. falciparum [54]. Compound 25 could serve as a starting molecule, for the structurebased design of novel inhibitors as potential antiplasmodial and transmission-blocking agents.

\section{Experimental section}

\subsection{Chemistry}

Starting materials and solvents were purchased from commercial suppliers and used without further purification. Reaction progress was monitored by TLC using silica gel 60 F254 $(0.040-0.063 \mathrm{~mm})$ with detection by UV. Silica gel 60 (0.040-0.063 mm) was used for column chromatography ${ }^{1} \mathrm{H}$ NMR and ${ }^{13} \mathrm{C}$ NMR spectra were recorded on a Varian $300 \mathrm{MHz}$, or a Bruker $400 \mathrm{MHz}$ spectrometer using the residual signal of the deuterated solvent as internal standard. Splitting patterns are described as singlet $(\mathrm{s})$, doublet $(\mathrm{d})$, triplet $(\mathrm{t})$, quartet $(\mathrm{q})$, and broad (br); the value of chemical shifts $(\delta)$ are given in ppm and coupling constants $(J)$ in Hertz $(\mathrm{Hz})$. Mass spectra were recorded utilizing electron spray ionization (ESI) Agilent 1100 Series LC/MSD spectrometer. Melting points were determined using a Büchi Melting point B-540. Yields refer to purified products and are not optimized. All moisture-sensitive reactions were performed under argon atmosphere using oven-dried glassware and anhydrous solvents. All compounds that were tested in the biological assays were analyzed by combustion analysis ( $\mathrm{CHN}$ ) to confirm the purity $>95 \%$.

\subsubsection{5-(4-Bromo-2-chlorophenyl)furan-2-carbaldehyde (5a)}

Method A: To a solution of 3a $(150 \mathrm{mg}, 0.47 \mathrm{mmol})$ in a mixture of dry DME ( $3 \mathrm{~mL}$ ) and dry EtOH ( $3 \mathrm{~mL}$ ), bis(triphenylphosphine) palladium (II) dichloride (17 mg, $0.02 \mathrm{mmol}$ ) was added. After $30 \mathrm{~min}$, a solution of sodium carbonate ( $299 \mathrm{mg}, 2.82 \mathrm{mmol}$ ) in $\mathrm{H}_{2} \mathrm{O}$ $(2 \mathrm{~mL})$ and a solution of 5-formyl-2-furanylboronic acid $4(93 \mathrm{mg}$, $0.66 \mathrm{mmol})$ in dry EtOH $(1.5 \mathrm{~mL})$ were added in this order. The reaction was heated under reflux for $12 \mathrm{~h}$. After this time, $\mathrm{H}_{2} \mathrm{O}(4 \mathrm{~mL})$ was added at $25^{\circ} \mathrm{C}$ and the organic phase was extracted with EtOAc $(3 \times 5 \mathrm{~mL})$, dried over sodium sulfate, filtered and evaporated in vacuo. The crude product was purified by flash chromatography on silica gel (2\% EtOAc in petroleum ether) to give $\mathbf{5 a}$ as orange solid (79 mg, 60\%). Method B: To a suspension of 16a (1.0 g, $4.8 \mathrm{mmol})$ in $\mathrm{H}_{2} \mathrm{O}(20 \mathrm{~mL}), \mathrm{HCl}(37 \%, 2 \mathrm{~mL})$ was added. The resulting solution was cooled at $0{ }^{\circ} \mathrm{C}$ and a solution of sodium nitrite $(397 \mathrm{mg}, 5.76 \mathrm{mmol})$ in $\mathrm{H}_{2} \mathrm{O}(2 \mathrm{~mL})$ was added dropwise. After $1 \mathrm{~h}$, a solution of 17 ( $400 \mu \mathrm{L}, 4.8 \mathrm{mmol}$ ) in acetone ( $2 \mathrm{~mL}$ ) and solid copper (II) chloride $(128 \mathrm{mg}, 0.96 \mathrm{mmol})$ were added. The mixture kept at $25^{\circ} \mathrm{C}$ for $12 \mathrm{~h}$. EtOAc was added $(3 \times 10 \mathrm{~mL})$ and the organic phase was separated, dried over sodium sulfate, filtered and evaporated in vacuo. The crude product was purified by flash chromatography on silica gel (2\% EtOAc in petroleum ether) to give $\mathbf{5 a}$ as orange solid (1.23 g, 90\%). mp (EtOAc/n-hexane) $141-144{ }^{\circ} \mathrm{C} ;{ }^{1} \mathrm{H}$ NMR $(300 \mathrm{MHz}$, $\left.\mathrm{CDCl}_{3}\right) \delta 9.69(\mathrm{~s}, 1 \mathrm{H}), 7.88(\mathrm{~d}, J=8.6 \mathrm{~Hz}, 1 \mathrm{H}), 7.65(\mathrm{~s}, 1 \mathrm{H}), 7.50(\mathrm{~d}$ $J=8.6 \mathrm{~Hz}, 1 \mathrm{H}), 7.33(\mathrm{~d}, J=3.8 \mathrm{~Hz}, 1 \mathrm{H}), 7.30(\mathrm{~d}, J=3.8 \mathrm{~Hz}, 1 \mathrm{H}) ;{ }^{13} \mathrm{C}$ $\operatorname{NMR}\left(75 \mathrm{MHz}, \mathrm{CDCl}_{3}\right) \delta 177.6,154.6,151.8,133.7,132.4,130.7,130.2$, 126.8, 123.6, 123.0, 113.6. MS (ESI) $m / z 308[\mathrm{M}+\mathrm{Na}]^{+}$.

\subsubsection{5-Phenylfuran-2-carbaldehyde (5b)}

Starting from 3b (100 mg, $0.49 \mathrm{mmol}$ ) and 4 (96 mg, $0.68 \mathrm{mmol}$ ), the title compound was prepared following the procedure described for the synthesis of compound 5a (Method A). The crude product was purified by flash chromatography on silica gel (5\% EtOAc in petroleum ether) to give $\mathbf{5 b}$ as a yellow oil $(70 \mathrm{mg}, 83 \%) .{ }^{1} \mathrm{H}$ 
Table 5

Effects of $\mathbf{1}$ and $\mathbf{2 5}$ on HR, RR, PQ QRS and QTc in Langendorff perfused rat hearts. ${ }^{\text {a }}$

\begin{tabular}{|c|c|c|c|c|c|c|}
\hline Cpd & $(\mu \mathrm{M})$ & HR (BPM) & $\mathrm{RR}(\mathrm{ms})$ & $\mathrm{PQ}(\mathrm{ms})$ & $\mathrm{QRS}(\mathrm{ms})$ & QTc (ms) \\
\hline 1 & None & $247.05 \pm 6.87$ & $242.23 \pm 5.93$ & $42.63 \pm 2.08$ & $14.35 \pm 0.47$ & $80.07 \pm 1.94$ \\
\hline 25 & & $275.90 \pm 5.43$ & $217.15 \pm 3.38$ & $41.13 \pm 1.64$ & $13.31 \pm 0.62$ & $76.45 \pm 1.15$ \\
\hline 1 & 0.1 & $256.15 \pm 7.19$ & $235.08 \pm 7.41$ & $42.29 \pm 2.30$ & $14.25 \pm 0.48$ & $81.51 \pm 1.95$ \\
\hline 25 & & $276.19 \pm 5.33$ & $218.32 \pm 4.37$ & $41.24 \pm 1.65$ & $14.20 \pm 0.61$ & $74.92 \pm 1.01$ \\
\hline 1 & 1 & $258.35 \pm 6.79$ & $232.48 \pm 6.38$ & $42.50 \pm 2.19$ & $15.80 \pm 0.39$ & $80.93 \pm 1.56$ \\
\hline 25 & & $275.47 \pm 4.14$ & $217.02 \pm 3.57$ & $41.59 \pm 1.60$ & $13.70 \pm 0.43$ & $77.21 \pm 2.25$ \\
\hline 1 & 3 & $257.71 \pm 7.88$ & $233.90 \pm 7.19$ & $47.90 \pm 2.95$ & $17.46 \pm 1.15$ & $82.10 \pm 2.16$ \\
\hline 25 & & $276.40 \pm 3.59$ & $216.73 \pm 2.48$ & $45.47 \pm 2.58$ & $14.65 \pm 0.91$ & $78.56 \pm 3.86$ \\
\hline 1 & 10 & $222.74 \pm 14.1^{*}$ & $272.57 \pm 17.8^{*}$ & $67.50 \pm 1.85^{* *}$ & $23.75 \pm 2.84^{* *}$ & $80.99 \pm 3.78$ \\
\hline 25 & & $259.41 \pm 6.79$ & $232.20 \pm 5.83$ & $65.08 \pm 10.15^{* *}$ & $17.91 \pm 1.33^{* *}$ & $83.77 \pm 4.58$ \\
\hline
\end{tabular}

a HR (frequency), RR (cycle length), PQ (atrio-ventricular conduction time), QRS (intraventricular conduction time), QTc (corrected overall action potential duration).

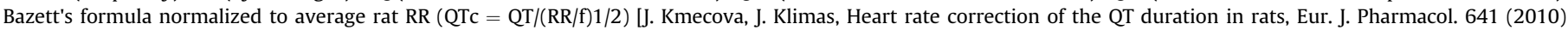
187-192] was used to correct QT. Each value represents mean \pm SEM ( $\mathrm{n}=4$ hearts). ${ }^{*} \mathrm{P}<0.05$, ${ }^{* *} \mathrm{P}<0.01$, repeated measures ANOVA and Dunnett's post test.

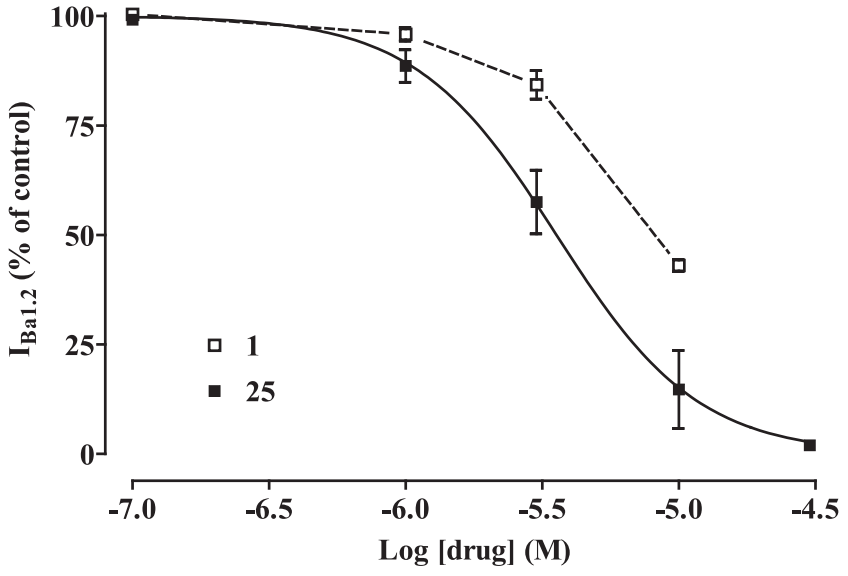

Fig. 4. Effect of compounds $\mathbf{1}$ and $\mathbf{2 5}$ on $\mathrm{I}_{\mathrm{Ba} 1.2}$ in single rat tail artery myocytes. Concentration-dependent effect of $\mathbf{1}$ and $\mathbf{2 5}$ at the peak of $\mathrm{I}_{\mathrm{Ba} 1.2}$ trace. On the ordinate scale, response is reported as percentage of control. Data points are mean \pm SEM $(\mathrm{n}=3-6$ cells, isolated from at least 3 animals).

$\operatorname{NMR}\left(400 \mathrm{MHz}, \mathrm{CDCl}_{3}\right) \delta 9.61(\mathrm{~s}, 1 \mathrm{H}), 7.78(\mathrm{~d}, J=7.6 \mathrm{~Hz}, 2 \mathrm{H}), 7.38$ (ddd, $J=14.4,7.9,4.3 \mathrm{~Hz}, 3 \mathrm{H}), 7.28(\mathrm{~d}, J=2.4 \mathrm{~Hz}, 1 \mathrm{H}), 6.80$ (d, $J=2.4 \mathrm{~Hz}, 1 \mathrm{H}) ; \mathrm{MS}(\mathrm{ESI}) \mathrm{m} / z 173[\mathrm{M}+\mathrm{H}]^{+}, 195[\mathrm{M}+\mathrm{Na}]^{+}$.

\subsubsection{5-(4-Bromophenyl)furan-2-carbaldehyde (5c)}

Starting from $3 c(100 \mathrm{mg}, 0.35 \mathrm{mmol})$ and $4(65 \mathrm{mg}, 0.46 \mathrm{mmol})$, the title compound was prepared following the procedure described for the synthesis of compound 5a (Method A). The crude product was purified by flash chromatography on silica gel (5\% EtOAc in petroleum ether) to give $\mathbf{5 c}$ as a yellow solid (60 mg, $68 \%$ ). $\mathrm{mp}$ (EtOAc/n-hexane) $152-155^{\circ} \mathrm{C} ;{ }^{1} \mathrm{H}$ NMR $\left(400 \mathrm{MHz}, \mathrm{CDCl}_{3}\right) \delta 9.62$ $(\mathrm{s}, 1 \mathrm{H}), 7.63(\mathrm{~d}, J=6.8 \mathrm{~Hz}, 2 \mathrm{H}), 7.53(\mathrm{~d}, J=4.8 \mathrm{~Hz}, 2 \mathrm{H}), 7.27$ (d, $J=3.6 \mathrm{~Hz}, 1 \mathrm{H}), 6.80(\mathrm{~d}, J=3.6 \mathrm{~Hz}, 1 \mathrm{H})$; MS (ESI) $m / z 252[\mathrm{M}+\mathrm{H}]^{+}$.

\subsubsection{5-(4-Fluorophenyl)furan-2-carbaldehyde (5d)}

Starting from 3d (100 mg, $0.45 \mathrm{mmol})$ and 4 ( $88 \mathrm{mg}, 0.63 \mathrm{mmol})$, the title compound was prepared following the procedure described for the synthesis of compound 5a (Method A). The crude product was purified by flash chromatography on silica gel (5\% EtOAc in petroleum ether) to give $\mathbf{5 d}$ as a yellow oil $(70 \mathrm{mg}, 82 \%) .{ }^{1} \mathrm{H}$ NMR $\left(400 \mathrm{MHz}, \mathrm{CDCl}_{3}\right) \delta 9.59(\mathrm{~s}, 1 \mathrm{H}), 7.78-7.72(\mathrm{~m}, 2 \mathrm{H}), 7.27$ (d, $J=3.5 \mathrm{~Hz}, 1 \mathrm{H}), 7.14-7.04(\mathrm{~m}, 2 \mathrm{H}), 6.74(\mathrm{~d}, J=3.4 \mathrm{~Hz}, 1 \mathrm{H})$; MS (ESI) $\mathrm{m} / z 191[\mathrm{M}+\mathrm{H}]^{+}, 213[\mathrm{M}+\mathrm{Na}]^{+}$.

\subsubsection{5-(2-Methoxyphenyl)furan-2-carbaldehyde (5e)}

Starting from 3e $(160 \mathrm{mg}, 0.75 \mathrm{mmol})$ and 4 (147 mg, $1.05 \mathrm{mmol})$, the title compound was prepared following the procedure described for the synthesis of compound 5a (Method A). The crude product was purified by flash chromatography on silica gel (5\% EtOAc in petroleum ether) to give $\mathbf{5 e}$ as a yellow oil $(50 \mathrm{mg}$, 33\%). ${ }^{1} \mathrm{H}$ NMR (300 MHz, $\left.\mathrm{CDCl}_{3}\right) \delta 9.63(\mathrm{~s}, 1 \mathrm{H}), 8.03(\mathrm{~d}, J=5.2 \mathrm{~Hz}$, $1 \mathrm{H}), 7.40-7.34(\mathrm{~m}, 1 \mathrm{H}), 7.32(\mathrm{dd}, J=3.8,1.2 \mathrm{~Hz}, 1 \mathrm{H}), 7.12(\mathrm{dd}, J=3.7$, $1.1 \mathrm{~Hz}, 1 \mathrm{H}), 7.08-6.96(\mathrm{~m}, 2 \mathrm{H}), 3.93(\mathrm{~s}, 3 \mathrm{H})$; MS (ESI) m/z 225 $[\mathrm{M}+\mathrm{Na}]^{+}$.

4.1.5.1. 5-(2-Benzyloxyphenyl)furan-2-carbaldehyde Starting from 3f $(250 \mathrm{mg}, 0.80 \mathrm{mmol})$ and $4(158 \mathrm{mg}, 1.12 \mathrm{mmol})$, the title compound was prepared following the procedure described for the synthesis of compound 5a (Method A). The crude product was purified by flash chromatography on silica gel $(5 \%$ EtOAc in petroleum ether) to give $\mathbf{5 f}$ as a yellow oil (122 $\mathrm{mg}, 55 \%)$. ${ }^{1} \mathrm{H}$ NMR $\left(300 \mathrm{MHz}, \mathrm{CDCl}_{3}\right) \delta 9.58(\mathrm{~s}, 1 \mathrm{H}), 8.05(\mathrm{~d}, J=7.8 \mathrm{~Hz}, 1 \mathrm{H})$, 7.47-7.35 (m, 5H), 7.35-7.26 (m, $1 \mathrm{H}), 7.26(\mathrm{~d}, J=1.1 \mathrm{~Hz}, 1 \mathrm{H})$, 7.08-7.01 (m, 3H), $5.14(\mathrm{~s}, 2 \mathrm{H})$; MS (ESI) $m / z 301[\mathrm{M}+\mathrm{Na}]^{+}$.

4.1.5.2. 5-(2-Hydroxyphenyl)furan-2-carbaldehyde (6). To a solution of $\mathbf{5 f}(122 \mathrm{mg}, 0.43 \mathrm{mmol})$, in dry dichloromethane (DCM) $(7 \mathrm{~mL})$, boron trichloride $(395 \mu \mathrm{L}, 4.38 \mathrm{mmol})$ was added at $-78^{\circ} \mathrm{C}$. After $3 \mathrm{~h}$, the mixture warmed to $25^{\circ} \mathrm{C}$ and the solvent was removed in vacuo. The crude product was purified by flash chromatography on silica gel ( $2 \% \mathrm{MeOH}$ in DCM) to give $\mathbf{6}$ as yellow oil (97 mg, 55\%). ${ }^{1} \mathrm{H}$ NMR $\left(75 \mathrm{MHz}, \mathrm{CDCl}_{3}\right) \delta 9.63(\mathrm{~s}, 1 \mathrm{H}), 7.60(\mathrm{~d}$, $J=6.5 \mathrm{~Hz}, 1 \mathrm{H}), 7.26$ (d, $J=1.1 \mathrm{~Hz}, 1 \mathrm{H}), 7.13-7.08(\mathrm{~m}, 1 \mathrm{H}), 6.92-6.84$ $(\mathrm{m}, 2 \mathrm{H}), 6.76(\mathrm{~d}, J=3.3 \mathrm{~Hz}, 1 \mathrm{H}), 6.28(\mathrm{~d}, J=2.0 \mathrm{~Hz}, 1 \mathrm{H}) ; \mathrm{MS}(\mathrm{ESI}) \mathrm{m} / \mathrm{z}$ $189[\mathrm{M}+\mathrm{H}]^{+}$.

\subsubsection{1-(5-(4-Bromo-2-chlorophenyl)furan-2-yl)-N-(piperidin-4- ylmethyl)methanamine (1)}

A solution of $5 \mathbf{a}(90 \mathrm{mg}, 0.31 \mathrm{mmol})$ and $7(67 \mathrm{mg}, 0.31 \mathrm{mmol})$ in $\mathrm{MeOH}(10 \mathrm{~mL})$, was heated under reflux for $12 \mathrm{~h}$. After this time, the reaction was cooled to $0{ }^{\circ} \mathrm{C}$ and sodium borohydride $(12 \mathrm{mg}$, $0.31 \mathrm{mmol}$ ) was added. After $1 \mathrm{~h}$, the solvent was removed in vacuo, EtOAc was added $(10 \mathrm{~mL})$ and the organic phase was washed with a saturated solution of ammonium chloride $(1 \times 3 \mathrm{~mL})$, dried over sodium sulfate, filtered and evaporated in vacuo. The crude product was purified by flash chromatography on silica gel $(2 \% \mathrm{MeOH}$ in DCM) to give the $\mathrm{N}$-Boc protected intermediate as yellow oil (90 mg, 60\%). ${ }^{1} \mathrm{H}$ NMR (300 MHz, $\left.\mathrm{CDCl}_{3}\right) \delta 7.65(\mathrm{~d}, J=8.6 \mathrm{~Hz}, 1 \mathrm{H})$, $7.53(\mathrm{~d}, J=1.9 \mathrm{~Hz}, 1 \mathrm{H}), 7.37(\mathrm{dd}, J=8.5,1.9 \mathrm{~Hz}, 1 \mathrm{H}), 7.02(\mathrm{~d}$, $J=3.3 \mathrm{~Hz}, 1 \mathrm{H}), 6.27$ (d, $J=3.3 \mathrm{~Hz}, 1 \mathrm{H}), 4.06(\mathrm{~d}, J=9.6 \mathrm{~Hz}, 2 \mathrm{H}), 3.79$ $(\mathrm{s}, 2 \mathrm{H}), 2.66(\mathrm{dd}, J=22.1,9.9 \mathrm{~Hz}, 2 \mathrm{H}), 2.50(\mathrm{~d}, J=6.6 \mathrm{~Hz}, 2 \mathrm{H}), 1.67(\mathrm{~d}$, $J=13.0 \mathrm{~Hz}, 2 \mathrm{H}), 1.61-1.49(\mathrm{~m}, 1 \mathrm{H}), 1.47-1.36(\mathrm{~m}, 9 \mathrm{H}), 1.08$ (d, $J=16.2, \mathrm{~Hz}, 2 \mathrm{H}) ;{ }^{13} \mathrm{C}$ NMR $\left(75 \mathrm{MHz}, \mathrm{CDCl}_{3}\right) \delta 155.1,152.9,148.9$, 133.4, 130.6, 130.3, 128.6, 128.4, 120.6, 112.3, 111.0, 79.5, 59.6, 57.6, $50.8,34.7,30.6,28.7$; MS (ESI) $m / z 506[\mathrm{M}+\mathrm{Na}]^{+}$. A solution $1 \mathrm{~N}$ 

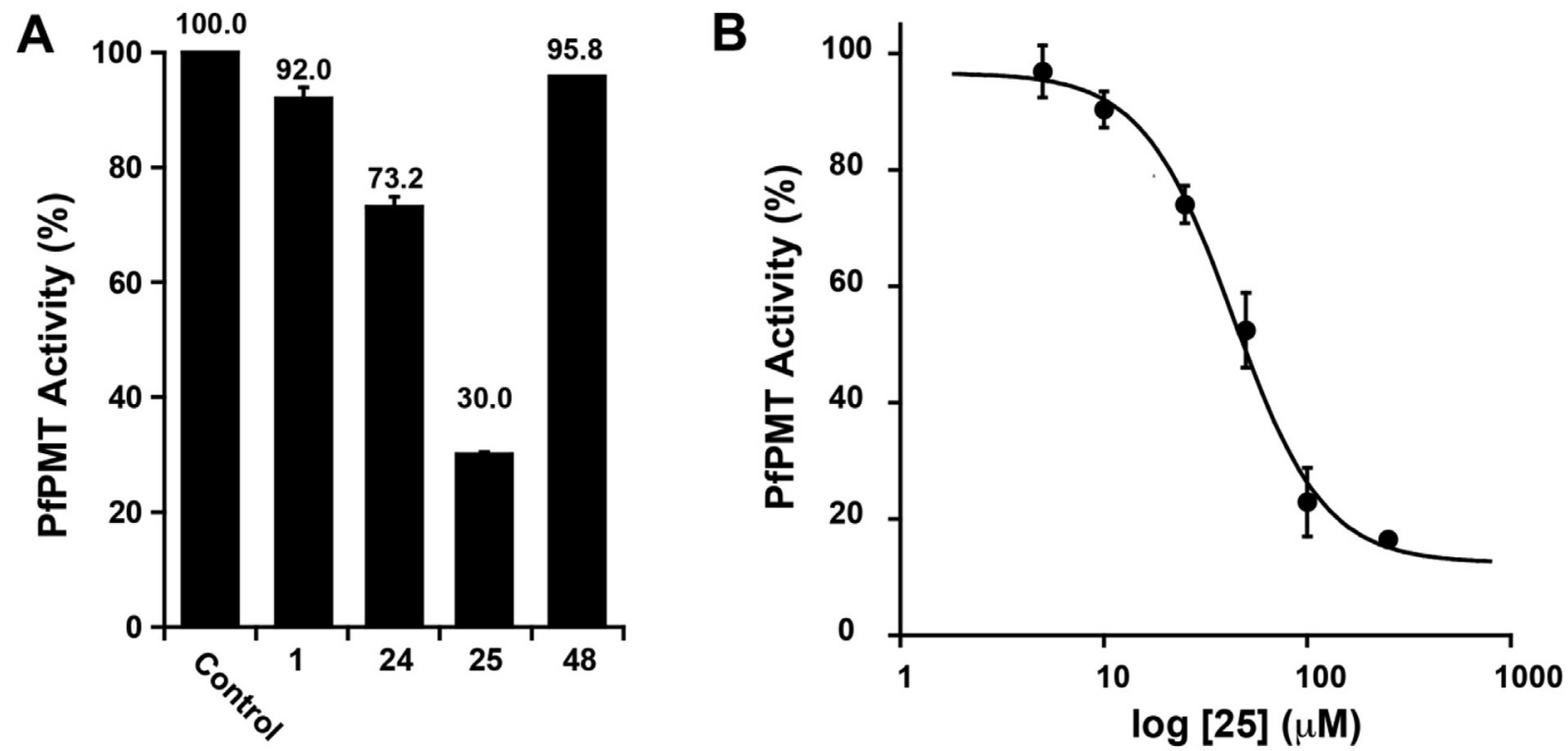

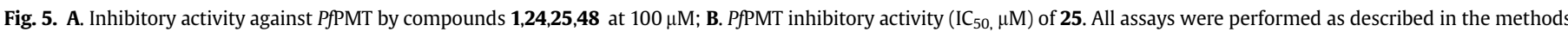
section with values shown as mean \pm standard deviation $(n=3)$.

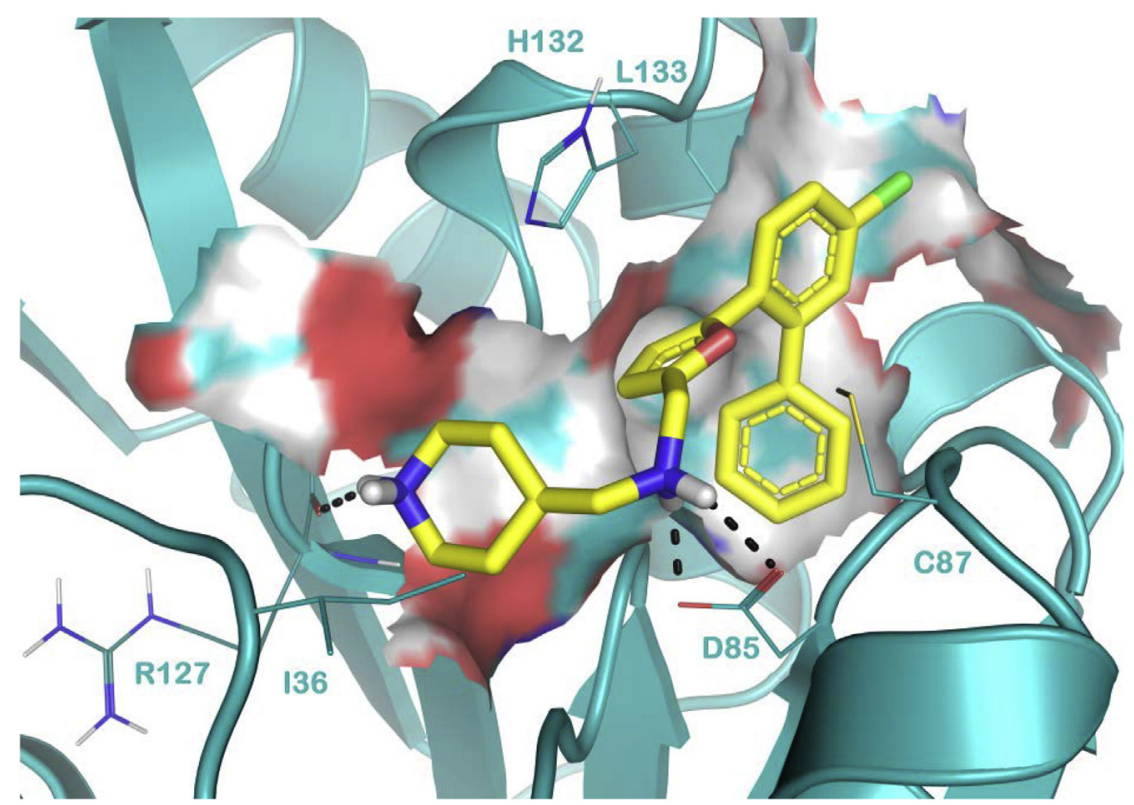

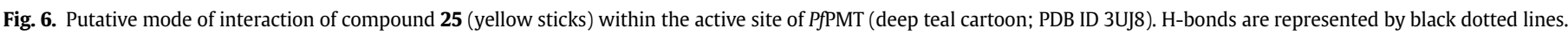

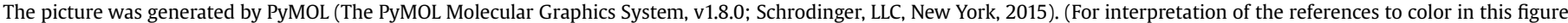
legend, the reader is referred to the Web version of this article.)

$\mathrm{HCl}$ was prepared using acetyl chloride $(355 \mu \mathrm{L}, 4.97 \mathrm{mmol})$ in $\mathrm{MeOH}(4.64 \mathrm{~mL})$. This solution $(540 \mu \mathrm{L}, 0.54 \mathrm{mmol})$ was added to the above described intermediate $(90 \mathrm{mg}, 0.18 \mathrm{mmol})$ at $0{ }^{\circ} \mathrm{C}$ and the mixture kept at $25^{\circ} \mathrm{C}$ for $4 \mathrm{~h}$. The solvent was removed in vacuo, a saturated solution of sodium bicarbonate was added and the organic phase was extracted with EtOAc $(3 \times 4 \mathrm{~mL})$, dried over sodium sulfate, filtered and evaporated in vacuo, giving the product 1 as yellow oil without further purification (68 mg, 100\%). ${ }^{1} \mathrm{H}$ NMR $\left(300 \mathrm{MHz}, \mathrm{CD}_{3} \mathrm{OD}\right) \delta 7.88(\mathrm{~d}, J=8.5 \mathrm{~Hz}, 1 \mathrm{H}), 7.72(\mathrm{~d}, J=1.8 \mathrm{~Hz}, 1 \mathrm{H})$, $7.58(\mathrm{~d}, J=6.8 \mathrm{~Hz}, 1 \mathrm{H}), 7.19(\mathrm{~d}, J=3.3 \mathrm{~Hz}, 1 \mathrm{H}), 6.85(\mathrm{~d}, J=3.3 \mathrm{~Hz}, 1 \mathrm{H})$, $4.42(\mathrm{~s}, 2 \mathrm{H}), 3.44(\mathrm{~d}, J=12.7 \mathrm{~Hz}, 2 \mathrm{H}), 3.05(\mathrm{dd}, J=17.7,9.1 \mathrm{~Hz}, 2 \mathrm{H})$, 2.17 (brs, 1H), 2.06 (d, $J=14.3 \mathrm{~Hz}, 2 \mathrm{H}$ ), 1.55 (dd, $J=23.5,11.6 \mathrm{~Hz}$,
$2 \mathrm{H}) ;{ }^{13} \mathrm{C}$ NMR $\left(75 \mathrm{MHz}, \mathrm{CD}_{3} \mathrm{OD}\right) \delta$ 150.6, 147.1, 133.1, 130.8, 130.4, 129.2, 127.8, 121.4, 113.7, 112.37, 51.9, 43.9, 43.4, 31.9, 26.4. MS (ESI) $m / z 383[\mathrm{M}+\mathrm{H}]^{+}$. Anal. $\left(\mathrm{C}_{17} \mathrm{H}_{20} \mathrm{BrClN}_{2} \mathrm{O}\right) \mathrm{C}, \mathrm{H}, \mathrm{N}$.

\subsubsection{1-(5-Phenylfuran-2-yl)-N-piperidin-4-ylmethyl-} methanamine $(\boldsymbol{8})$

Starting from $\mathbf{5 b}$ (30 $\mathrm{mg}, 0.17 \mathrm{mmol}$ ) and 7 (36 $\mathrm{mg}, 0.17 \mathrm{mmol}$ ), the $N$-Boc-protected intermediate was prepared and deprotected as described for the synthesis of $\mathbf{1}$ to afford $\mathbf{8}$ as yellow oil $(29 \mathrm{mg}, 64 \%$ over two steps). ${ }^{1} \mathrm{H}$ NMR $\left(400 \mathrm{MHz}, \mathrm{CDCl}_{3}\right) \delta 7.61(\mathrm{~d}, J=7.6 \mathrm{~Hz}, 2 \mathrm{H})$, $7.34(\mathrm{t}, J=7.6 \mathrm{~Hz}, 2 \mathrm{H}), 7.22(\mathrm{dd}, J=12.1,4.9 \mathrm{~Hz}, 1 \mathrm{H}), 6.55(\mathrm{~d}$, $J=3.1 \mathrm{~Hz}, 1 \mathrm{H}), 6.23(\mathrm{~d}, J=3.1 \mathrm{~Hz}, 1 \mathrm{H}), 3.80(\mathrm{~s}, 2 \mathrm{H}), 3.33$ (d, 
$J=12.5 \mathrm{~Hz}, 2 \mathrm{H}), 2.78(\mathrm{t}, J=11.6 \mathrm{~Hz}, 2 \mathrm{H}), 2.56(\mathrm{~d}, J=6.5 \mathrm{~Hz}, 2 \mathrm{H}), 1.90$ $(\mathrm{d}, J=13.5 \mathrm{~Hz}, 2 \mathrm{H}), 1.64(\mathrm{~d}, J=3.0 \mathrm{~Hz}, 1 \mathrm{H}), 1.54-1.40(\mathrm{~m}, 2 \mathrm{H}) ;{ }^{13} \mathrm{C}$ $\operatorname{NMR}\left(75 \mathrm{MHz}, \mathrm{CDCl}_{3}\right) \delta 154.0,153.3,131.1,128.8,127.3,123.8,109.2$, 105.8, 55.7, 46.8, 36.8; MS (ESI) $m / z 271[\mathrm{M}+\mathrm{H}]^{+}$. Anal. $\left(\mathrm{C}_{17} \mathrm{H}_{22} \mathrm{~N}_{2} \mathrm{O}\right)$ C, $\mathrm{H}, \mathrm{N}$.

\subsubsection{1-(5-(4-Bromophenyl)furan-2-yl)-N-(piperidin-4-ylmethyl) methanamine $(\mathbf{9})$}

Starting from 5c (64 mg, $0.25 \mathrm{mmol})$ and 7 (53 $\mathrm{mg}, 0.17 \mathrm{mmol}$ ), the $N$-Boc-protected intermediate was prepared and deprotected as described for the synthesis of $\mathbf{1}$. The crude product was purified by flash chromatography on silica gel ( $10 \% \mathrm{MeOH}, 1 \% \mathrm{NH}_{4} \mathrm{OH}$, in DCM) to give 9 as yellow oil ( $38 \mathrm{mg}, 64 \%$ over two steps). ${ }^{1} \mathrm{H}$ NMR $\left(400 \mathrm{MHz}, \mathrm{CD}_{3} \mathrm{OD}\right) \delta 7.59(\mathrm{~d}, J=8.5 \mathrm{~Hz}, 2 \mathrm{H}), 7.48(\mathrm{~d}, J=8.6 \mathrm{~Hz}, 2 \mathrm{H})$, $6.78(\mathrm{~d}, J=3.3 \mathrm{~Hz}, 1 \mathrm{H}), 6.68(\mathrm{~d}, J=3.2 \mathrm{~Hz}, 1 \mathrm{H}), 4.34(\mathrm{~s}, 2 \mathrm{H}), 3.38$ (d, $J=12.5 \mathrm{~Hz}, 2 \mathrm{H}), 3.02(\mathrm{~d}, J=6.8 \mathrm{~Hz}, 2 \mathrm{H}), 2.95(\mathrm{~d}, J=11.4 \mathrm{~Hz}, 2 \mathrm{H}), 2.11$ (brs, $1 \mathrm{H}), 2.01(\mathrm{~d}, J=13.6 \mathrm{~Hz}, 2 \mathrm{H}), 1.51(\mathrm{dd}, J=23.4,11.3 \mathrm{~Hz}, 2 \mathrm{H}) ;{ }^{13} \mathrm{C}$ NMR $\left(75 \mathrm{MHz}, \mathrm{CD}_{3} \mathrm{OD}\right) \delta 154.8,144.8,131.8,129.3,125.6,121.6$, 114.9, 106.8, 51.3, 43.7, 43.2, 31.3, 26.2; MS (ESI) $m / z 349[\mathrm{M}+\mathrm{H}]^{+}$. Anal. $\left(\mathrm{C}_{17} \mathrm{H}_{21} \mathrm{BrN}_{2} \mathrm{O}\right) \mathrm{C}, \mathrm{H}, \mathrm{N}$.

\subsubsection{1-(5-(4-Fluorophenyl)furan-2-yl)-N-(piperidin-4-ylmethyl) methanamine (10)}

Starting from 5d (32 mg, $0.17 \mathrm{mmol}$ ) and 7 (36 mg, $0.17 \mathrm{mmol}$ ), the $N$-Boc-protected intermediate was prepared and deprotected as described for the synthesis of $\mathbf{1}$. The crude product was purified by flash chromatography on silica gel ( $10 \% \mathrm{MeOH}, 1 \% \mathrm{NH}_{4} \mathrm{OH}$, in DCM) to give 10 as yellow oil (37 mg, 75\% over two steps). ${ }^{1} \mathrm{H}$ NMR $\left(400 \mathrm{MHz}, \mathrm{CD}_{3} \mathrm{OD}\right) \delta 7.76(\mathrm{~d}, J=5.6 \mathrm{~Hz}, 2 \mathrm{H}), 7.16(\mathrm{~d}, J=8.7 \mathrm{~Hz}, 2 \mathrm{H})$, $6.79(\mathrm{~d}, J=3.2 \mathrm{~Hz}, 1 \mathrm{H}), 6.74(\mathrm{~d}, J=3.2 \mathrm{~Hz}, 1 \mathrm{H}), 4.40(\mathrm{~s}, 2 \mathrm{H}), 3.44$ (d, $J=12.1 \mathrm{~Hz}, 2 \mathrm{H}), 3.07(\mathrm{~d}, J=6.6 \mathrm{~Hz}, 2 \mathrm{H}), 3.00(\mathrm{~d}, J=13.2 \mathrm{~Hz}, 2 \mathrm{H}), 2.15$ (brs, $1 \mathrm{H}), 2.04$ (d, $J=12.3 \mathrm{~Hz}, 2 \mathrm{H}), 1.54(\mathrm{dd}, J=23.4,11.3 \mathrm{~Hz}, 2 \mathrm{H}) ;{ }^{13} \mathrm{C}$ NMR $\left(75 \mathrm{MHz}, \mathrm{CD}_{3} \mathrm{OD}\right) \delta 164.4,161.1,155.0,144.5,144.5,126.8$, 126.7, 126.0, 125.9, 115.7, 115.4, 114.9, 105.9, 105.9, 51.3, 43.7, 43.2, 31.3, 26.2; MS (ESI) $m / z 289[\mathrm{M}+\mathrm{H}]^{+}$. Anal. $\left(\mathrm{C}_{17} \mathrm{H}_{21} \mathrm{FN}_{2} \mathrm{O}\right) \mathrm{C}, \mathrm{H}, \mathrm{N}$.

\subsubsection{1-(5-(2-Methoxyphenyl)furan-2-yl)-N-(piperidin-4-}

ylmethyl)methanamine (11)

Starting from 5e (50 mg, $0.25 \mathrm{mmol})$ and 7 (53 $\mathrm{mg}, 0.25 \mathrm{mmol})$, the $N$-Boc-protected intermediate was prepared and deprotected as described for the synthesis of $\mathbf{1}$. The crude product was purified by flash chromatography on silica gel $\left(10 \% \mathrm{MeOH}, 1 \% \mathrm{NH}_{4} \mathrm{OH}\right.$, in DCM) to give $\mathbf{1 1}$ as yellow oil ( $49 \mathrm{mg}, 65 \%$ over two steps). ${ }^{1} \mathrm{H}$ NMR $\left(300 \mathrm{MHz}, \mathrm{CD}_{3} \mathrm{OD}\right) \delta 7.81(\mathrm{~d}, J=7.8 \mathrm{~Hz}, 1 \mathrm{H}), 7.22(\mathrm{t}, J=7.8 \mathrm{~Hz}, 1 \mathrm{H})$, $7.07-6.94(\mathrm{~m}, 2 \mathrm{H}), 6.84(\mathrm{~d}, J=3.2 \mathrm{~Hz}, 1 \mathrm{H}), 6.33(\mathrm{~d}, J=2.6 \mathrm{~Hz}, 1 \mathrm{H})$, $3.92(\mathrm{~s}, 3 \mathrm{H}), 3.80(\mathrm{~s}, 2 \mathrm{H}), 3.05(\mathrm{~d}, J=12.4 \mathrm{~Hz}, 2 \mathrm{H}), 2.61(\mathrm{t}, J=12.5 \mathrm{~Hz}$, $2 \mathrm{H}), 2.50(\mathrm{~d}, J=6.6 \mathrm{~Hz}, 2 \mathrm{H}), 1.77(\mathrm{~d}, J=13.0 \mathrm{~Hz}, 2 \mathrm{H}), 1.65(\mathrm{~m}, 1 \mathrm{H})$, 1.21-1.08 (m, 2H); MS (ESI) $m / z 301[\mathrm{M}+\mathrm{H}]^{+}, 323[\mathrm{M}+\mathrm{Na}]^{+}$. Anal. $\left(\mathrm{C}_{18} \mathrm{H}_{24} \mathrm{~N}_{2} \mathrm{O}_{2}\right) \mathrm{C}, \mathrm{H}, \mathrm{N}$.

\subsubsection{1-(5-(2-Hydroxyphenyl)furan-2-yl)- $\mathrm{N}$-(piperidin-4- ylmethyl)methanamine (12)}

Starting from $6(80 \mathrm{mg}, 0.42 \mathrm{mmol})$ and $7(90 \mathrm{mg}, 0.42 \mathrm{mmol})$, the $N$-Boc-protected intermediate was prepared and deprotected as described for the synthesis of $\mathbf{1}$. The crude product was purified by flash chromatography on silica gel $\left(10 \% \mathrm{MeOH}, 1 \% \mathrm{NH}_{4} \mathrm{OH}\right.$, in DCM) to give 16 as yellow oil (72 mg, 60\% over two steps). ${ }^{1} \mathrm{H}$ NMR $\left(300 \mathrm{MHz}, \mathrm{CD}_{3} \mathrm{OD}\right) \delta 7.75-7.71(\mathrm{~m}, 1 \mathrm{H}), 7.09-7.02(\mathrm{~m}, 1 \mathrm{H})$, $6.91-6.81(\mathrm{~m}, 3 \mathrm{H}), 6.32(\mathrm{~d}, J=2.7 \mathrm{~Hz}, 1 \mathrm{H}), 3.78(\mathrm{~s}, 2 \mathrm{H}), 3.00(\mathrm{~d}$, $J=12.4 \mathrm{~Hz}, 2 \mathrm{H}), 2.57(\mathrm{~d}, J=12.2 \mathrm{~Hz}, 2 \mathrm{H}), 2.48(\mathrm{~d}, J=6.7 \mathrm{~Hz}, 2 \mathrm{H}), 1.72$ $(\mathrm{d}, J=13.2 \mathrm{~Hz}, 2 \mathrm{H}), 1.66-1.55(\mathrm{~m}, 1 \mathrm{H}), 1.21-1.02(\mathrm{~m}, 2 \mathrm{H})$; MS (ESI) $\mathrm{m} / \mathrm{z} 287[\mathrm{M}+\mathrm{H}]^{+}$. Anal. $\left(\mathrm{C}_{17} \mathrm{H}_{22} \mathrm{~N}_{2} \mathrm{O}_{2}\right) \mathrm{C}, \mathrm{H}, \mathrm{N}$.

\subsubsection{2. tert-Butyl 4-formylpiperidine-1-carboxylate (14)}

To a solution of (methoxymethyl)triphenylphosphonium chloride $(6.3 \mathrm{~g}, 18.3 \mathrm{mmol})$ in dry tetrahydrofuran (THF, $20 \mathrm{~mL}$ ), sodium bis(trimethylsilyl)amide (1 M in dry THF, $45 \mathrm{mmol}$ ) was added dropwise at $0^{\circ} \mathrm{C}$. After $1 \mathrm{~h}$, a solution of $\mathbf{1 3}(2.8 \mathrm{~g}, 14.1 \mathrm{mmol})$ in dry THF $(20 \mathrm{~mL})$ was slowly added at $0{ }^{\circ} \mathrm{C}$ and the mixture kept at $25^{\circ} \mathrm{C}$ for $12 \mathrm{~h}$. The solvent was removed in vacuo, $\mathrm{H}_{2} \mathrm{O}$ and EtOAC were added and the organic phase was separated, washed with an aqueous solution of $\mathrm{HCl} 1 \mathrm{~N}(1 \times 5 \mathrm{~mL})$ and with a saturated solution of sodium bicarbonate $(1 \times 5 \mathrm{~mL})$, dried over sodium sulfate, filtered and evaporated in vacuo. The crude reaction mixture was purified by flash chromatography on silica gel (2\% EtOAc in petroleum ether) to give the enolether intermediate tert-butyl 4(methoxymethylene)piperidine-1-carboxylate as yellow oil (1.28 g, 40\%). ${ }^{1} \mathrm{H}$ NMR (300 MHz, $\left.\mathrm{CDCl}_{3}\right) \delta 5.81(\mathrm{~s}, 1 \mathrm{H}), 3.51(\mathrm{~s}, 3 \mathrm{H}), 3.33(\mathrm{t}$, $J=6.3 \mathrm{~Hz}, 4 \mathrm{H}), 2.20(\mathrm{t}, J=6.0 \mathrm{~Hz}, 2 \mathrm{H}), 1.96(\mathrm{t}, J=6.0 \mathrm{~Hz}, 2 \mathrm{H}), 1.42(\mathrm{~s}$, $9 \mathrm{H})$; MS (ESI) $m / z 250[\mathrm{M}+\mathrm{Na}]^{+}$. To a solution of the abovedescribed compound ( $807 \mathrm{mg}, 3.6 \mathrm{mmol}$ ) in $\mathrm{CH}_{3} \mathrm{CN}(20 \mathrm{~mL}$ ), cerium chloride (530 mg, $1.4 \mathrm{mmol}$ ) and sodium iodide ( $160 \mathrm{mg}, 1.1 \mathrm{mmol}$ ) were added. The reaction mixture was heated under reflux for $12 \mathrm{~h}$. The solvent was removed in vacuo and the crude product was purified by flash chromatography on silica gel $\left(10 \% \mathrm{MeOH}, 1 \% \mathrm{NH}_{4} \mathrm{OH}\right.$, in DCM) to give 14 as yellow oil $(667 \mathrm{mg}, 87 \%) .{ }^{1} \mathrm{H}$ NMR $(300 \mathrm{MHz}$, $\left.\mathrm{CDCl}_{3}\right) \delta 9.57(\mathrm{~s}, 1 \mathrm{H}), 3.88(\mathrm{~d}, J=13.3 \mathrm{~Hz}, 2 \mathrm{H}), 2.84(\mathrm{t}, J=10.9 \mathrm{~Hz}$, $2 \mathrm{H}), 2.39-2.28(\mathrm{~m}, 1 \mathrm{H}), 1.80(\mathrm{~d}, J=13.5,2 \mathrm{H}), 1.49-1.41(\mathrm{~m}, 2 \mathrm{H}), 1.36$ (s, 9H). MS (ESI) $m / z 268[\mathrm{M}+\mathrm{MeOH}+\mathrm{K}]^{+}$.

\subsubsection{3. tert-Butyl 4-(azidomethyl)piperidine-1-carboxylate (15)}

To a solution of $14(660 \mathrm{mg}, 3.1 \mathrm{mmol})$ in $\mathrm{MeOH}(10 \mathrm{~mL})$, sodium borohydride ( $117 \mathrm{mg}, 3.1 \mathrm{mmol}$ ) was added at $0{ }^{\circ} \mathrm{C}$ and the mixture kept at $25^{\circ} \mathrm{C}$ for $1 \mathrm{~h}$. The solvent was removed in vacuo, EtOAc was added $(15 \mathrm{~mL})$ and the organic phase was washed with a saturated solution of ammonium chloride $(1 \times 5 \mathrm{~mL})$, dried over sodium sulfate, filtered and evaporated in vacuo. The alcohol tert-butyl 4(hydroxymethyl)piperidine-1-carboxylate was obtained as yellow oil without further purification (666 mg, 100\%). ${ }^{1} \mathrm{H} \mathrm{NMR}(300 \mathrm{MHz}$, $\left.\mathrm{CDCl}_{3}\right) \delta 4.03-3.90(\mathrm{~d}, J=12.6 \mathrm{~Hz}, 2 \mathrm{H}), 3.31(\mathrm{~d}, J=6.2 \mathrm{~Hz}, 2 \mathrm{H}), 2.56$ $(\mathrm{t}, J=12.8 \mathrm{~Hz}, 2 \mathrm{H}), 1.67-1.54(\mathrm{~m}, 2 \mathrm{H}), 1.54-1.42(\mathrm{~m}, 1 \mathrm{H}), 1.32(\mathrm{~s}, 9 \mathrm{H})$, 1.07-0.90 (m, 2H); ${ }^{13} \mathrm{C}$ NMR (75 MHz, $\left.\mathrm{CDCl}_{3}\right) \delta 154.9,79.3,67.6$, 67.0, 43.7, 38.8, 38.7, 37.7, 28.4; MS (ESI) $m / z 238[\mathrm{M}+\mathrm{Na}]^{+}$. To a solution of the above-described alcohol $(666 \mathrm{mg}, 3.1 \mathrm{mmol})$ in dry DCM $(30 \mathrm{~mL})$, triethylamine $(2.6 \mathrm{~mL}, 18.6 \mathrm{mmol})$ and methanesulfonyl chloride $(959 \mu \mathrm{L}, 12.4 \mathrm{mmol})$ were added dropwise at $0{ }^{\circ} \mathrm{C}$. The reaction mixture was kept at $25{ }^{\circ} \mathrm{C}$ for $12 \mathrm{~h}$. A saturated solution of sodium bicarbonate $(5 \mathrm{~mL})$ was added and the organic phase was extracted with DCM $(3 \times 10 \mathrm{~mL})$, dried over sodium sulfate, filtered and evaporated in vacuo. The crude product was purified by flash chromatography on silica gel (2\% $\mathrm{MeOH}$ in DCM) to give mesylate intermediate as yellow oil (900 mg, 99\%). ${ }^{1} \mathrm{H}$ NMR $\left(300 \mathrm{MHz}, \mathrm{CDCl}_{3}\right) \delta 3.98-3.73(\mathrm{~m}, 2 \mathrm{H}), 2.97-2.84(\mathrm{~m}, 2 \mathrm{H}), 2.79(\mathrm{~s}$, $3 \mathrm{H}), 2.48(\mathrm{t}, J=13.1 \mathrm{~Hz}, 2 \mathrm{H}), 1.67(\mathrm{br} \mathrm{s}, 1 \mathrm{H}), 1.50(\mathrm{~d}, J=13.2 \mathrm{~Hz}, 2 \mathrm{H})$, $1.21(\mathrm{~s}, 9 \mathrm{H}), 1.05-0.92(\mathrm{~m}, 2 \mathrm{H})$; 13C NMR (75 MHz, CDCl3) $\delta 154.8$, 79.6, 73.7, 43.3, 37.3, 36.0, 31.8, 28.5, 28.3; MS (ESI) $\mathrm{m} / \mathrm{z} 294$ $[\mathrm{M}+\mathrm{H}]+$. To a solution of the above compound $(900 \mathrm{mg}, 3.1 \mathrm{mmol})$ in dry $N, N$-dimethylformamide (DMF) $(10 \mathrm{~mL})$, sodium azide ( $400 \mathrm{mg}, 6.2 \mathrm{mmol}$ ) was added at $0^{\circ} \mathrm{C}$. The reaction was heated under reflux at $90^{\circ} \mathrm{C}$ for $12 \mathrm{~h}$. The solvent was removed in vacuo and the product 15 was obtained as yellow oil without further purification $(0.52 \mathrm{~g}, 70 \%) .{ }^{1} \mathrm{H}$ NMR $\left(300 \mathrm{MHz}, \mathrm{CDCl}_{3}\right) \delta 4.01$ (d, $J=12.1 \mathrm{~Hz}, 2 \mathrm{H}), 3.08(\mathrm{~d}, J=6.3 \mathrm{~Hz}, 2 \mathrm{H}), 2.57(\mathrm{t}, J=12.8 \mathrm{~Hz}, 2 \mathrm{H})$, $1.68-1.49(\mathrm{~m}, 3 \mathrm{H}), 1.34(\mathrm{~s}, 9 \mathrm{H}), 1.15-0.96(\mathrm{~m}, 1 \mathrm{H}) ;{ }^{13} \mathrm{C} \mathrm{NMR}$ $\left(75 \mathrm{MHz}, \mathrm{CDCl}_{3}\right) \delta 111.3,79.7,57.2,43.4,36.7,29.8,28.6$; MS (ESI) $\mathrm{m} /$ $z 263[\mathrm{M}+\mathrm{Na}]+$.

\subsubsection{4. tert-Butyl 4-(aminomethyl)piperidine-1-carboxylate (7)}

To a solution of $\mathbf{1 5}(520 \mathrm{mg}, 2.1 \mathrm{mmol})$ in $\mathrm{MeOH}(15 \mathrm{~mL})$, a catalytic amount of palladium on carbon $10 \mathrm{wt} . \%$ was added under 
argon atmosphere. The reaction environment was saturated with hydrogen gas. The mixture was stirred at $25^{\circ} \mathrm{C}$ for $3 \mathrm{~h}$. The suspension was filtered on paper and concentrated in vacuo giving 7 as colorless oil without further purification (427 mg, 95\%). ${ }^{1} \mathrm{H}$ NMR $\left(300 \mathrm{MHz}, \mathrm{CDCl}_{3}\right) \delta 3.88(\mathrm{~d}, J=13.1 \mathrm{~Hz}, 2 \mathrm{H}), 2.50(\mathrm{~d}, J=17.4 \mathrm{~Hz}, 4 \mathrm{H})$, 2.45-2.33 (m, 2H), 1.50 (d, $J=13.0 \mathrm{~Hz}, 2 \mathrm{H}), 1.38-1.27(\mathrm{~m}, 1 \mathrm{H}), 1.27$ (s, 9H), 0.90-0.45 (m, 2H); ${ }^{13} \mathrm{C} \mathrm{NMR}\left(75 \mathrm{MHz}, \mathrm{CDCl}_{3}\right) \delta$ 155.0, 79.3, 48.1, 43.4, 39.7, 29.9, 28.6; MS (ESI) $m / z 215[\mathrm{M}+\mathrm{H}]^{+}$.

\subsubsection{5-(4-Chloro-2-bromophenyl)furan-2-carbaldehyde (18b)}

Starting from 16b $(2.0 \mathrm{~g}, 9.7 \mathrm{mmol})$ and $\mathbf{1 7}(802 \mu \mathrm{L}, 9.7 \mathrm{mmol})$, the title compound was prepared following the procedure described for the synthesis of compound 5a (Method B). The crude product was purified by flash chromatography on silica gel (5\% EtOAc in petroleum ether) to give $\mathbf{1 8 b}$ as an orange solid $(2.5 \mathrm{~g}$, 90\%). mp (EtOAc/n-hexane) $141-144{ }^{\circ} \mathrm{C} ;{ }^{1} \mathrm{H}$ NMR $\left(300 \mathrm{MHz}, \mathrm{CDCl}_{3}\right)$ $\delta 9.69(\mathrm{~s}, 1 \mathrm{H}), 7.89(\mathrm{~d}, J=8.5 \mathrm{~Hz}, 1 \mathrm{H}), 7.71(\mathrm{~d}, J=2.0 \mathrm{~Hz}, 1 \mathrm{H}), 7.40(\mathrm{~d}$, $J=8.6, \mathrm{~Hz}, 1 \mathrm{H}), 7.35$ (q, $J=3.8 \mathrm{~Hz}, 2 \mathrm{H}) ;{ }^{13} \mathrm{C} \mathrm{NMR}\left(75 \mathrm{MHz}, \mathrm{CDCl}_{3}\right)$ $\delta$ 177.6, 154.6, 151.8, 133.7, 132.4, 130.7, 130.2, 126.8, 123.6, 123.0, 113.6. MS (ESI) $m / z 308[\mathrm{M}+\mathrm{Na}]^{+}$.

\subsubsection{5-(2-Chlorophenyl)furan-2-carbaldehyde (18c)}

Starting from 16c $(100 \mathrm{mg}, 0.78 \mathrm{mmol})$ and $17(65 \mu \mathrm{L}$, $0.78 \mathrm{mmol}$ ), the title compound was prepared following the procedure described for the synthesis of compound 5a (Method B). The crude product was purified by flash chromatography on silica gel (10\% EtOAc in petroleum ether) to give $\mathbf{1 8 c}$ as a yellow solid (112 mg, 70\%). mp (EtOAc/n-hexane) $68-72{ }^{\circ} \mathrm{C} ;{ }^{1} \mathrm{H}$ NMR $(400 \mathrm{MHz}$, $\left.\mathrm{CDCl}_{3}\right) \delta 9.66(\mathrm{~s}, 1 \mathrm{H}), 7.97(\mathrm{~d}, J=5.9 \mathrm{~Hz}, 1 \mathrm{H}), 7.44(\mathrm{~d}, J=6.5 \mathrm{~Hz}, 1 \mathrm{H})$, 7.36-7.26 (m, 4H); MS (ESI) $m / z 207[\mathrm{M}+\mathrm{H}]^{+}, 228[\mathrm{M}+\mathrm{Na}]^{+}$.

\subsubsection{5-(4-(Trifluoromethyl)phenyl)furan-2-carbaldehyde (18d)}

Starting from 16d (300 $\mathrm{mg}, 1.86 \mathrm{mmol}$ ) and furaldehyde $\mathbf{1 7}$ (154 $\mu \mathrm{L}, 1.86 \mathrm{mmol}$ ), the title compound was prepared following the procedure described for the synthesis of compound 5a (Method B). The crude product was purified by flash chromatography on silica gel (5\% EtOAc in petroleum ether) to give 18d as yellow solid (312 mg, 70\%). mp (EtOAc/n-hexane) $64-66{ }^{\circ} \mathrm{C} ;{ }^{1} \mathrm{H}$ NMR $(300 \mathrm{MHz}$, $\left.\mathrm{CDCl}_{3}\right) \delta 9.65(\mathrm{~s}, 1 \mathrm{H}), 7.85(\mathrm{~d}, J=8.6 \mathrm{~Hz}, 2 \mathrm{H}), 7.64(\mathrm{~d}, J=8.6 \mathrm{~Hz}, 2 \mathrm{H})$, $7.30(\mathrm{~d}, J=3.8 \mathrm{~Hz}, 1 \mathrm{H}), 6.91(\mathrm{~d}, J=3.8 \mathrm{~Hz}, 1 \mathrm{H})$; MS (ESI) $m / z 263$ $[\mathrm{M}+\mathrm{Na}]^{+}$.

\subsubsection{4-(5-Formylfuran-2-yl)benzonitrile (18e)}

Starting from $16 \mathbf{e}(600 \mathrm{mg}, 5.1 \mathrm{mmol})$ and furaldehyde 17 ( $421 \mu \mathrm{L}, 1.86 \mathrm{mmol}$ ), the title compound was prepared following the procedure described for the synthesis of compound 5a (Method B). The crude product was purified by flash chromatography on silica gel (15\% EtOAc in petroleum ether) to give 18e as brown solid (753 mg, 75\%). mp (EtOAc/n-hexane) $145-150{ }^{\circ} \mathrm{C} ;{ }^{1} \mathrm{H} \quad \mathrm{NMR}$ $\left(300 \mathrm{MHz}, \mathrm{CDCl}_{3}\right) \delta 9.71(\mathrm{~s}, 1 \mathrm{H}), 7.92(\mathrm{~d}, J=8.6 \mathrm{~Hz}, 2 \mathrm{H}), 7.76(\mathrm{~d}$, $J=8.6 \mathrm{~Hz}, 2 \mathrm{H}), 7.34(\mathrm{~d}, J=3.4 \mathrm{~Hz}, 1 \mathrm{H}), 6.97(\mathrm{~d}, J=3.4 \mathrm{~Hz}, 1 \mathrm{H})$; MS (ESI) $m / z 220[\mathrm{M}+\mathrm{Na}]^{+}$.

\subsubsection{5-(4-Phenyl-2-chlorophenyl)furan-2-carbaldehyde (19a)}

Triphenylphosphine $(220 \mathrm{mg}, 0.84 \mathrm{mmol}$ ) and palladium (II) acetate $(12 \mathrm{mg}, 0.05 \mathrm{mmol})$ were dissolved in dry toluene $(3 \mathrm{~mL})$ under argon atmosphere. After $30 \mathrm{~min}$, a solution of $\mathbf{5 a}(300 \mathrm{mg}$, $1.05 \mathrm{mmol}$ ) in dry toluene ( $5 \mathrm{~mL}$ ) was added. After further $30 \mathrm{~min}$, a solution of sodium carbonate ( $701 \mathrm{mg}, 6.6 \mathrm{mmol})$ in $\mathrm{H}_{2} \mathrm{O}(3 \mathrm{~mL})$ and powdered phenyl boronic acid ( $128 \mathrm{mg}, 1.05 \mathrm{mmol}$ ) were added in this order. Reaction was heated under reflux for $12 \mathrm{~h}$. The solvent was removed under vacuo. $\mathrm{H}_{2} \mathrm{O}(2 \mathrm{~mL})$ and EtOAc $(8 \mathrm{~mL})$ were added, the organic phase was separated, dried over sodium sulfate, filtered and evaporated in vacuo. The crude product was purified by flash chromatography on silica gel (5\% EtOAc in petroleum ether) to give 19a as yellow oil (254 mg, 85\%). ${ }^{1} \mathrm{H}$ NMR (300 $\left.\mathrm{MHz}, \mathrm{CDCl}_{3}\right)$ $\delta 9.69(\mathrm{~s}, 1 \mathrm{H}), 8.08(\mathrm{~d}, J=1.5 \mathrm{~Hz}, 1 \mathrm{H}), 7.70(\mathrm{~d}, J=1.6 \mathrm{~Hz}, 1 \mathrm{H})$, 7.62-7.56 (m, 3H), 7.50-7.36 (m, 3H), $7.35(\mathrm{~d}, J=0.8 \mathrm{~Hz}, 2 \mathrm{H}) ;{ }^{13} \mathrm{C}$ NMR $\left(75 \mathrm{MHz}, \mathrm{CDCl}_{3}\right) \delta 177.6,157.7,151.5,142.6,140.0,135.4,131.1$, $129.8,129.4,129.0$ (2C), 127.5, 127.3, 126.4 (2C), 115.6, 112.3; MS (ESI) $m / z 305[\mathrm{M}+\mathrm{Na}]^{+}$.

\subsubsection{5-(2-Phenyl-4-chlorophenyl)furan-2-carbaldehyde (19b)}

Starting from $18 \mathbf{b}(80 \mathrm{mg}, 0.28 \mathrm{mmol})$ and phenylboronic acid (35 $\mathrm{mg}, 0.28 \mathrm{mmol}$ ), the title compound was prepared following the procedure reported for compound 19a. The crude product was purified by flash chromatography on silica gel (5\% EtOAc in petroleum ether) to give $\mathbf{1 9 b}$ as yellow oil $(50 \mathrm{mg}, 63 \%) .{ }^{1} \mathrm{H}$ NMR $\left(300 \mathrm{MHz}, \mathrm{CDCl}_{3}\right) \delta 9.55(\mathrm{~s}, 1 \mathrm{H}), 7.93(\mathrm{~d}, J=5.3 \mathrm{~Hz}, 1 \mathrm{H}), 7.44-7.40$ (m, 5H), $7.33(\mathrm{~d}, J=2.7 \mathrm{~Hz}, 2 \mathrm{H}), 7.02(\mathrm{~d}, J=3.1 \mathrm{~Hz}, 1 \mathrm{H}), 5.62(\mathrm{~d}$, $J=3.7 \mathrm{~Hz}, 1 \mathrm{H}) ;{ }^{13} \mathrm{C}$ NMR $\left(75 \mathrm{MHz}, \mathrm{CDCl}_{3}\right) \delta 177.6,157.7,151.5,142.6$, 140.0, 135.4, 131.1, 129.8, 129.4, 129.0 (2C), 127.5, 127.4, 126.4, 120.4, 115.6, 112.3; MS (ESI) $m / z 305[\mathrm{M}+\mathrm{Na}]^{+}$.

\subsubsection{1-(5-(2-Bromo-4-chlorophenyl)furan-2-yl)-N-(piperidin-4-} ylmethyl)methanamine (21)

Starting from $\mathbf{1 8 b}$ ( $50 \mathrm{mg}, 0.18 \mathrm{mmol}$ ) and 7 (38 $\mathrm{mg}, 0.18 \mathrm{mmol}$ ), the $N$-Boc-protected intermediate was prepared and deprotected as described for the synthesis of $\mathbf{1}$. The crude product was purified by flash chromatography on silica gel $\left(10 \% \mathrm{MeOH}, 1 \% \mathrm{NH}_{4} \mathrm{OH}\right.$, in DCM) to give 21 as yellow oil (48 mg, 70\% over two steps). ${ }^{1} \mathrm{H}$ NMR $\left(300 \mathrm{MHz}, \mathrm{CDCl}_{3}\right) \delta 7.65(\mathrm{~d}, J=1.2 \mathrm{~Hz}, 1 \mathrm{H}), 7.61(\mathrm{~s}, 1 \mathrm{H}), 7.28(\mathrm{~d}$, $J=2.2 \mathrm{~Hz}, 1 \mathrm{H}), 7.05(\mathrm{~s}, 1 \mathrm{H}), 6.27(\mathrm{~s}, 1 \mathrm{H}), 3.78(\mathrm{~s}, 2 \mathrm{H}), 3.30(\mathrm{~d}$, $J=11.1 \mathrm{~Hz}, 2 \mathrm{H}), 2.74(\mathrm{t}, J=11.8 \mathrm{~Hz}, 2 \mathrm{H}), 2.53(\mathrm{~d}, J=5.2 \mathrm{~Hz}, 2 \mathrm{H}), 1.86$ $(\mathrm{d}, J=12.9 \mathrm{~Hz}, 2 \mathrm{H}), 1.61(\mathrm{~s}, 1 \mathrm{H}), 1.48-1.30(\mathrm{~m}, 2 \mathrm{H}) ;{ }^{13} \mathrm{C}$ NMR (75 MHz, CD ${ }_{3} \mathrm{OD}$ ) $\delta 153.7,149.5,133.1,132.9,129.8,129.1,127.5$, 118.9, 111.5, 109.2, 54.3, 45.3, 44.7, 34.9, 29.2; MS (ESI) $m / z 383$ $[\mathrm{M}+\mathrm{H}]^{+}$. Anal. $\left(\mathrm{C}_{17} \mathrm{H}_{20} \mathrm{BrClN}_{2} \mathrm{O}\right) \mathrm{C}, \mathrm{H}, \mathrm{N}$.

\subsubsection{1-(5-(2-Chlorophenyl)furan-2-yl)-N-(piperidin-4-ylmethyl)} methanamine (22)

Starting from 18c ( $45 \mathrm{mg}, 0.22 \mathrm{mmol}$ ) and 7 ( $47 \mathrm{mg}, 0.22 \mathrm{mmol}$ ), the $N$-Boc-protected intermediate was prepared and deprotected as described for the synthesis of $\mathbf{1}$. The crude product was purified by flash chromatography on silica gel $\left(10 \% \mathrm{MeOH}, 1 \% \mathrm{NH}_{4} \mathrm{OH}\right.$, in DCM) to give 22 as yellow oil (48 mg, $68 \%$ over two steps). ${ }^{1} \mathrm{H}$ NMR (300 MHz, CD $\left.{ }_{3} \mathrm{OD}\right) \delta 7.91(\mathrm{dd}, J=7.8,1.7 \mathrm{~Hz}, 1 \mathrm{H}), 7.51-7.47(\mathrm{~m}, 1 \mathrm{H})$, $7.41-7.26(\mathrm{~m}, 2 \mathrm{H}), 7.12(\mathrm{~d}, J=3.5 \mathrm{~Hz}, 1 \mathrm{H}), 6.75(\mathrm{~d}, J=3.5 \mathrm{~Hz}, 1 \mathrm{H})$, $4.32(\mathrm{~s}, 2 \mathrm{H}), 3.40(\mathrm{~d}, J=2.4 \mathrm{~Hz}, 2 \mathrm{H}), 3.30(\mathrm{dt}, J=2.3,1.6 \mathrm{~Hz}, 2 \mathrm{H})$ 3.04-2.94 (m, 2H), 2.15-2.07 (m, 1H), $2.02(\mathrm{~d}, J=14.3 \mathrm{~Hz}, 2 \mathrm{H}), 1.52$ $(\mathrm{td}, J=14.7,4.0 \mathrm{~Hz}, 2 \mathrm{H}) ;{ }^{13} \mathrm{C}$ NMR $\left(75 \mathrm{MHz}, \mathrm{CD}_{3} \mathrm{OD}\right) \delta 151.7,146.3$, 130.7, 130.2, 129.0, 128.6, 128.2, 127.1, 113.8, 111.8, 51.7, 43.9, 43.3, 31.7, 26.4; MS (ESI) $m / z 305[\mathrm{M}+\mathrm{H}]^{+}$. Anal. $\left(\mathrm{C}_{17} \mathrm{H}_{21} \mathrm{ClN}_{2} \mathrm{O}\right) \mathrm{C}, \mathrm{H}, \mathrm{N}$.

\subsubsection{1-(5-(4-Trifluoromethylphenyl)furan-2-yl)-N-(piperidin-4-} ylmethyl)methanamine (23)

Starting from 18d (100 mg, $0.41 \mathrm{mmol})$ and 7 (89 mg $0.41 \mathrm{mmol}$ ), the $N$-Boc-protected intermediate was prepared and deprotected as described for the synthesis of $\mathbf{1}$. The crude product was purified by flash chromatography on silica gel $(10 \% \mathrm{MeOH}, 1 \%$ $\mathrm{NH}_{4} \mathrm{OH}$, in DCM) to give 23 as yellow oil $(90 \mathrm{mg}, 65 \%$ over two steps). ${ }^{1} \mathrm{H}$ NMR $\left(300 \mathrm{MHz}, \mathrm{CD}_{3} \mathrm{OD}\right) \delta 7.86(\mathrm{~d}, J=8.1 \mathrm{~Hz}, 2 \mathrm{H}), 7.66(\mathrm{~d}$ $J=7.6 \mathrm{~Hz}, 2 \mathrm{H}), 6.89(\mathrm{~d}, J=3.3 \mathrm{~Hz}, 1 \mathrm{H}), 6.42(\mathrm{~d}, J=3.3 \mathrm{~Hz}, 1 \mathrm{H}), 3.83$ (s, $2 \mathrm{H}), 3.16(\mathrm{~d}, J=11.7 \mathrm{~Hz}, 2 \mathrm{H}), 2.72(\mathrm{t}, J=12.4 \mathrm{~Hz}, 2 \mathrm{H}), 2.53$ (d, $J=6.3 \mathrm{~Hz}, 2 \mathrm{H}), 1.85$ (d, $J=14.0 \mathrm{~Hz}, 2 \mathrm{H}), 1.70$ (brs, $1 \mathrm{H}), 1.28-1.15$ (m, $2 \mathrm{H}) ;{ }^{13} \mathrm{C}$ NMR $\left(75 \mathrm{MHz}, \mathrm{CD}_{3} \mathrm{OD}\right) \delta 154.3,151.6,134.2,128.5,128.1$, 125.4, 125.3, 125.3, 125.2, 123.3, 109.7, 107.8, 54.6, 45.3, 45.1, 35.4 30.0; MS (ESI) $m / z 338[\mathrm{M}+\mathrm{H}]^{+}$. Anal. $\left(\mathrm{C}_{18} \mathrm{H}_{21} \mathrm{~F}_{3} \mathrm{~N}_{2} \mathrm{O}\right) \mathrm{C}, \mathrm{H}, \mathrm{N}$. 
4.1.24. 1-(5-(4-Cyanophenyl)furan-2-yl)-N-(piperidin-4-ylmethyl) methanamine (24)

Starting from 18e (51 mg, $0.26 \mathrm{mmol}$ ) and 7 (55 mg, $0.41 \mathrm{mmol}$ ), the $N$-Boc-protected intermediate was prepared and deprotected as described for the synthesis of $\mathbf{1}$. The crude product was purified by flash chromatography on silica gel $\left(10 \% \mathrm{MeOH}, 1 \% \mathrm{NH}_{4} \mathrm{OH}\right.$, in DCM) to give 24 as yellow oil (51 mg, 67\% over two steps). ${ }^{1} \mathrm{H}$ NMR $\left(300 \mathrm{MHz}, \mathrm{CD}_{3} \mathrm{OD}\right) \delta 7.88(\mathrm{~d}, J=8.6 \mathrm{~Hz}, 2 \mathrm{H}), 7.72(\mathrm{~d}, J=8.6 \mathrm{~Hz}, 2 \mathrm{H})$, $7.03(\mathrm{~d}, J=3.5 \mathrm{~Hz}, 1 \mathrm{H}), 6.77(\mathrm{~d}, J=3.5 \mathrm{~Hz}, 1 \mathrm{H}), 4.41(\mathrm{~s}, 2 \mathrm{H})$, $3.47-3.37(\mathrm{~m}, 2 \mathrm{H}), 3.08(\mathrm{t}, J=7.7 \mathrm{~Hz}, 2 \mathrm{H}), 3.02-2.93(\mathrm{~m}, 2 \mathrm{H}), 2.14$ (brs, $1 \mathrm{H}), 2.08-2.00(\mathrm{~m}, 2 \mathrm{H}), 1.51(\mathrm{dd}, J=18.7,8.6 \mathrm{~Hz}, 2 \mathrm{H}) ;{ }^{13} \mathrm{C} \mathrm{NMR}$ $\left(75 \mathrm{MHz}, \mathrm{CD}_{3} \mathrm{OD}\right) \delta 153.7,146.3,134.2,132.6,131.9,124.4,118.5$, 115.15, 110.6, 109.4, 51.4, 43.6, 43.2, 31.3, 26.2; MS (ESI) m/z 296 $[\mathrm{M}+\mathrm{H}]^{+}$. Anal. $\left(\mathrm{C}_{18} \mathrm{H}_{21} \mathrm{~N}_{3} \mathrm{O}\right) \mathrm{C}, \mathrm{H}, \mathrm{N}$.

\subsubsection{1-(5-(2-Phenyl-4-chlorophenyl)furan-2-yl)-N-(piperidin-4-} ylmethyl)methanamine (25)

Starting from 19b (50 mg, $0.17 \mathrm{mmol}$ ) and 7 (38 $\mathrm{mg}, 0.17 \mathrm{mmol}$ ), the $N$-Boc-protected intermediate was prepared and deprotected as described for the synthesis of $\mathbf{1}$. The crude product was purified by flash chromatography on silica gel $\left(10 \% \mathrm{MeOH}, 1 \% \mathrm{NH}_{4} \mathrm{OH}\right.$, in DCM) to give 25 as yellow oil (52 mg, 80\% over two steps). ${ }^{1} \mathrm{H}$ NMR $\left(300 \mathrm{MHz}, \mathrm{CD}_{3} \mathrm{OD}\right) \delta 7.76(\mathrm{~d}, J=8.5 \mathrm{~Hz}, 1 \mathrm{H}), 7.43-7.35(\mathrm{~m}, 4 \mathrm{H})$, $7.27-7.21(\mathrm{~m}, 3 \mathrm{H}), 6.10(\mathrm{~d}, J=3.1 \mathrm{~Hz}, 1 \mathrm{H}), 5.60(\mathrm{~d}, J=3.3 \mathrm{~Hz}, 1 \mathrm{H})$, $3.63(\mathrm{~s}, 2 \mathrm{H}), 3.05(\mathrm{~d}, J=12.4 \mathrm{~Hz}, 2 \mathrm{H}), 2.60(\mathrm{t}, J=11.7 \mathrm{~Hz}, 2 \mathrm{H}), 2.39$ (d, $J=6.7 \mathrm{~Hz}, 2 \mathrm{H}), 1.72(\mathrm{~d}, J=13.0 \mathrm{~Hz}, 2 \mathrm{H}), 1.64-1.53(\mathrm{~m}, 1 \mathrm{H}), 1.20-1.04$ $(\mathrm{m}, 2 \mathrm{H}) ;{ }^{13} \mathrm{C}$ NMR $\left(75 \mathrm{MHz}, \mathrm{CD}_{3} \mathrm{OD}\right) \delta 171.8,152.7,151.4,141.1,141.1$, 132.7, 130.3, 128.7, 128.4, 128.2, 127.6, 127.5, 110.0, 109.2, 53.7, 45.3, 44.0, 33.9, 27.4; MS (ESI) $m / z 381[\mathrm{M}+\mathrm{H}]^{+}$. Anal. for $\left(\mathrm{C}_{23} \mathrm{H}_{25} \mathrm{ClN}_{2} \mathrm{O}\right)$ C, $\mathrm{H}, \mathrm{N}$.

\subsubsection{1-(5-(4-Phenyl-2-chlorophenyl)furan-2-yl)-N-(piperidin-4-} ylmethyl)methanamine (26)

Starting from 19a ( $50 \mathrm{mg}, 0.17 \mathrm{mmol}$ ) and 7 (38 mg, $0.17 \mathrm{mmol}$ ), the $N$-Boc-protected intermediate was prepared and deprotected as described for the synthesis of $\mathbf{1}$. The crude product was purified by flash chromatography on alumina gel $\left(2 \% \mathrm{MeOH}, 0.5 \% \mathrm{NH}_{4} \mathrm{OH}\right.$, in DCM) to give $\mathbf{2 6}$ as yellow oil ( $33 \mathrm{mg}, 51 \%$ over two steps). ${ }^{1} \mathrm{H}$ NMR $\left(300 \mathrm{MHz}, \mathrm{CD}_{3} \mathrm{OD}\right) \delta 7.97(\mathrm{~d}, J=8.3 \mathrm{~Hz}, 1 \mathrm{H}), 7.72(\mathrm{~d}, J=1.9 \mathrm{~Hz}, 1 \mathrm{H})$, $7.68-7.60(\mathrm{~m}, 3 \mathrm{H}), 7.54-7.34(\mathrm{~m}, 3 \mathrm{H}), 7.11(\mathrm{~d}, J=3.3 \mathrm{~Hz}, 1 \mathrm{H}), 6.44(\mathrm{~d}$, $J=3.3 \mathrm{~Hz}, 1 \mathrm{H}), 3.84(\mathrm{~s}, 2 \mathrm{H}), 3.06(\mathrm{~d}, J=12.2 \mathrm{~Hz}, 2 \mathrm{H}), 2.61(\mathrm{t}$, $J=11.6 \mathrm{~Hz}, 2 \mathrm{H}), 2.52(\mathrm{~d}, J=6.9 \mathrm{~Hz}, 2 \mathrm{H}), 1.78(\mathrm{~d}, J=13.6 \mathrm{~Hz}, 2 \mathrm{H}), 1.66$ (brs, $1 \mathrm{H}), 1.25-1.08(\mathrm{~m}, 2 \mathrm{H}) ;{ }^{13} \mathrm{C}$ NMR $\left(75 \mathrm{MHz}, \mathrm{CDCl}_{3}\right) \delta 154.3$, 149.4, 140.9, 139.4, 133.4, 130.4, 130.3, 129.3, 129.1, 128.8, 128.2, 128.1, 127.1, 125.6, 112.0, 109.4, 55.7, 46.8, 46.7, 36.8, 31.6; MS (ESI) $\mathrm{m} / \mathrm{z} 381[\mathrm{M}+\mathrm{H}]^{+}$. Anal. for $\left(\mathrm{C}_{23} \mathrm{H}_{25} \mathrm{ClN}_{2} \mathrm{O}\right) \mathrm{C}, \mathrm{H}, \mathrm{N}$.

\subsubsection{5-(4-Bromo-2-chlorophenyl)thiophene-2-carbaldehyde (28a)}

Starting from 16a (300 mg, $1.5 \mathrm{mmol}$ ) and 27 (135 $\mu \mathrm{L}, 1.5 \mathrm{mmol})$, the title compound was prepared following the procedure described for the synthesis of compound 5a (Method B). The crude product was purified by flash chromatography on silica gel (10\% EtOAc in petroleum ether) to give 28a as yellow oil (360 mg, 80\%). ${ }^{1} \mathrm{H} \mathrm{NMR}\left(300 \mathrm{MHz}, \mathrm{CDCl}_{3}\right) \delta 9.93(\mathrm{~s}, 1 \mathrm{H}), 7.75(\mathrm{~d}, J=3.9 \mathrm{~Hz}, 1 \mathrm{H}), 7.72$ $(\mathrm{d}, J=2.0 \mathrm{~Hz}, 1 \mathrm{H}), 7.41(\mathrm{~s}, 1 \mathrm{H}), 7.38-7.35(\mathrm{~m}, 2 \mathrm{H}) ;{ }^{13} \mathrm{C} \mathrm{NMR}(75 \mathrm{MHz}$, $\left.\mathrm{CDCl}_{3}\right) \delta 183.1,148.7,144.2,136.3,133.5,133.5,132.4,131.1,130.7$, 129.1, 123.5; MS (ESI) $m / z 302[\mathrm{M}+\mathrm{H}]^{+}$.

\subsubsection{5-(2-Bromo-4-chlorophenyl)thiophene-2-carbaldehyde} (28b)

Starting from 16b $(200 \mathrm{mg}, 0.97 \mathrm{mmol})$ and $27(87 \mu \mathrm{L}$, $0.97 \mathrm{mmol}$ ), the title compound was prepared following the procedure described for the synthesis of compound 5a (Method B). The crude product was purified by flash chromatography on silica gel (10\% EtOAc in petroleum ether) to give $\mathbf{2 8 b}$ as yellow oil (227 mg, 78\%). ${ }^{1} \mathrm{H}$ NMR (300 MHz, $\left.\mathrm{CDCl}_{3}\right) \delta 9.93(\mathrm{~s}, 1 \mathrm{H}), 7.75$ (d, $J=3.9 \mathrm{~Hz}, 1 \mathrm{H}), 7.72(\mathrm{~d}, J=2.0 \mathrm{~Hz}, 1 \mathrm{H}), 7.41(\mathrm{~s}, 1 \mathrm{H}), 7.38-7.35(\mathrm{~m}$, 2H). ${ }^{13} \mathrm{C}$ NMR: $\left(75 \mathrm{MHz}, \mathrm{CDCl}_{3}\right) \delta$ 183.1, 148.7, 144.2, 136.3, 133.5, 133.5, 132.4, 131.1, 130.7, 129.1, 123.5. MS (ESI) $m / z 302[\mathrm{M}+\mathrm{H}]^{+}$.

\subsubsection{1-(5-(4-Bromo-2-chlorophenyl)thiophen-2-yl)-N- (piperidin-4-ylmethyl)methanamine (29)}

Starting from 28a (88 $\mathrm{mg}, 0.4 \mathrm{mmol})$ and 7 ( $85 \mathrm{mg}, 0.4 \mathrm{mmol})$, the $N$-Boc-protected intermediate was prepared and deprotected as described for the synthesis of $\mathbf{1}$. The crude product was purified by flash chromatography on silica gel $\left(10 \% \mathrm{MeOH}, 1 \% \mathrm{NH}_{4} \mathrm{OH}\right.$, in DCM) to give 29 as yellow oil ( $115 \mathrm{mg}, 72 \%$ over two steps). ${ }^{1} \mathrm{H}$ NMR $\left(300 \mathrm{MHz}, \mathrm{CDCl}_{3}\right) \delta 7.62(\mathrm{~s}, 1 \mathrm{H}), 7.38(\mathrm{~d}, J=1.6 \mathrm{~Hz}, 1 \mathrm{H}), 7.26(\mathrm{~d}$, $J=0.9 \mathrm{~Hz}, 1 \mathrm{H}), 7.20(\mathrm{~d}, J=2.4 \mathrm{~Hz}, 1 \mathrm{H}), 6.90(\mathrm{~d}, J=2.7 \mathrm{~Hz}, 1 \mathrm{H}), 3.98$ $(\mathrm{s}, 2 \mathrm{H}), 3.08(\mathrm{~d}, J=12.2 \mathrm{~Hz}, 2 \mathrm{H}), 2.57(\mathrm{~d}, J=6.5 \mathrm{~Hz}, 2 \mathrm{H}), 1.74(\mathrm{~m}, 4 \mathrm{H})$, 1.61 (brs, 2H), $1.29-1.07$ (m, 3H); ${ }^{13} \mathrm{C}$ NMR $\left(75 \mathrm{MHz}, \mathrm{CDCl}_{3}\right) \delta 207.2$, 146.4, 137.9, 133.2, 132.6, 132.3, 130.3, 127.8, 125.0, 121.4, 55.6, 49.0, 46.3, 36.6, 31.1; MS (ESI) $m / z 400[\mathrm{M}+\mathrm{H}]^{+}$. Anal. $\left(\mathrm{C}_{17} \mathrm{H}_{20} \mathrm{BrClN}_{2} \mathrm{~S}\right) \mathrm{C}$, $\mathrm{H}, \mathrm{N}$.

\subsubsection{1-(5-(2-Bromo-4-chlorophenyl)thiophen-2-yl)-N- (piperidin-4-ylmethyl)methanamine (30)}

Starting from $\mathbf{2 8 b}$ ( $48 \mathrm{mg}, 0.2 \mathrm{mmol}$ ) and 7 (43 $\mathrm{mg}, 0.2 \mathrm{mmol}$ ), the $N$-Boc-protected intermediate was prepared and deprotected as described for the synthesis of $\mathbf{1}$. The crude product was purified by flash chromatography on silica gel $\left(10 \% \mathrm{MeOH}, 1 \% \mathrm{NH}_{4} \mathrm{OH}\right.$, in DCM) to give 30 as yellow oil (50 mg, 63\% over two steps). ${ }^{1} \mathrm{H}$ NMR $\left(300 \mathrm{MHz}, \mathrm{CD}_{3} \mathrm{OD}\right) \delta 7.73(\mathrm{~s}, 1 \mathrm{H}), 7.46(\mathrm{~d}, J=8.4 \mathrm{~Hz}, 1 \mathrm{H}), 7.40-7.37$ $(\mathrm{m}, 1 \mathrm{H}), 7.14(\mathrm{~d}, J=1.5 \mathrm{~Hz}, 1 \mathrm{H}), 6.98(\mathrm{~d}, J=2.7 \mathrm{~Hz}, 1 \mathrm{H}), 3.95(\mathrm{~s}, 2 \mathrm{H})$, $3.06(\mathrm{~d}, J=12.8 \mathrm{~Hz}, 2 \mathrm{H}), 2.62(\mathrm{t}, J=13.3, \mathrm{~Hz}, 2 \mathrm{H}), 2.51(\mathrm{~d}, J=6.6 \mathrm{~Hz}$, $2 \mathrm{H}), 1.78(\mathrm{~d}, J=13.2 \mathrm{~Hz}, 2 \mathrm{H}), 1.65(\mathrm{~m}, 1 \mathrm{H}), 1.28-1.08(\mathrm{~m}, 2 \mathrm{H}) ;{ }^{13} \mathrm{C}$ NMR $\left(75 \mathrm{MHz}, \mathrm{CDCl}_{3}\right) \delta 207.2,146.4,137.9,133.2,132.6,132.29$, 130.3, 127.8, 125.0, 121.4, 55.6, 49.0, 46.3, 36.6, 31.1; MS (ESI) $m / z$ $400[\mathrm{M}+\mathrm{H}]^{+}$. Anal. $\left(\mathrm{C}_{17} \mathrm{H}_{20} \mathrm{BrClN}_{2} \mathrm{~S}\right) \mathrm{C}, \mathrm{H}, \mathrm{N}$.

\subsubsection{1-(5-Bromobenzothiophen-2-yl)-N-(piperidin-4-ylmethyl)} methanamine (32)

Starting from 31 ( $40 \mathrm{mg}, 0.21 \mathrm{mmol})$, the $N$-Boc-protected intermediate was prepared and deprotected as described for the synthesis of $\mathbf{1}$. The crude product was purified by flash chromatography on silica gel $\left(10 \% \mathrm{MeOH}, 1 \% \mathrm{NH}_{4} \mathrm{OH}\right.$, in DCM) to give 32 as yellow oil (41 mg, $60 \%$ over two steps). ${ }^{1} \mathrm{H}$ NMR (300 MHz, $\mathrm{CD}_{3} \mathrm{OD}$ ) $\delta 7.97(\mathrm{~s}, 1 \mathrm{H}), 7.61(\mathrm{~d}, J=8.5 \mathrm{~Hz}, 1 \mathrm{H}), 7.41(\mathrm{~d}, J=4.2, \mathrm{~Hz}, 1 \mathrm{H}), 7.20(\mathrm{~s}$, $1 \mathrm{H}), 4.01$ (s, 2H), 3.03 (d, $J=12.4 \mathrm{~Hz}, 2 \mathrm{H}), 2.58(\mathrm{t}, J=12.4, \mathrm{~Hz}, 2 \mathrm{H})$, $2.49(\mathrm{~d}, J=6.7 \mathrm{~Hz}, 2 \mathrm{H}), 1.75(\mathrm{~d}, J=13.2 \mathrm{~Hz}, 2 \mathrm{H}), 1.71-1.56(\mathrm{~m}, 1 \mathrm{H})$, $1.13(\mathrm{~m}, 2 \mathrm{H}) ;{ }^{13} \mathrm{C}$ NMR $\left(75 \mathrm{MHz}, \mathrm{CD}_{3} \mathrm{OD}\right) \delta 145.9,141.6,138.9,127.4$, 124.5, 124.3, 121.5, 117.3, 54.8, 45.4, 35.9, 30.4; MS (ESI) $m / z 362$ $[\mathrm{M}+\mathrm{Na}]^{+}$. Anal. $\left(\mathrm{C}_{15} \mathrm{H}_{19} \mathrm{BrN}_{2} \mathrm{~S}\right) \mathrm{C}, \mathrm{H}, \mathrm{N}$.

\subsubsection{4-Benzyl-3-(4-chlorophenyl)-4H-1,2,4-triazole (34)}

To a solution of $33(239.0 \mathrm{mg}, 0.95 \mathrm{mmol})$ in $\mathrm{MeCN}(10 \mathrm{~mL})$, DMF-DMA ( $128 \mu \mathrm{L}, 0.95 \mathrm{mmol})$ was added. The reaction was heated to $50^{\circ} \mathrm{C}$ for $1 \mathrm{~h}$. After this time, benzylamine $(101 \mu \mathrm{L}, 0.85 \mathrm{mmol})$ and acetic acid $(2 \mathrm{~mL})$ were added and reaction was heated at $120^{\circ} \mathrm{C}$ for $12 \mathrm{~h}$. The solvent was removed under vacuo. The crude product was purified by flash chromatography on silica gel ( $2 \%$ $\mathrm{MeOH}$ in EtOAc) to give 34 (198 mg, 60\%) as yellow oil. ${ }^{1} \mathrm{H}$ NMR $\left(300 \mathrm{MHz}, \mathrm{CDCl}_{3}\right) \delta 8.19(\mathrm{~s}, 1 \mathrm{H}), 7.46(\mathrm{dd}, J=8.5,2.1 \mathrm{~Hz}, 2 \mathrm{H})$, 7.41-7.33 (m, 2H), 7.30-7.23 (m, 3H), 7.06-6.96 (m, 1H), 5.17 (s, $2 \mathrm{H}) ; \mathrm{MS}(\mathrm{ESI}) \mathrm{m} / z 350[\mathrm{M}+\mathrm{H}]^{+}$.

\subsubsection{3. (4-Benzyl-5-(4-chlorophenyl)-4H-1,2,4-triazol-3-yl)} methanol (35)

A solution of $34(100 \mathrm{mg}, 0.29)$ in formaldehyde (aq. sol. $37 \%$, 
$2.8 \mathrm{~mL}$ ) was heated under reflux for $12 \mathrm{~h}$. The solvent was removed under vacuo. The crude product was purified by flash chromatography on silica gel (2\% MeOH in EtOAc) to give $\mathbf{3 5}$ as yellow oil. ${ }^{1} \mathrm{H}$ NMR (300 MHz, CD $\left.{ }_{3} \mathrm{OD}\right) \delta 7.55-7.44(\mathrm{~m}, 4 \mathrm{H}), 7.32-7.26(\mathrm{~m}, 2 \mathrm{H})$, 7.03-6.97 (m, 2H), 5.45 (s, 2H), 4.81 (d, J=1.2 Hz, 2H). (43 mg, 50\%). MS (ESI) $m / z 300[\mathrm{M}+\mathrm{H}]^{+}$.

\subsubsection{4-Benzyl-3-(chloromethyl)-5-(4-chlorophenyl)-4H-1,2,4- triazole (36a)}

To a solution of 35 (40 mg, $0.13 \mathrm{mmol})$ in dry DCM $(4 \mathrm{~mL})$, pyridine $(12 \mu \mathrm{L}, 0.14 \mathrm{mmol})$ and thionyl chloride $(13 \mu \mathrm{L}, 0.16 \mathrm{mmol})$ were added at $0{ }^{\circ} \mathrm{C}$. After $3 \mathrm{~h}$ an aqueous solution of sodium bicarbonate was added and the organic phase was extracted with DCM, dried over sodium sulfate, filtered and evaporated in vacuo. The crude product was purified by flash chromatography on silica gel $\left(2 \% \mathrm{MeOH}\right.$ in DCM) to give $\mathbf{3 6 a}$ as yellow oil $(20 \mathrm{mg}, 50 \%) .{ }^{1} \mathrm{H}$ NMR (300 MHz, CD $30 D) \delta 7.55-7.44(\mathrm{~m}, 4 \mathrm{H}), 7.32-7.26(\mathrm{~m}, 2 \mathrm{H})$, 7.03-6.97 (m, 2H), $5.43(\mathrm{~s}, 2 \mathrm{H}), 4.92(\mathrm{~s}, 2 \mathrm{H})$; MS (ESI) m/z 319 $[\mathrm{M}+\mathrm{H}]^{+}$.

\subsubsection{2-(2-Bromo-4-chlorophenyl)-5-(chloromethyl)-1,3,4-} oxadiazole ( $36 \boldsymbol{b}$ )

To a solution of 33 (200 mg, $0.8 \mathrm{mmol}$ ) in phosphoryl chloride $(2 \mathrm{~mL})$, chloroacetic aid ( $76 \mathrm{mg}, 0.8 \mathrm{mmol}$ ) was added. The reaction mixture was heated under reflux for $12 \mathrm{~h}$. After this time the mixture was cooled at $0{ }^{\circ} \mathrm{C}$, and an aqueous solution of sodium bicarbonate $(2 \mathrm{~mL})$ was slowly added. The organic phase was extracted with EtOAc $(3 \times 5 \mathrm{~mL})$, dried over sodium sulfate, filtered and evaporated in vacuo. The crude product was purified by flash chromatography on silica gel (15\% EtOAc in petroleum ether) to give 36b as yellow oil (49 mg, 20\%). ${ }^{1} \mathrm{H}$ NMR (300 MHz, CD $\left.{ }_{3} \mathrm{OD}\right) \delta 8.04$ (d, $J=8.7 \mathrm{~Hz}, 1 \mathrm{H}), 7.94-7.89(\mathrm{~m}, 1 \mathrm{H}), 7.60(\mathrm{~d}, J=8.0 \mathrm{~Hz}, 1 \mathrm{H}), 4.96(\mathrm{~s}$, $2 \mathrm{H}) ;{ }^{13} \mathrm{C}$ NMR $\left(75 \mathrm{MHz}, \mathrm{CD}_{3} \mathrm{OD}\right) \delta 139.13,134.11,132.61,131.86$, 130.09, 129.56, 128.36, 122.05, 32.49. MS (ESI) $\mathrm{m} / z 308[\mathrm{M}+\mathrm{H}]^{+}$, $330[\mathrm{M}+\mathrm{Na}]^{+}$.

\subsubsection{1-(5-(4-Chlorophenyl)-4H-1,2,4-triazol-3-yl)-N-(piperidin-} 4-ylmethyl)methanamine (37)

To a solution of $\mathbf{3 6 a}(19 \mathrm{mg}, 0.060 \mathrm{mmol})$ in dry $\mathrm{MeCN}(1 \mathrm{~mL})$, a solution of $7(20 \mathrm{mg}, 0.065 \mathrm{mmol})$ in dry MeCN $(2 \mathrm{~mL})$, potassium carbonate $(134 \mathrm{mg}, 0.97 \mathrm{mmol}$ ) and a catalytic amount of potassium iodide were slowly added. The reaction mixture was heated under reflux for $1 \mathrm{~h}$. After this time, the solvent was removed in vacuo. $\mathrm{H}_{2} \mathrm{O}(1 \mathrm{~mL})$ and EtOAc $(5 \mathrm{~mL})$ were added and the organic phase was separated, dried over sodium sulfate, filtered and evaporated in vacuo. The crude product was purified by flash chromatography on silica gel $(2 \% \mathrm{MeOH}$ in DCM) to give 4-(4benzyl-5-(4-chlorophenyl)-4H-1,2,4-triazol-3-yl)methylamino- $N$ tert-butoxy carbonylpiperidine as colorless oil $(21 \mathrm{mg}, 72 \%) .{ }^{1} \mathrm{H}$ NMR (300 MHz, CD $\left.{ }_{3} \mathrm{OD}\right) \delta$ 7.55-7.44 (m, 5H), 7.34-7.26 (m, 2H), $6.98(\mathrm{~d}, J=8.0 \mathrm{~Hz}, 2 \mathrm{H}), 5.47(\mathrm{~s}, 2 \mathrm{H}), 4.02(\mathrm{~d}, J=13.4 \mathrm{~Hz}, 2 \mathrm{H}), 3.91(\mathrm{~s}$, $2 \mathrm{H}), 2.69(\mathrm{~s}, 2 \mathrm{H}), 2.49(\mathrm{~s}, 2 \mathrm{H}), 1.65(\mathrm{~d}, J=13.5 \mathrm{~Hz}, 2 \mathrm{H}), 1.61-1.50(\mathrm{~m}$, $1 \mathrm{H}), 1.44(\mathrm{~s}, 9 \mathrm{H}), 1.11-0.94(\mathrm{~m}, 2 \mathrm{H})$; MS (ESI) $\mathrm{m} / z 497[\mathrm{M}+\mathrm{H}]^{+}, 535$ $[\mathrm{M}+\mathrm{K}]^{+}$. To a solution of the above product $(20 \mathrm{mg}, 0.04 \mathrm{mmol})$ in DMSO $(30 \mu \mathrm{L})$, a solution of potassium tert-butoxide (34 mg, $0.30 \mathrm{mmol})$ in dry THF $(1 \mathrm{~mL})$ was added. The reaction environment was saturated with oxygen. After $2 \mathrm{~h}$ an aqueous solution of ammonium chloride $(0.5 \mathrm{~mL})$ was added and the organic phase was extracted with EtOAc $(3 \times 3 \mathrm{~mL})$, dried over sodium sulfate, filtered and evaporated in vacuo. The crude product was purified by flash chromatography on silica gel (2\% MeOH in DCM) to give [5-(4chlorophenyl)-4H-1,2,4-triazol-3-yl]methylamino-methyl- $N$-tertbutoxy-carbonyl piperidine as yellow oil (14 mg, 87\%). ${ }^{1} \mathrm{H}$ NMR $\left(300 \mathrm{MHz}, \mathrm{CD}_{3} \mathrm{OD}\right) \delta 7.97(\mathrm{~d}, J=8.2 \mathrm{~Hz}, 2 \mathrm{H}), 7.48(\mathrm{~d}, J=7.9 \mathrm{~Hz}, 2 \mathrm{H})$, $4.07(\mathrm{~d}, J=13.2,2 \mathrm{H}), 3.96(\mathrm{~s}, 2 \mathrm{H}), 2.77(\mathrm{~d}, J=12.0 \mathrm{~Hz}, 2 \mathrm{H}), 2.58(\mathrm{~d}$,
$J=6.0 \mathrm{~Hz}, 2 \mathrm{H}), 1.76(\mathrm{~d}, J=12.4 \mathrm{~Hz}, 2 \mathrm{H}), 1.44(\mathrm{~s}, 9 \mathrm{H}), 1.31-1.21(\mathrm{~m}$, $2 \mathrm{H}), 1.15-1.04(\mathrm{~m}, 1 \mathrm{H})$. MS (ESI) $m / z 407[\mathrm{M}+\mathrm{H}]^{+}$. Starting from the above compound (15 mg, $0.03 \mathrm{mmol})$ and $\mathrm{HCl} 1 \mathrm{~N}(120 \mu \mathrm{L}$, $0.12 \mathrm{mmol}$ ), the title compound was deprotected as described for the synthesis of $\mathbf{1}$. The crude product $\mathbf{3 7}$ was obtained as yellow oil without further purification (11 mg, 84\%). ${ }^{1} \mathrm{H} \mathrm{NMR}(300 \mathrm{MHz}$, $\left.\mathrm{CD}_{3} \mathrm{OD}\right) \delta 8.03(\mathrm{~d}, J=8.2 \mathrm{~Hz}, 2 \mathrm{H}), 7.63(\mathrm{~d}, J=8.1 \mathrm{~Hz}, 2 \mathrm{H}), 4.62(\mathrm{~s}, 2 \mathrm{H})$, $3.46(\mathrm{~d}, J=12.1 \mathrm{~Hz}, 2 \mathrm{H}), 3.11(\mathrm{t}, J=11.8 \mathrm{~Hz}, 2 \mathrm{H}), 2.83$ (brs, $2 \mathrm{H}), 2.32$ (brs, $1 \mathrm{H}), 2.14$ (d, $J=11.9 \mathrm{~Hz}, 2 \mathrm{H}), 1.68$ (d, $J=11.1 \mathrm{~Hz}, 2 \mathrm{H})$; MS (ESI) $m / z 397[\mathrm{M}+\mathrm{H}]^{+}$. Anal. $\left(\mathrm{C}_{15} \mathrm{H}_{20} \mathrm{ClN}_{5}\right) \mathrm{C}, \mathrm{H}, \mathrm{N}$.

\subsubsection{1-(5-(2-Bromo-4-chlorophenyl)-1,3,4-oxadiazol-2-yl)- $N$ - (piperidin-4-ylmethyl)methan amine (38)}

To a solution of $\mathbf{3 6 b}(12 \mathrm{mg}, 0.06 \mathrm{mmol})$ in dry $\mathrm{MeCN}(1 \mathrm{~mL})$, a solution of $7(20 \mathrm{mg}, 0.065 \mathrm{mmol})$ in dry $\mathrm{MeCN}(2 \mathrm{~mL})$, potassium carbonate $(134 \mathrm{mg}, 0.97 \mathrm{mmol}$ ) and a catalytic amount of potassium iodide were slowly added. The reaction mixture was heated under reflux for $1 \mathrm{~h}$. After this time, the solvent was removed in vacuo. $\mathrm{H}_{2} \mathrm{O}(1 \mathrm{~mL})$ and EtOAc $(5 \mathrm{~mL})$ were added and the organic phase was separated, dried over sodium sulfate, filtered and evaporated in vacuo. The crude product was purified by flash chromatography on silica gel (2\% $\mathrm{MeOH}$ in DCM) to give (5-(2bromo-4-chlorophenyl)-1,3,4-oxadiazol-2-yl)methylaminomethyl$\mathrm{N}$-tert-butoxy carbonylpiperidine as yellow oil $(25 \mathrm{mg}, 81 \%) .{ }^{1} \mathrm{H}$ NMR $\left(300 \mathrm{MHz}, \mathrm{CD}_{3} \mathrm{OD}\right) \delta 8.02(\mathrm{~d}, J=8.6 \mathrm{~Hz}, 1 \mathrm{H}), 7.89(\mathrm{~d}, J=5.0 \mathrm{~Hz}$, $1 \mathrm{H}), 7.59(\mathrm{dd}, J=8.5,1.9 \mathrm{~Hz}, 1 \mathrm{H}), 4.08(\mathrm{~d}, J=5.8 \mathrm{~Hz}, 2 \mathrm{H}), 4.03(\mathrm{~s}, 2 \mathrm{H})$, $2.74(\mathrm{~s}, 2 \mathrm{H}), 2.57(\mathrm{~s}, 2 \mathrm{H}), 1.74(\mathrm{~d}, J=13.9 \mathrm{~Hz}, 2 \mathrm{H}), 1.69-1.61(\mathrm{~m}, 1 \mathrm{H})$, 1,44 (s, 9H) 1.17-0.99 (m, 2H); MS (ESI) m/z $508[\mathrm{M}+\mathrm{H}]^{+}$. Starting from the above compound ( $20 \mathrm{mg}, 0.04 \mathrm{mmol})$ and $\mathrm{HCl} 1 \mathrm{~N}(160 \mu \mathrm{L}$, $0.16 \mathrm{mmol}$ ), the title compound was prepared following the procedure reported for compound 37. The solvent was removed in vacuo. A saturated solution of sodium bicarbonate $(1 \mathrm{~mL})$ was added and the organic phase was extracted with EtOAc $(3 \times 3 \mathrm{~mL})$, dried over sodium sulfate, filtered and evaporated in vacuo. The crude product was purified by flash chromatography on silica gel (10\% $\mathrm{MeOH}, 1 \% \mathrm{NH}_{4} \mathrm{OH}$, in $\left.\mathrm{DCM}\right)$ to give 38 as yellow oil $(13 \mathrm{mg}$, 82\%). ${ }^{1} \mathrm{H}$ NMR (300 MHz, CD $\left.3 \mathrm{OD}\right) \delta 8.03(\mathrm{~d}, J=8.3 \mathrm{~Hz}, 1 \mathrm{H}), 7.91$ (d, $J=4.9,1 \mathrm{H}), 7.59(\mathrm{~d}, J=8.5 \mathrm{~Hz}, 1 \mathrm{H}), 5.48(\mathrm{~s}, 2 \mathrm{H}), 3.39(\mathrm{~d}, J=12.5 \mathrm{~Hz}$, $2 \mathrm{H}), 3.32-3.27(\mathrm{~m}, 2 \mathrm{H}), 2.97(\mathrm{t}, J=12.4 \mathrm{~Hz}, 2 \mathrm{H}), 2.07-1.98(\mathrm{~m}, 2 \mathrm{H})$, 1.90-1.82 (m, 1H), 1.50-1.24 (m, 2H); MS (ESI) $m / z 386[\mathrm{M}+\mathrm{H}]^{+}$. Anal. for $\left(\mathrm{C}_{15} \mathrm{H}_{18} \mathrm{BrClN}_{4} \mathrm{O}\right) \mathrm{C}, \mathrm{H}, \mathrm{N}$.

\subsubsection{2-Methyl-6-(4-(trifluoromethyl)phenyl)pyridine (41)}

Triphenylphosphine (366 mg, $1.4 \mathrm{mmol}$ ) and palladium (II) acetate $(20 \mathrm{mg}, 0.1 \mathrm{mmol}$ ) were dissolved in a mixture of dry DMF $(7 \mathrm{~mL})$ and $\mathrm{H}_{2} \mathrm{O}(3 \mathrm{~mL})$ under argon atmosphere. After $30 \mathrm{~min}, 39$ $(198 \mu \mathrm{L}, 1.7 \mathrm{mmol})$ was added. After further $30 \mathrm{~min}$, potassium carbonate $(721 \mathrm{mg}, 5.2 \mathrm{mmol})$ and powered 4-trifluoromethylphenyl boronic acid 40 (331 mg, $1.7 \mathrm{mmol}$ ) were added in this order. The reaction mixture was heated at reflux for $12 \mathrm{~h}$. The solvent was removed under vacuo. $\mathrm{H}_{2} \mathrm{O}(2 \mathrm{~mL})$ and EtOAc $(8 \mathrm{~mL})$ were added, the organic phase was separated, dried over sodium sulfate, filtered and evaporated in vacuo. The crude product was purified by flash chromatography on silica gel (2\% EtOAc in petroleum ether) to give 41 as white solid (336 mg, 81\%). ${ }^{1} \mathrm{H}$ NMR $\left(300 \mathrm{MHz}, \mathrm{CDCl}_{3}\right)$ $\delta 8.13-8.01(\mathrm{~d}, J=7,83 \mathrm{~Hz}, 2 \mathrm{H}), 7.67(\mathrm{~d}, J=8.6 \mathrm{~Hz}, 2 \mathrm{H}), 7.56(\mathrm{t}$, $J=7.73 \mathrm{~Hz}, 1 \mathrm{H}$ ), 7.44 (d, $J=8.0 \mathrm{~Hz}, 1 \mathrm{H}), 7.07$ (d, $J=7.8 \mathrm{~Hz}, 1 \mathrm{H}), 2.61$ (s, 3H). MS (ESI) $m / z 238[\mathrm{M}+\mathrm{H}]^{+}$.

\subsubsection{2-(Bromomethyl)-6-(4-trifluoromethyl)phenylpyridine (42)}

To a solution of $41(336 \mathrm{mg}, 1.4 \mathrm{mmol})$ in $\mathrm{CCl}_{4}(14 \mathrm{~mL})$, NBS (904 mg, $5.1 \mathrm{mmol}$ ) and AIBN (98 mg, $0.6 \mathrm{mmol}$ ) were added portion wise. The reaction was heated under reflux for $12 \mathrm{~h}$. The mixture was filtered on paper and the filtrate was concentrated under vacuo. The crude product was purified by flash 
chromatography on silica gel (20\% DCM in petroleum ether) to give 42 as white solid (132 mg, 30\%). ${ }^{1} \mathrm{H}$ NMR $\left(300 \mathrm{MHz}, \mathrm{CDCl}_{3}\right) \delta 8.13$ (d, $J=8.00 \mathrm{~Hz}, 2 \mathrm{H}), 7.81(\mathrm{t}, J=7.8 \mathrm{~Hz}, 1 \mathrm{H}), 7.73(\mathrm{~d}, J=8.12 \mathrm{~Hz}, 2 \mathrm{H}), 7.68$ $(\mathrm{d}, J=8.0 \mathrm{~Hz}, 1 \mathrm{H}), 7.46(\mathrm{~d}, J=7.6 \mathrm{~Hz}, 1 \mathrm{H}), 4.63(\mathrm{~s}, 2 \mathrm{H})$; MS (ESI) $m / z$ $317[\mathrm{M}+\mathrm{H}]^{+}$.

\subsubsection{1-(Piperidin-4-yl)-N-((6-(4-(trifluoromethyl)phenyl) pyridin-2-yl)methyl)methanamine (43)}

To a solution of 7 (66 mg, $0.3 \mathrm{mmol})$ in dry $\mathrm{MeCN}(1 \mathrm{~mL})$, was slowly added a solution of $\mathbf{4 2}(49 \mathrm{mg}, 0.2 \mathrm{mmol})$ in dry MeCN $(3 \mathrm{~mL})$ and powered potassium carbonate ( $171 \mathrm{mg}, 1.2 \mathrm{mmol})$. After $12 \mathrm{~h}$, the solvent was removed in vacuo. $\mathrm{H}_{2} \mathrm{O}(1 \mathrm{~mL})$ and EtOAc $(5 \mathrm{~mL})$ were added and the organic phase was washed with an aqueous solution $\mathrm{NaOH}(1 \mathrm{~N}, 2 \mathrm{~mL})$ dried over sodium sulfate, filtered and evaporated in vacuo. The crude product was purified by flash chromatography on silica gel ( $2 \% \mathrm{MeOH}$ in $\mathrm{DCM})$ to give the alkylation product 6-[4-(trifluoromethyl)phenyl-pyridin-2-yl] methylamino-methyl- $N$-tert-butoxycarbonyl piperidine as colorless oil. (18 mg, 20\%). ${ }^{1} \mathrm{H}$ NMR: (300 MHz, CD $\left.\mathrm{CD}_{3} \mathrm{OD}\right) \delta 8.25$ (d, $J=8.1 \mathrm{~Hz}, 2 \mathrm{H}), 7.87-7.82(\mathrm{~m}, 2 \mathrm{H}), 7.78(\mathrm{~d}, J=8.1 \mathrm{~Hz}, 2 \mathrm{H}), 7.40(\mathrm{~d}$, $J=7.0 \mathrm{~Hz}, 1 \mathrm{H}), 4.06(\mathrm{~d}, J=13.5 \mathrm{~Hz}, 2 \mathrm{H}), 3.99(\mathrm{~s}, 2 \mathrm{H}), 2.76(\mathrm{t}$, $J=12.7 \mathrm{~Hz}, 2 \mathrm{H}), 2.60(\mathrm{~d}, J=6.2 \mathrm{~Hz}, 2 \mathrm{H}), 1.78(\mathrm{~d}, J=12.0 \mathrm{~Hz}, 2 \mathrm{H}), 1.44$ (s, 9H), $1.28(\mathrm{~s}, 1 \mathrm{H}), 1.17-1.04(\mathrm{~m}, 2 \mathrm{H})$; MS (ESI) $m / z 450[\mathrm{M}+\mathrm{H}]^{+}$, $472[\mathrm{M}+\mathrm{Na}]^{+}$. Starting from the above alkylation product $(30 \mathrm{mg}$, $0.06 \mathrm{mmol})$ and $\mathrm{HCl} 1 \mathrm{~N}(240 \mu \mathrm{L}, 0.24 \mathrm{mmol})$, the title compound was prepared following the deprotection procedure reported for compound 1. The crude product was purified by flash chromatography on silica gel $\left(10 \% \mathrm{MeOH}, 1 \% \mathrm{NH}_{4} \mathrm{OH}\right.$, in DCM) to give 43 as yellow oil (20 mg, 98\%). ${ }^{1} \mathrm{H}$ NMR $\left(300 \mathrm{MHz}, \mathrm{CD}_{3} \mathrm{OD}\right) \delta 8.25$ (d, $J=8.2 \mathrm{~Hz}, 2 \mathrm{H}), 7.87(\mathrm{~d}, J=7.3 \mathrm{~Hz}, 2 \mathrm{H}), 7.78(\mathrm{~d}, J=8.2 \mathrm{~Hz}, 2 \mathrm{H}), 7.40$ (d, $J=7.1 \mathrm{~Hz}, 1 \mathrm{H}), 3.96(\mathrm{~s}, 2 \mathrm{H}), 3.21(\mathrm{~d}, J=12.4 \mathrm{~Hz}, 2 \mathrm{H}), 2.78(\mathrm{t}$, $J=11.4 \mathrm{~Hz}, 2 \mathrm{H}), 2.58(\mathrm{~d}, J=6.6 \mathrm{~Hz}, 2 \mathrm{H}), 1.91(\mathrm{~d}, J=13.4 \mathrm{~Hz}, 2 \mathrm{H}), 1.80$ (brs, $1 \mathrm{H}), 1.27(\mathrm{~m}, 2 \mathrm{H}) ;{ }^{13} \mathrm{C}$ NMR $\left(75 \mathrm{MHz}, \mathrm{CD}_{3} \mathrm{OD}\right) \delta 162.1,159.1$, 155.3, 149.1, 143.0, 138.0, 130.8, 130.4, 127.4, 126.3, 125.5, 125.4, 119.5, 54.7, 54.1, 44.7, 35.0, 29.5, 29.0, 21.8, 17.6, 13.2, 7.1, -9.3. MS (ESI) $m / z 350[\mathrm{M}+\mathrm{H}]^{+}$. Anal. f $\left(\mathrm{C}_{19} \mathrm{H}_{22} \mathrm{~F}_{3} \mathrm{~N}_{3}\right) \mathrm{C}, \mathrm{H}, \mathrm{N}$.

\subsubsection{1. $N^{\prime}-[(5-(4-B r o m o-2-c h l o r o p h e n y l) f u r a n-2-y l) m e t h y l]-N^{\prime}, N^{\prime}-$ dimethylpropane-1,3-diamine (45)}

To a solution of $N^{1}, N^{1}$-dimethylpropane-1,3-diamine $44(22 \mu \mathrm{L}$, $0.17 \mathrm{mmol})$ in dry DCM $(2 \mathrm{~mL})$, was added a solution of aldehyde $\mathbf{5 a}$ $(45 \mathrm{mg} 0.16 \mathrm{mmol})$ in dry DCM $(5 \mathrm{~mL})$. After $1 \mathrm{~h}$ sodium triacetoxyborohydride ( $51 \mathrm{mg}, 0.24 \mathrm{mmol}$ ) was added at $0^{\circ} \mathrm{C}$ and the mixture kept at $25^{\circ} \mathrm{C}$ for $12 \mathrm{~h}$. After this time, sodium cyanoborohydride $(20 \mathrm{mg}, 0.32 \mathrm{mmol}$ ) was added and the solution was maintained at the same temperature for further $1 \mathrm{~h}$. A saturated solution of sodium bicarbonate $(3 \mathrm{~mL})$ was added and the organic phase was extracted with DCM $(3 \times 5 \mathrm{~mL})$, dried over sodium sulfate, filtered and evaporated in vacuo. The crude product was purified by flash chromatography on silica gel $\left(10 \% \mathrm{MeOH}, 1 \% \mathrm{NH}_{4} \mathrm{OH}\right.$, in DCM) to give 45 as yellow oil (50 mg, 85\%). ${ }^{1} \mathrm{H}$ NMR $(300 \mathrm{MHz}$, $\left.\mathrm{CD}_{3} \mathrm{OD}\right) \delta 7.82(\mathrm{~d}, J=6.1 \mathrm{~Hz}, 1 \mathrm{H}), 7.66(\mathrm{~s}, 1 \mathrm{H}), 7.51(\mathrm{~d}, J=6.5 \mathrm{~Hz}, 1 \mathrm{H})$, 7.09 (d, $J=3.2 \mathrm{~Hz}, 1 \mathrm{H}), 6.43(\mathrm{~d}, J=3.1 \mathrm{~Hz}, 1 \mathrm{H}), 3.83(\mathrm{~d}, J=2.1 \mathrm{~Hz}$, 2H), $2.66(\mathrm{t}, J=6.1 \mathrm{~Hz}, 2 \mathrm{H}), 2.43-2.36(\mathrm{~m}, 2 \mathrm{H}), 2.26(\mathrm{~s}, 6 \mathrm{H})$, $1.74-1.70(\mathrm{~m}, 2 \mathrm{H}) ;{ }^{13} \mathrm{C}$ NMR $\left(75 \mathrm{MHz}, \mathrm{CD}_{3} \mathrm{OD}\right) \delta 153.7,148.7,132.9$, 130.3, 130.3, 128.8, 128.4, 120.4, 112.2, 109.8, 57.4, 46.9, 45.2, 44.1, 25.6; MS (ESI) $m / z 394[\mathrm{M}+\mathrm{Na}]^{+}$. Anal. $\left(\mathrm{C}_{16} \mathrm{H}_{20} \mathrm{BrClN}_{2} \mathrm{O}\right) \mathrm{C}, \mathrm{H}, \mathrm{N}$.

\subsubsection{2. tert-Butyl [(5-(4-chloro-2-bromophenyl)furan-2-yl-} methyl]-3-dimethylaminopropyl carbamate (46)

Starting from $44(65 \mu \mathrm{L}, 0.5 \mathrm{mmol})$ and $18 \mathbf{b}(130 \mathrm{mg}, 0.5 \mathrm{mmol})$, the title compound was prepared following the procedure reported for compound $\mathbf{4 5}$. The crude product was purified by flash chromatography on silica gel ( $10 \% \mathrm{MeOH}, 1 \% \mathrm{NH}_{4} \mathrm{OH}$, in DCM) to give $N^{1}$-[(5-(4-chloro-2-bromophenyl)furan-2-yl-methyl]- $N^{3}, N^{3}$ - dimethylpropane-1,3-diamine as yellow oil (92 mg, 50\%). ${ }^{1} \mathrm{H}$ NMR $\left(300 \mathrm{MHz}, \mathrm{CD}_{3} \mathrm{OD}\right) \delta 7.80(\mathrm{~d}, J=8.6 \mathrm{~Hz}, 1 \mathrm{H}), 7.68(\mathrm{~s}, 1 \mathrm{H}), 7.43$ (d, $J=9.0 \mathrm{~Hz}, 1 \mathrm{H}), 7.12(\mathrm{~d}, J=3.4 \mathrm{~Hz}, 1 \mathrm{H}), 6.41(\mathrm{~d}, J=3.4 \mathrm{~Hz}, 1 \mathrm{H}), 3.87$ (s, $2 \mathrm{H}), 2.64(\mathrm{t}, J=7.3 \mathrm{~Hz}, 2 \mathrm{H}), 2.41-2.26(\mathrm{~m}, 2 \mathrm{H}), 2.22(\mathrm{~s}, 6 \mathrm{H}), 1.80$ $(\mathrm{t} J=6.0 \mathrm{~Hz}, 2 \mathrm{H}) ;{ }^{13} \mathrm{C}$ NMR $\left(75 \mathrm{MHz}, \mathrm{CD}_{3} \mathrm{OD}\right) \delta 153.7,148.7,132.9$, 130.3, 130.3, 128.8, 128.4, 120.4, 112.2, 109.8, 57.4, 46.86, 45.2, 44.1, 25.6; MS (ESI) $m / z 394[\mathrm{M}+\mathrm{Na}]^{+}$. To a solution of the above secondary amine ( $57 \mathrm{mg}, 0.2 \mathrm{mmol}$ ) in dry $\mathrm{MeOH}(4 \mathrm{~mL})$, triethylamine $(63 \mu \mathrm{L}, 0.5 \mathrm{mmol})$ and di-tert-butyl dicarbonate $(49 \mathrm{mg}, 0.2 \mathrm{mmol})$ were added. The reaction mixture was kept at $25^{\circ} \mathrm{C}$ for $4 \mathrm{~h}$. After this time, the solvent was removed in vacuo. $\mathrm{H}_{2} \mathrm{O}(2 \mathrm{~mL})$ was added and the organic phase was extracted with EtOAc $(3 \times 3 \mathrm{~mL})$, dried over sodium sulfate, filtered and evaporated in vacuo. The crude product was purified by flash chromatography on silica gel $(5 \%$ $\mathrm{MeOH}$ in DCM) to give $\mathbf{4 6}$ as yellow oil (82 mg, 87\%). ${ }^{1} \mathrm{H}$ NMR $\left(400 \mathrm{MHz}, \mathrm{CDCl}_{3}\right) \delta 7.65$ (d, $\left.J=8.5 \mathrm{~Hz}, 1 \mathrm{H}\right), 7.60(\mathrm{~s}, 1 \mathrm{H}), 7.27$ (d, $J=8.5,1 \mathrm{H}$ ), 7.06 (s, 1H), 6,28 (br s, $1 \mathrm{H}), 4.42$ (br s, 2H), 3.29 (br s, 2H), 2.19 (s, 6H), 1.67 (brs, 4H), 1.44 (s, 9H); MS (ESI) m/z $394[\mathrm{M}+\mathrm{H}]^{+}$.

\subsubsection{3-[(5-(4-Chloro-2-bromophenyl)furan-2-yl-methyl)amino]- $\mathrm{N}, \mathrm{N}, \mathrm{N}$-trimethylpropan-1-ammonium chloride (47)}

To a solution of $46(30 \mathrm{mg}, 0.1 \mathrm{mmol})$ in dry acetone $(2 \mathrm{~mL})$, iodomethane $(16 \mu \mathrm{L}, 0.3 \mathrm{mmol})$ was added. Reaction refluxed for $72 \mathrm{~h}$. The solvent was removed under vacuo. The crude product was purified by flash chromatography on alumina gel $(33 \% \mathrm{MeCN}$ in DCM) to give (5-(2-bromo-4-chlorophenyl)furan-2-yl)methyl) (tert-butoxycarbonyl)amino)- $\mathrm{N}, \mathrm{N}, \mathrm{N}$-trimethylpropan-1-ammo-

nium iodide as yellow oil (29 mg, 60\%). ${ }^{1} \mathrm{H}$ NMR (300 MHz, $\left.\mathrm{CD}_{3} \mathrm{OD}\right)$ $\delta 7.78-7.72(\mathrm{~m}, 2 \mathrm{H}), 7.44(\mathrm{~d}, J=8.6 \mathrm{~Hz}, 1 \mathrm{H}), 7.12(\mathrm{~d}, J=3.4 \mathrm{~Hz}, 1 \mathrm{H})$, 6.49 (d, $J=3.4 \mathrm{~Hz}, 1 \mathrm{H}), 4.54(\mathrm{~s}, 2 \mathrm{H}), 3.43(\mathrm{t}, J=6.9 \mathrm{~Hz}, 2 \mathrm{H}), 3.30(\mathrm{~s}$, $2 \mathrm{H}$ ), 3.10 (s, 9H), 2.03 (br s, 2H), 1.50 (s, 9H). MS (ESI) $m / z 485$ $[\mathrm{M}+\mathrm{H}]^{+}$. To a solution of the above compound $(10 \mathrm{mg}, 0.02 \mathrm{mmol})$ in $\mathrm{MeOH}(2 \mathrm{~mL})$, a solution of $\mathrm{HCl} 1 \mathrm{~N}(110 \mu \mathrm{L})$, prepared using acetyl chloride $(355 \mu \mathrm{L}, 4.97 \mathrm{mmol})$ in $\mathrm{MeOH}(4.64 \mathrm{~mL})$ was added at $0{ }^{\circ} \mathrm{C}$. The reaction mixture was kept at $25^{\circ} \mathrm{C}$ for $4 \mathrm{~h}$. The solvent was removed under vacuo to give the $\mathbf{4 7}$ as colorless oil without further purification $(7 \mathrm{mg}, 95 \%) .{ }^{1} \mathrm{H}$ NMR $\left(300 \mathrm{MHz}, \mathrm{CD}_{3} \mathrm{OD}\right) \delta 7.89$ $(\mathrm{d}, J=7,011 \mathrm{H}), 7.48(\mathrm{~s}, 1 \mathrm{H}), 7.21(\mathrm{~d}, J=3.4 \mathrm{~Hz}, 1 \mathrm{H}), 6.85(\mathrm{~d}$, $J=3.4 \mathrm{~Hz}, 1 \mathrm{H}$ ), 4.46 (s, 2H), 3.53 (br s, $4 \mathrm{H}$ ), 3.20 (s, 9H), 2.28 (br s, $2 \mathrm{H})$. (ESI) $m / z 385[\mathrm{M}+\mathrm{H}]^{+}$. Anal. for $\left(\mathrm{C}_{17} \mathrm{H}_{23} \mathrm{BrCl}_{2} \mathrm{~N}_{2} \mathrm{O}\right) \mathrm{C}, \mathrm{H}, \mathrm{N}$.

\subsubsection{N-Benzyl-3-[(5-(4-chloro-2-bromophenyl)furan-2-yl-} methyl)amino]-N,N-dimethylpropan-1-ammonium chloride (48)

To a solution of 46 (30 mg, $0.1 \mathrm{mmol})$ in dry acetone $(2 \mathrm{~mL})$, benzyl bromide ( $38 \mu \mathrm{L}, 0.3 \mathrm{mmol}$ ) was added. The reaction mixture was heated under reflux for $72 \mathrm{~h}$. The solvent was removed under vacuo. The crude product was purified by flash chromatography on silica gel ( $5 \% \mathrm{MeOH}$ in $\mathrm{DCM})$ to give the benzyldimethylammonium bromide salt as yellow oil ( $32 \mathrm{mg}, 58 \%) .{ }^{1} \mathrm{H}$ NMR $\left(300 \mathrm{MHz}, \mathrm{CD}_{3} \mathrm{OD}\right)$ $\delta$ 7.80-7.62 (m, 2H), 7.57-7.45 (m, 5H), $7.41(\mathrm{~d}, J=8.5 \mathrm{~Hz}, 1 \mathrm{H}), 7.09$ (d, $J=3.5 \mathrm{~Hz}, 1 \mathrm{H}), 6.47$ (d, J=3.3 Hz, 1H), $4.54(\mathrm{~s}, 2 \mathrm{H}), 4.49(\mathrm{~s}, 2 \mathrm{H})$, $3.46(\mathrm{t}, J=6.7 \mathrm{~Hz}, 1 \mathrm{H}), 3.38-3.21(\mathrm{~m}, 2 \mathrm{H}), 3.00(\mathrm{~s}, 6 \mathrm{H}), 2.14(\mathrm{t}$, $J=9.0 \mathrm{~Hz}, 2 \mathrm{H}), 1.49(\mathrm{~s}, 9 \mathrm{H})$; MS (ESI) $m / z 562[\mathrm{M}+\mathrm{H}]^{+}$. To a solution of the above compound ( $21 \mathrm{mg}, 0.04 \mathrm{mmol}$ ) in $\mathrm{MeOH}(2 \mathrm{~mL}), \mathrm{a}$ solution of $\mathrm{HCl} 1 \mathrm{~N}(222 \mu \mathrm{L})$, prepared using acetyl chloride $(355 \mu \mathrm{L}$, $4.97 \mathrm{mmol})$ in $\mathrm{MeOH}(4.64 \mathrm{~mL})$ was added at $0{ }^{\circ} \mathrm{C}$. The reaction mixture was kept at $25^{\circ} \mathrm{C}$ for $4 \mathrm{~h}$. The solvent was removed under vacuo to give $\mathbf{4 8}$ as yellow oil without further purification $(17 \mathrm{mg}$, 94\%). ${ }^{1} \mathrm{H}$ NMR (300 MHz, CD $\left.{ }_{3} \mathrm{OD}\right) \delta 7.90(\mathrm{~d}, J=7.7 \mathrm{~Hz}, 1 \mathrm{H}), 7.73$ (s, $1 \mathrm{H}), 7.65-7.42(\mathrm{~m}, 6 \mathrm{H}), 7,20(\mathrm{~s}, 1 \mathrm{H}), 6.85(\mathrm{~s}, 1 \mathrm{H}), 4.60(\mathrm{~s}, 2 \mathrm{H}), 4.45(\mathrm{~s}$, 2H), 3.51 (br s, 2H), 3.22 (br s, 2H), 3.09 (s, 6H), 2.39 (br s, 2H); MS (ESI) $m / z 462[\mathrm{M}+\mathrm{H}]^{+}$. Anal. $\left(\mathrm{C}_{23} \mathrm{H}_{27} \mathrm{BrCl}_{2} \mathrm{~N}_{2} \mathrm{O}\right) \mathrm{C}, \mathrm{H}, \mathrm{N}$. 


\subsection{Pan-assay interference compounds}

Reference (1) and synthesized compounds were investigated for their potential capability to behave as pan-assay interference compounds (PAINS) by means of FAFDrugs4.0 [55,56]. Remarkably, none of compounds contain sub-structural features that would label them as "frequent hitters" in high throughput screens.

\subsection{Antiplasmodial and gametocytocidal activity evaluation}

\subsubsection{Parasite growth of D10 and W2 strains}

The CQ sensitive (D10) and the CQ resistant (W2) strains of P. falciparum were maintained in vitro at $5 \%$ haematocrit (human type A-positive red blood cells) in RPMI 1640 (EuroClone, Celbio) medium with the addition of $1 \%$ AlbuMax (Invitrogen, Milan, Italy), $0.01 \%$ hypoxanthine, $20 \mathrm{mM}$ HEPES, and $2 \mathrm{mM}$ glutamine, at $37^{\circ} \mathrm{C}$ in a standard gas mixture consisting of $1 \% \mathrm{O}_{2}, 5 \% \mathrm{CO}_{2}$, and $94 \% \mathrm{~N}_{2}$ [39].

\subsubsection{Antiplasmodial activity against D10 and W2 strains}

Compounds were dissolved in DMSO and then diluted with medium to achieve the required concentrations (final DMSO concentration $<1 \%$, which is nontoxic to the parasite). Drugs were placed in 96 well flat-bottom microplates (COSTAR) and serial dilutions made. Asynchronous cultures with parasitemia of $1-1.5 \%$ and $1 \%$ final haematocrit were aliquoted into the plates and incubated for $72 \mathrm{~h}$ at $37^{\circ} \mathrm{C}$. Parasite growth was determined spectrophotometrically $\left(\mathrm{OD}_{650}\right)$ by measuring the activity of the parasite lactate dehydrogenase ( $\mathrm{pLDH}$ ), according to a modified version of Makler's method in control and drug-treated cultures [39]. Antiplasmodial activity is expressed as the 50\%inhibitory concentrations $\left(\mathrm{IC}_{50}\right)$. Each $\mathrm{IC}_{50}$ value is the mean \pm standard deviation of at least three separate experiments performed in duplicate.

\subsubsection{Gametocytocidal activity against P. falciparum 3D7 strain 3D7elo1-pfs16-CBG99}

Gametocytes were obtained from the transgenic $P$. falciparum 3D7 strain 3D7elo1-pfs16-CBG99 expressing the Pyrophorus plagiophthalamus CBG99 luciferase under the gametocyte specific promoter $p f s 16$. Late-stage gametocytes (stage IV-V, evaluated by Giemsa staining) were exposed to compounds at day 8-10 after $N$ acetylglucosamine (NAG) addition. For drug susceptibility assay, compounds were prepared by serial dilution, in 96-well plate, in complete medium. Epoxomicin or methylene blue were used as reference drugs. After $72 \mathrm{~h}$ incubation, drug-treated gametocyte samples at $2 \%$ haematocrit were transferred to 96 -well black microplates and D-luciferin ( $1 \mathrm{mM}$ in citrate buffer $0.1 \mathrm{M}, \mathrm{pH} 5.5$ ) was added at a 1:1 vol ratio. After $10 \mathrm{~min}$ incubation, gametocytes viability was measured as luciferase activity using a Sinergy 4 (Biotek) microplate reader ( $500 \mathrm{~ms}$ integration time). The $\mathrm{IC}_{50}$ was extrapolated from the non-linear regression analysis of the concentration-response curve [23].

\subsubsection{NF54}

Asexual blood stage parasites were seeded at a density of $0.83 \%$ in $1.5 \%$ haematocrit in RPMI1640 medium with $10 \%$ human serum and combined with compounds serially diluted in DMSO and RPMI1640 medium to reach a final DMSO concentration of $0.1 \%$ in a volume of $60 \mu \mathrm{L}$. Following a $72 \mathrm{~h}$ incubation at $37{ }^{\circ} \mathrm{C}, 3 \% \mathrm{O}_{2}, 4 \% \mathrm{CO}_{2}$, $30 \mu \mathrm{L}$ of diluted Sybrgeen reagent was added according to the instructions of the manufacturer (Life Technologies) and fluorescence intensity was quantified using a Biotek Synergy 2 plate reader.

\subsubsection{NF54 gametocytes}

Gametocytes were obtained from a culture flask inoculated with
$1 \%$ asexual blood stage parasites in 5\% haematocrit in RPMI1640 medium with $10 \%$ human serum. From day 4 to day 9 post-inoculation, cultures were treated with $50 \mathrm{mM}$ NAG to eliminate asexual blood stage parasites. At day 11 post inoculation, gametocytes (predominantly stage IV) were isolated by Percoll density gradient centrifugation as described previously (PMID 25667405). Gametocytes were seeded at a density of 5000 cells/well in a 384 well plate and combined with compound diluted in DMSO and subsequently in RPMI1640 medium to reach a final DMSO concentration of $0.1 \%$ in a volume of $60 \mu \mathrm{L}$ RPMI1640 medium with $10 \%$ human serum. Following a $72 \mathrm{~h}$ incubation at $37{ }^{\circ} \mathrm{C}, 3 \% \mathrm{O}_{2}, 4 \% \mathrm{CO}_{2}, 30 \mu \mathrm{L}$ of ONEGlo reagent (Promega) was added and luminescence was quantified using a Biotek Synergy 2 reader.

\subsection{Liver-stage analysis}

20'000 mCherry expressing $P$. berghei (ANKA strain) sporozoites (PbmCherryhsp70, [57]) were used to infect mouse primary hepatocytes grown on 96-well plate (isolated as published in Prado et al. [58]). 2 hpi the cells were exposed to different concentrations of $\mathbf{2 5}$, as control DMSO (equal to the highest concentration of 25) was used. Medium/Drug was renewed at 24 hpi. At 48 hpi parasite number and size of unfixed cells were determined by automated microscopy (INcell Analyzer, 2000, Gelifesciences). At 65 hpi detached cells (DC) were transferred to new wells and counted by fluorescent microscopy (Leica DMI 6000B). The detached cell assay is presented as detached cell formation rate (DC number in \% of $48 \mathrm{~h}$ number). Statistical analysis was done by performing One-way ANOVA with Dunnet's Multiple Comparisons (Prism, GraphPad) $\left({ }^{*} \mathrm{p}<0.05,{ }^{* *} \mathrm{p}<0.01,{ }^{* * *} \mathrm{p}<0.001, \mathrm{~ns} /\right.$ not significant $\left.>0.05\right)$.

\subsection{Isolated rat heart experiments}

\subsubsection{Animals}

All animal care and experimental protocols conformed to the European Union Guidelines for the Care and the Use of Laboratory Animals (European Union Directive, 2010/63/EU) and were approved by the Italian Department of Health (666/2015-PR). Male Wistar rats (300-350 g, Charles River Italia, Calco, Italy) were anaesthetized (i.p.) with a mixture of Zoletil ${ }^{\circledR} 100(7.5 \mathrm{mg} / \mathrm{kg}$ tiletamine $\mathrm{HCl}+7.5 \mathrm{mg} / \mathrm{kg}$ zolazepam $\mathrm{HCl}$; Virbac srl, Milano) e Rompun $^{\circledR}$ (4 mg/kg xylazine $\mathrm{HCl}$; Bio 98, San Lazzaro, Bologna), containing heparin $(5000 \mathrm{U} / \mathrm{kg})$, decapitated and exsanguinated.

\subsubsection{Isolated rat heart preparation and perfusion}

The hearts, spontaneously beating, were rapidly explanted and mounted on a Langendorff apparatus for retrograde perfusion via the aorta at a constant flow rate of $10 \mathrm{~mL} / \mathrm{min}$ with a Krebs-Henseleit solution of the following composition (mM): $\mathrm{NaCl}$ 118, $\mathrm{KCl}$ 4.7, $\mathrm{CaCl}_{2} 2.5, \mathrm{MgSO}_{4} 1.2, \mathrm{NaHCO}_{3} 25, \mathrm{KH}_{2} \mathrm{PO}_{4} 1.2$, glucose 11.5, Na pyruvate 2, and EDTA 0.5 , bubbled with a $95 \% \mathrm{O}_{2}-5 \% \mathrm{CO}_{2}$ gas mixture ( $\mathrm{pH} 7.4$ ), and kept at $37^{\circ} \mathrm{C}$, as described elsewhere [59]. The hearts were allowed to equilibrate for at least $20 \mathrm{~min}$ before drug exposure. Heart contractility was measured as LVP by means of latex balloon, inserted into the left ventricle via the mitral valve and connected to a pressure transducer (BLPR, WPI, Berlin, Germany). The balloon was inflated with deionized water from a microsyringe until a left ventricular end diastolic pressure of $10 \mathrm{mmHg}$ was obtained. Alteration in CPP, arising from changes in coronary vascular resistance, were recorded by pressure transducer (BLPR, WPI, Berlin, Germany) placed in the inflow line. A surface ECG was recorded at a sampling rate of $1 \mathrm{kHz}$ by means of two steel electrodes, one placed on the apex and the other on the left atrium of the heart. The ECG analysis included the following measurements: RR (cycle length), HR (frequency), PQ (atrioventricular 
conduction time), QRS (intraventricular conduction time), and QT (overall action potential duration) [60]. LVP, CPP, and ECG were recorded with a digital PowerLab data acquisition system (PowerLab 8/30; ADInstruments, Castle Hill, Australia) and analyzed by using Chart Pro for Windows software (PowerLab; ADInstruments, Castle Hill, Australia). LVP was calculated by subtracting the left ventricular diastolic pressure from the left ventricular systolic pressure. As the QT interval is affected by heart rate changes (e.g., it shortens when heart rate increases), Bazett's formula normalized to average rat $\mathrm{RR}$ (corrected $\mathrm{QT}, \mathrm{QTc}=\mathrm{QT} /(\mathrm{RR} / \mathrm{f}) 1 / 2$ ) [61] was routinely used to correct it, in order to avoid confounding effects. In our experiments, " $\mathrm{f}$ ", the normalization factor according to the basal RR duration was $242.23 \mathrm{~ms}$ for compound 1 and $217.15 \mathrm{~ms}$ for compound 25, as it was the average cardiac cycle length. Analysis of data was accomplished using GraphPad Prism version 5.04 (GraphPad Software, San Diego, USA). Statistical analyses and significance as measured by repeated measures ANOVA (followed by Dunnett's post test) were obtained using GraphPad InStat version 3.06 (GraphPad Software, San Diego, USA). In all comparisons, $\mathrm{P}<0.05$ was considered significant. Compounds $\mathbf{1}$ and 25 were dissolved in DMSO. Solvent failed to alter the response of the preparations (data not shown).

\subsection{Electrophysiological experiments}

\subsubsection{Cell isolation procedure and whole-cell patch-clamp recording}

Rat tail was cut immediately, cleaned of skin and placed in physiological solution (namely external solution). The tail main artery was dissected free of its connective tissue and cells or rings prepared as detailed below. Smooth muscle cells were freshly isolated from the tail main artery under the following conditions: a 5$\mathrm{mm}$ long piece of artery was incubated at $37^{\circ} \mathrm{C}$ for $40-45 \mathrm{~min}$ in $2 \mathrm{~mL}$ of $0.1 \mathrm{mM} \mathrm{Ca}^{2+}$ external solution (in $\mathrm{mM}$ : $130 \mathrm{NaCl}, 5.6 \mathrm{KCl}, 10$ Hepes, 20 glucose, $1.2 \mathrm{MgCl}_{2}$, and 5 Na-pyruvate; $\mathrm{pH} 7.4$ ) containing $20 \mathrm{mM}$ taurine (prepared by replacing $\mathrm{NaCl}$ with equimolar taurine), $1.35 \mathrm{mg} / \mathrm{mL}$ collagenase (type $\mathrm{XI}$ ), $1 \mathrm{mg} / \mathrm{mL}$ soybean trypsin inhibitor, and $1 \mathrm{mg} / \mathrm{mL}$ bovine serum albumin (Sigma Chimica, Milan, Italy), which was gently bubbled with a $95 \% \mathrm{O}_{2}-5 \%$ $\mathrm{CO}_{2}$ gas mixture to gently stir the enzyme solution, as previously described [62]. Cells, stored in $0.05 \mathrm{mM} \mathrm{Ca}^{2+}$ external solution containing $20 \mathrm{mM}$ taurine and $0.5 \mathrm{mg} / \mathrm{mL}$ bovine serum albumin at $4{ }^{\circ} \mathrm{C}$ under normal atmosphere, were used for experiments within two days after isolation [63]. Cells were continuously superfused with external solution containing $0.1 \mathrm{mM} \mathrm{Ca}^{2+}$ and $30 \mathrm{mM}$ tetraethylammonium (TEA, Sigma Chimica, Milan, Italy) using a peristaltic pump (LKB 2132, Bromma, Sweden), at a flow rate of $400 \mu \mathrm{L} /$ min. The conventional whole-cell patch-clamp method was employed to voltage-clamp smooth muscle cells. Recording electrodes were pulled from borosilicate glass capillaries (WPI, Berlin, Germany) and fire-polished to obtain a pipette resistance of 2-5 $\mathrm{M} \Omega$ when filled with internal solution. The internal solution (pCa 8.4) consisted of (in mM): $100 \mathrm{CsCl}, 10$ HEPES, 11 EGTA, 2 $\mathrm{MgCl}_{2}, 1 \mathrm{CaCl}_{2}, 5 \mathrm{Na}$-pyruvate, 5 succinic acid, 5 oxaloacetic acid, 3 $\mathrm{Na}_{2}$-ATP and 5 phosphocreatine; $\mathrm{pH}$ was adjusted to 7.4 with $\mathrm{CsOH}$. An Axopatch 200B patch-clamp amplifier (Molecular Devices Corporation, Sunnyvale, USA) was used to generate and apply voltage pulses to the clamped cells and record the corresponding membrane currents. At the beginning of each experiment, the junction potential between the pipette and bath solution was electronically adjusted to zero. Current signals, after compensation for whole-cell capacitance and series resistance (between $70 \%$ and $75 \%$ ), were low-pass filtered at $1 \mathrm{kHz}$ and digitized at $3 \mathrm{kHz}$ prior to being stored on the computer hard disk. Electrophysiological responses were tested at room temperature $\left(20-22^{\circ} \mathrm{C}\right)$. The current through
$\mathrm{Ca}_{\mathrm{v}} 1.2$ channels was recorded in external solution containing $30 \mathrm{mM} \mathrm{TEA}$ and $5 \mathrm{mM} \mathrm{Ba}^{2+}$. Current was elicited with 250-ms clamp pulses $(0.067 \mathrm{~Hz})$ to $0 \mathrm{mV}$ from a $\mathrm{V}_{\mathrm{h}}$ of $-50 \mathrm{mV}$. Data were collected once the current amplitude had been stabilized (usually 7-10 min after the whole-cell configuration had been obtained). Under these conditions, the current did not run down during the following $40 \mathrm{~min}$ [64]. $\mathrm{K}^{+}$currents were blocked with $30 \mathrm{mM}$ TEA in the external solution and $\mathrm{Cs}^{+}$in the internal solution. Current values were corrected for leakage and residual outward currents using $10 \mu \mathrm{M}$ nifedipine (Sigma Chimica, Milan, Italy), which completely blocked I $\mathrm{Ca}_{1.2}$. The osmolarity of the $30 \mathrm{mM}$ TEA- and $5 \mathrm{mM} \mathrm{Ba}^{2+}$-containing external solution (320 mosmol) and that of the internal solution (290 mosmol) were measured with an osmometer (Osmostat OM 6020, Menarini Diagnostics, Florence, Italy). Acquisition and analysis of data were accomplished using pClamp 9.2.1.9 software (Molecular Devices Corporation, Sunnyvale, USA) and GraphPad Prism version 5.04 (GraphPad Software, San Diego, USA). Compounds 1 and 25 were dissolved in DMSO (below 0.01). Solvent failed to alter the response of the preparations (data not shown).

\subsection{Enzyme assays and $I C_{50}$ analysis}

For biochemical analysis of compounds, PfPMT was expressed in and purified from E. coli, as previously described [53]. Methyltransferase activity was monitored using a radiochemical assay [52]. Standard reaction conditions were $0.1 \mathrm{M}$ Hepes $\mathrm{KOH}(\mathrm{pH} 8.0)$, $2 \mathrm{mM} \mathrm{Na}{ }_{2}$ EDTA, 10\% (v/v) glycerol, 5\% (v/v) DMSO, $30 \mu \mathrm{M} \mathrm{SAM}$ $\left(100 \mathrm{nCi}\right.$ of $\left[\right.$ methyl $\left.\left.-{ }^{14} \mathrm{C}\right] \mathrm{SAM}\right)$, and $55 \mu \mathrm{M}$ phosphoethanolamine in $100 \mu \mathrm{L}$ with $2 \mu \mathrm{g}$ of purified protein. Initial screening of compounds 1, 24, 25 and 48 as potential PfPMT inhibitors was performed at $100 \mu \mathrm{M}$. For determination of the $\mathrm{IC}_{50}$ for compound $\mathbf{2 5}$ versus PfPMT, assays were performed with varied inhibitor concentration (0-250 $\mu \mathrm{M}$; final 5\% (v/v) DMSO) with $100 \%$ activity defined as the control reaction (conditions as above)). Data were plotted as percentage of activity versus inhibitor concentration and were fit to $\mathrm{y}=100 /\left(1+\left([\mathrm{I}] / \mathrm{IC}_{50}\right)\right)$ using Kaleidagraph (Synergy Software), where $\mathrm{IC}_{50}$ is the inhibitor concentration at $50 \%$ activity.

\subsection{Computational details}

All calculations in this work were performed on a system comprising 72 Intel Xeon E5-2695 v4@2.10 GHz processors and two NVIDIA GeForce 1070 GTX GPU with Ubuntu 16.04 LTS (long-term support) operating system, running Schrödinger Molecular Modelling Environment Release 2015. Among the software in the molecular modelling suite we used Maestro, version 10.1; MacroModel, version 10.7; LigPrep, version 3.3; SiteMap version 3.4; Glide, version 6.6; Prime version 4.1 and PyMOL v1.8.4.0.

\subsubsection{Protein and ligands preparation}

We retrieved from the PDB database all proteins relevant for the Plasmodium biology for a total of 108 crystal structures. All the crystal structures were analyzed, removing the water molecules, ions not involved in the enzymatic reactions and molecules used for the crystallization process. For the proteins with the co-crystallized ligands (inhibitors, substrates etc) we extracted them for a redocking procedure to assess the reliability of the docking protocol (see next paragraph for further details). The selected crystal structures were prepared by means of Protein Preparation Wizard (PPW) protocol implemented in Maestro, for acquiring appropriate starting complexes for the subsequent computational analyses. In particular, the protocol includes three steps to: (1) add hydrogens, (2) optimize the orientation of hydroxyl groups, Asn, and Gln, and the protonation state of $\mathrm{His}$, and (3) perform a constrained 
refinement by employing impref software ( $\max R M S D=0.30$ ), consisting of a cycles of energy minimization based on the impact molecular mechanics engine employing OPLS_2005 as force field. Regarding PfPMT, the crystal structure with the code 3UJ8 from PDB containing the inhibitor sinefungin (adenosyl-ornithine) was selected. For the redocking procedure we consider also the natural substrate SAM extracted from the PfPMT crystal structure 3UJ6. Compounds $\mathbf{1}$ and $\mathbf{2 5}$ as well as all the ligands in the Plasmodium proteins (Sinefungin and SAM in the case of PfPMT) were treated by means of MacroModel for retrieving the lower energy conformers to use as input in molecular docking experiments. The calculation was performed using OPLS-2005 as force field. The GeneralizedBorn/Surface-Area (GB/SA) model for simulating the solvent effects was used. No cutoff for non-bonded interactions was used. PRCG method was employed with 1000 maximum iterations and 0.001 gradient convergence threshold for performing the molecular energy minimizations. MCMM (Monte Carlo Multiple Minimum) was employed as torsional sampling method for the conformational searches, performing automatic setup with $21 \mathrm{~kJ} / \mathrm{mol}(5.02 \mathrm{Kcal} /$ $\mathrm{mol}$ ) in the energy window for saving structure and $0.5 \AA$ was used as cutoff distance for redundant conformers. The lower conformers were treated by LigPrep application, generating the most plausible ionization state at cellular $\mathrm{pH}$ value $(7.4 \pm 0.2)$.

\subsubsection{Molecular docking}

Molecular Docking was carried out by Glide using the ligands and the protein prepared as above-mentioned, applying Glide extra precision (XP) method. Energy grid was prepared using default value of protein atom scaling factor $(1.0 \AA)$ within a cubic box centered on the crystallized ligands were present, while for the Plasmodium proteins without any ligand we selected the binding site by analysing the literature data and/or performing a SiteMap calculation to find potential binding sites. Considering PfPMT, the cubic box centered on the sinefungin. After grid generation, the ligands and the crystallized inhibitor were docked into the enzymes with default parameters (no constraints were added). The number of poses entered to post-docking minimization was set to 50. Glide XP score was evaluated. The interactions of compounds with proteins were assessed using ligand-interaction diagram and a script for displaying hydrophobic interactions (display_hydrophobic_interactions.py) downloaded from Schrödinger website and implemented in Maestro. The RMSD between the docked poses and the co-crystallized compounds was calculated by using the script rmsd. py available in Maestro. We chose the Glide $\mathrm{XP}$ protocol since it demonstrated in this virtual screening procedure better accuracy in retrieving the binding mode of the crystallized ligands, showing lower RMSD over the Glide standard precision (SP) protocol as highlighted also for PfPMT. In fact, although the docking protocols were able to correctly accommodate the considered ligands (sinefungin and SAM), the Glide XP protocol showed low RMSD between the docked poses and crystallized ligands (sinefungin Glide XP RMSD $=0.21$; Glide SP $\mathrm{RMSD}=0.66$. SAM Glide XP RMSD $=0.48$; Glide SP RMSD $=1.05$ ).

\subsubsection{Evaluation of ligand binding energy}

The Prime/MM-GBSA method (Prime software) computes the difference between both the states, free and complex, of the ligand and the protein after energy minimization as reported [50]. The calculated absolute values are not necessarily in agreement with observed binding affinities. Nonetheless, the ranking of the ligands based on the binding energies calculations (MM/GBSA $\Delta G_{\text {bind }}$ ) can agree reasonably well with ranking based on observed binding affinity, particularly in the case of congeneric series. As the MM/ GBSA binding energies are approximate free energies of binding, a more negative value indicates stronger binding. The technique was used on the docked complexes (ligand-protein). For each ligand the software was employed to assess its ligand binding energy $\left(\Delta \mathrm{G}_{\text {bind }}\right)$ exploiting the following equation:

$\Delta \mathrm{G}_{\text {bind }}=\Delta \mathrm{E}_{\mathrm{MM}}+\Delta \mathrm{G}_{\text {solv }}+\Delta \mathrm{G}_{\mathrm{sa}}$

$\Delta \mathrm{E}_{\mathrm{MM}}$ is the difference in the minimized energies calculated for the complex and the sum of the energies of the unbounded protein and ligand. $\Delta G_{\text {solv }}$ represents the difference in the GBSA solvation energy of the complex and the sum of these energies for the unbounded protein and ligand. $\Delta \mathrm{G}_{\mathrm{SA}}$ is the difference in the surface area (SA) energies for the complex and the sum of the SA energies for the unbounded protein and ligand.

\subsubsection{Picture preparation}

Fig. 6 was prepared by means of PyMOL (The PyMOL Molecular Graphics System, v1.8.4.0, Schrödinger LLC, New York, 2015).

\section{Acknowledgment}

Financial contribution from MIUR is acknowledged. S.G.L. and J.M.J. acknowledge support from the National Institutes of Health (AI-097119). S.G. and D.T. acknowledge support from the COST Action CM1307. This work was supported by the Global Health Program of the Bill \& Melinda Gates Foundation (Grant OPP1040394 to D.T.) and by MIUR- (Project 20154JRJPP to Gi.Ca. and D.T). The authors thank MMV (Medicine for Malaria Venture) for the availability of the malaria box compounds free of charge; a special acknowledgment to Laura Galastri, Paola Verducci, and Tiziana Bianchi from AVIS Comunale Milano for providing blood samples for $P$. falciparum parasite culture.

\section{Appendix A. Supplementary data}

Supplementary data related to this article can be found at https://doi.org/10.1016/j.ejmech.2018.03.024.

\section{References}

[1] World Malaria Report, 2016. http://www.who.int/malaria/publications/ world-malaria-report-2016/en/.

[2] T.N. Wells, R. Hooft van Huijsduijnen, W.C. Van Voorhis, Malaria medicines: a glass half full? Nat. Rev. Drug Discov. 14 (2015) 424-442.

[3] F.J. Gamo, L.M. Sanz, J. Vidal, C. de Cozar, E. Alvarez, J.L. Lavandera, D.E. Vanderwall, D.V. Green, V. Kumar, S. Hasan, J.R. Brown, C.E. Peishoff, L.R. Cardon, J.F. Garcia-Bustos, Thousands of chemical starting points for antimalarial lead identification, Nature 465 (2010) 305-310.

[4] M. Rottmann, C. McNamara, B.K. Yeung, M.C. Lee, B. Zou, B. Russell, P. Seitz D.M. Plouffe, N.V. Dharia, J. Tan, S.B. Cohen, K.R. Spencer, G.E. Gonzalez-Paez, S.B. Lakshminarayana, A. Goh, R. Suwanarusk, T. Jegla, E.K. Schmitt, H.P. Beck, R. Brun, F. Nosten, L. Renia, V. Dartois, T.H. Keller, D.A. Fidock, E.A. Winzeler T.T. Diagana, Spiroindolones, a potent compound class for the treatment of malaria, Science 329 (2010) 1175-1180.

[5] S. Nakazawa Hewitt, D.M. Dranow, B.G. Horst, J.A. Abendroth, B. Forte I. Hallyburton, C. Jansen, B. Baragana, R. Choi, K.L. Rivas, M.A. Hulverson, M. Dumais, T.E. Edwards, D.D. Lorimer, A.H. Fairlamb, D.W. Gray, K.D. Read, A.M. Lehane, K. Kirk, P.J. Myler, A. Wernimont, C.S. Walpole, R. Stacy, L.K. Barrett, I.H. Gilbert, W.C. Van Voorhis, Biochemical and structural characterization of selective allosteric inhibitors of the plasmodium falciparum drug target, prolyl-tRNA-synthetase, ACS Infect. Dis. 3 (2016) 34-44.

[6] B. Baragana, N.R. Norcross, C. Wilson, A. Porzelle, I. Hallyburton, R. Grimaldi M. Osuna-Cabello, S. Norval, J. Riley, L. Stojanovski, F.R. Simeons, P.G. Wyatt M.J. Delves, S. Meister, S. Duffy, V.M. Avery, E.A. Winzeler, R.E. Sinden, S. Wittlin, J.A. Frearson, D.W. Gray, A.H. Fairlamb, D. Waterson, S.F. Campbell, P. Willis, K.D. Read, I.H. Gilbert, Discovery of a quinoline-4-carboxamide derivative with a novel mechanism of action, multistage antimalarial activity, and potent in vivo efficacy, J. Med. Chem. 59 (2016) 9672-9685.

[7] R.L. Edwards, A.R. Odom John, Muddled mechanisms: recent progress towards antimalarial target identification, F1000Res 5 (2016) 2514

[8] K. Singh, J. Okombo, C. Brunschwig, F. Ndubi, L. Barnard, C. Wilkinson, P.M. Njogu, M. Njoroge, L. Laing, M. Machado, M. Prudencio, J. Reader, M. Botha, S. Nondaba, L.M. Birkholtz, S. Lauterbach, A. Churchyard T.L. Coetzer, J.N. Burrows, C. Yeates, P. Denti, L. Wiesner, T.J. Egan, S. Wittlin, 
K. Chibale, Antimalarial pyrido[1,2-a]benzimidazoles: lead optimization, parasite life cycle stage profile, mechanistic evaluation, killing kinetics, and in vivo oral efficacy in a mouse model, J. Med. Chem. 60 (2017) 1432-1448.

[9] C. Le Manach, T. Paquet, C. Brunschwig, M. Njoroge, Z. Han, D. Gonzalez Cabrera, S. Bashyam, R. Dhinakaran, D. Taylor, J. Reader, M. Botha, A. Churchyard, S. Lauterbach, T.L. Coetzer, L.M. Birkholtz, S. Meister, E.A. Winzeler, D. Waterson, M.J. Witty, S. Wittlin, M.B. Jimenez-Diaz, M. Santos Martinez, S. Ferrer, I. Angulo-Barturen, L.J. Street, K. Chibale, A novel pyrazolopyridine with in vivo activity in plasmodium berghei- and plasmodium falciparum-infected mouse models from structure-activity relationship studies around the core of recently identified antimalarial imidazopyridazines, J. Med. Chem. 58 (2015) 8713-8722.

[10] D. Gonzalez Cabrera, F. Douelle, C. Le Manach, Z. Han, T. Paquet, D. Taylor, M. Njoroge, N. Lawrence, L. Wiesner, D. Waterson, M.J. Witty, S. Wittlin, L.J. Street, K. Chibale, Structure-activity relationship studies of orally active antimalarial 2,4-Diamino-thienopyrimidines, J. Med. Chem. 58 (2015) $7572-7579$.

[11] D. Gonzalez Cabrera, C. Le Manach, F. Douelle, Y. Younis, T.S. Feng, T. Paquet, A.T. Nchinda, L.J. Street, D. Taylor, C. de Kock, L. Wiesner, S. Duffy, K.L. White, K.M. Zabiulla, Y. Sambandan, S. Bashyam, D. Waterson, M.J. Witty, S.A. Charman, V.M. Avery, S. Wittlin, K. Chibale, 2,4-Diaminothienopyrimidines as orally active antimalarial agents, J. Med. Chem. 57 (2014) $1014-1022$.

[12] C. Le Manach, D. Gonzalez Cabrera, F. Douelle, A.T. Nchinda, Y. Younis, D. Taylor, L. Wiesner, K.L. White, E. Ryan, C. March, S. Duffy, V.M. Avery, D. Waterson, M.J. Witty, S. Wittlin, S.A. Charman, L.J. Street, K. Chibale, Medicinal chemistry optimization of antiplasmodial imidazopyridazine hits from high throughput screening of a SoftFocus kinase library: part 1, J. Med. Chem. 57 (2014) 2789-2798.

[13] C. Le Manach, T. Paquet, D. Gonzalez Cabrera, Y. Younis, D. Taylor, L. Wiesner, N. Lawrence, S. Schwager, D. Waterson, M.J. Witty, S. Wittlin, L.J. Street, K. Chibale, Medicinal chemistry optimization of antiplasmodial imidazopyridazine hits from high throughput screening of a softfocus kinase library: part 2, J. Med. Chem. 57 (2014) 8839-8848.

[14] M. Pieroni, E. Azzali, N. Basilico, S. Parapini, M. Zolkiewski, C. Beato, G. Annunziato, A. Bruno, F. Vacondio, G. Costantino, Accepting the invitation to open innovation in malaria drug discovery: synthesis, biological evaluation, and investigation on the structure-activity relationships of benzo[b]thiophene-2-carboxamides as antimalarial agents, J. Med. Chem. 60 (2017) 1959-1970.

[15] J.D. Bowman, E.F. Merino, C.F. Brooks, B. Striepen, P.R. Carlier, M.B. Cassera, Antiapicoplast and gametocytocidal screening to identify the mechanisms of action of compounds within the malaria box, Antimicrob. Agents Chemother. 58 (2014) 811-819.

[16] M.J. Delves, A. Ruecker, U. Straschil, J. Lelievre, S. Marques, M.J. Lopez-Barragan, E. Herreros, R.E. Sinden, Male and female Plasmodium falciparum mature gametocytes show different responses to antimalarial drugs, Antimicrob. Agents Chemother. 57 (2013) 3268-3274

[17] S. Duffy, V.M. Avery, Identification of inhibitors of Plasmodium falciparum gametocyte development, Malar. J. 12 (2013) 408

[18] L. Lucantoni, S. Duffy, S.H. Adjalley, D.A. Fidock, V.M. Avery, Identification of MMV malaria box inhibitors of plasmodium falciparum early-stage gametocytes using a luciferase-based high-throughput assay, Antimicrob. Agents Chemother. 57 (2013) 6050-6062.

[19] A. Ruecker, D.K. Mathias, U. Straschil, T.S. Churcher, R.R. Dinglasan, D. Leroy, R.E. Sinden, M.J. Delves, A male and female gametocyte functional viability assay to identify biologically relevant malaria transmission-blocking drugs, Antimicrob. Agents Chemother. 58 (2014) 7292-7302.

[20] N.G. Sanders, D.J. Sullivan, G. Mlambo, G. Dimopoulos, A.K. Tripathi, Gametocytocidal screen identifies novel chemical classes with Plasmodium falciparum transmission blocking activity, PLoS One 9 (2014) e105817.

[21] D.M. Plouffe, M. Wree, A.Y. Du, S. Meister, F. Li, K. Patra, A. Lubar, S.L. Okitsu, E.L. Flannery, N. Kato, O. Tanaseichuk, E. Comer, B. Zhou, K. Kuhen, Y. Zhou, D. Leroy, S.L. Schreiber, C.A. Scherer, J. Vinetz, E.A. Winzeler, High-throughput assay and discovery of small molecules that interrupt malaria transmission, Cell Host Microbe 19 (2016) 114-126.

[22] W. Sun, T.Q. Tanaka, C.T. Magle, W. Huang, N. Southall, R. Huang, S.J. Dehdashti, J.C. McKew, K.C. Williamson, W. Zheng, Chemical signatures and new drug targets for gametocytocidal drug development, Sci. Rep. 4 (2014) 3743.

[23] S. D'Alessandro, G. Camarda, Y. Corbett, G. Siciliano, S. Parapini, L. Cevenini, E. Michelini, A. Roda, D. Leroy, D. Taramelli, P. Alano, A chemical susceptibility profile of the Plasmodium falciparum transmission stages by complementary cell-based gametocyte assays, J. Antimicrob. Chemother. 71 (2016) 1148-1158.

[24] S. D'Alessandro, F. Silvestrini, K. Dechering, Y. Corbett, S. Parapini, M. Timmerman, L. Galastri, N. Basilico, R. Sauerwein, P. Alano, D. Taramelli, A Plasmodium falciparum screening assay for anti-gametocyte drugs based on parasite lactate dehydrogenase detection, J. Antimicrob. Chemother. 68 (2013) 2048-2058.

[25] W.C. Van Voorhis, J.H. Adams, R. Adelfio, V. Ahyong, M.H. Akabas, P. Alano, A. Alday, Y. Aleman Resto, A. Alsibaee, A. Alzualde, K.T. Andrews, S.V. Avery, V.M. Avery, L. Ayong, M. Baker, S. Baker, C. Ben Mamoun, S. Bhatia, Q. Bickle, L. Bounaadja, T. Bowling, J. Bosch, L.E. Boucher, F.F. Boyom, J. Brea, M. Brennan, A. Burton, C.R. Caffrey, G. Camarda, M. Carrasquilla, D. Carter, M. Belen
Cassera, K. Chih-Chien Cheng, W. Chindaudomsate, A. Chubb, B.L. Colon, D.D. Colon-Lopez, Y. Corbett, G.J. Crowther, N. Cowan, S. D'Alessandro, N. Le Dang, M. Delves, J.L. DeRisi, A.Y. Du, S. Duffy, S. Abd El-Salam El-Sayed, M.T. Ferdig, J.A. Fernandez Robledo, D.A. Fidock, I. Florent, P.V. Fokou, A. Galstian, F.J. Gamo, S. Gokool, B. Gold, T. Golub, G.M. Goldgof, R. Guha, W.A. Guiguemde, N. Gural, R.K. Guy, M.A. Hansen, K.K. Hanson, A. Hemphill, R. Hooft van Huijsduijnen, T. Horii, P. Horrocks, T.B. Hughes, C. Huston, I. Igarashi, K. Ingram-Sieber, M.A. Itoe, A. Jadhav, A. Naranuntarat Jensen, L.T. Jensen, R.H. Jiang, A. Kaiser, J. Keiser, T. Ketas, S. Kicka, S. Kim, K. Kirk, V.P. Kumar, D.E. Kyle, M.J. Lafuente, S. Landfear, N. Lee, S. Lee, A.M. Lehane, F. Li, D. Little, L. Liu, M. Llinas, M.I. Loza, A. Lubar, L. Lucantoni, I. Lucet, L. Maes, D. Mancama, N.R. Mansour, S. March, S. McGowan, I. Medina Vera, S. Meister, L. Mercer, J. Mestres, A.N. Mfopa, R.N. Misra, S. Moon, J.P. Moore, F. Morais Rodrigues da Costa, J. Muller, A. Muriana, S. Nakazawa Hewitt, B. Nare, C. Nathan, N. Narraidoo, S. Nawaratna, K.K. Ojo, D. Ortiz, G. Panic, G. Papadatos, S. Parapini, K. Patra, N. Pham, S. Prats, D.M. Plouffe, S.A. Poulsen, A. Pradhan, C. Quevedo, R.J. Quinn, C.A. Rice, M. Abdo Rizk, A. Ruecker, R. St Onge, R. Salgado Ferreira, J. Samra, N.G. Robinett, U. Schlecht, M. Schmitt, F. Silva Villela, F. Silvestrini, R. Sinden, D.A. Smith, T. Soldati, A. Spitzmuller, S.M. Stamm, D.J. Sullivan, W. Sullivan, S. Suresh, B.M. Suzuki, Y. Suzuki, S.J. Swamidass, D. Taramelli, L.R. Tchokouaha, A. Theron, D. Thomas, K.F. Tonissen, S. Townson, A.K. Tripathi, V. Trofimov, K.O. Udenze, I. Ullah, C. Vallieres, E. Vigil, J.M. Vinetz, P. Voong Vinh, H. Vu, N.A. Watanabe, K. Weatherby, P.M. White, A.F. Wilks, E.A. Winzeler, E. Wojcik, M. Wree, W. Wu, N. Yokoyama, P.H. Zollo, N. Abla, B. Blasco, J. Burrows, B. Laleu, D. Leroy, T. Spangenberg, T. Wells, P.A. Willis, Open source drug discovery with the malaria box compound collection for neglected diseases and beyond, PLoS Pathog. 12 (2016) e1005763.

[26] T. Spangenberg, J.N. Burrows, P. Kowalczyk, S. McDonald, T.N. Wells, P. Willis, The open access malaria box: a drug discovery catalyst for neglected diseases, PLoS One 8 (2013), e62906.

[27] W.A. Guiguemde, A.A. Shelat, D. Bouck, S. Duffy, G.J. Crowther, P.H. Davis, D.C. Smithson, M. Connelly, J. Clark, F. Zhu, M.B. Jimenez-Diaz, M.S. Martinez, E.B. Wilson, A.K. Tripathi, J. Gut, E.R. Sharlow, I. Bathurst, F. El Mazouni, J.W. Fowble, I. Forquer, P.L. McGinley, S. Castro, I. Angulo-Barturen, S. Ferrer, P.J. Rosenthal, J.L. Derisi, D.J. Sullivan, J.S. Lazo, D.S. Roos, M.K. Riscoe, M.A. Phillips, P.K. Rathod, W.C. Van Voorhis, V.M. Avery, R.K. Guy, Chemical genetics of Plasmodium falciparum, Nature 465 (2010) 311-315.

[28] S. Meister, D.M. Plouffe, K.L. Kuhen, G.M. Bonamy, T. Wu, S.W. Barnes, S.E. Bopp, R. Borboa, A.T. Bright, J. Che, S. Cohen, N.V. Dharia, K. Gagaring, M. Gettayacamin, P. Gordon, T. Groessl, N. Kato, M.C. Lee, C.W. McNamara, D.A. Fidock, A. Nagle, T.G. Nam, W. Richmond, J. Roland, M. Rottmann, B. Zhou, P. Froissard, R.J. Glynne, D. Mazier, J. Sattabongkot, P.G. Schultz, T. Tuntland, J.R. Walker, Y. Zhou, A. Chatterjee, T.T. Diagana, E.A. Winzeler, Imaging of Plasmodium liver stages to drive next-generation antimalarial drug discovery, Science 334 (2011) 1372-1377.

[29] S. Kotha, K. Lahiri, D. Kashinath, Recent applications of the Suzuki-Miyaura cross-coupling reaction in organic synthesis, Tetrahedron 58 (2002) 9633-9695.

[30] S. Gemma, E. Gabellieri, S. Sanna Coccone, F. Marti, O. Taglialatela-Scafati, E. Novellino, G. Campiani, S. Butini, Synthesis of dihydroplakortin, 6-epidihydroplakortin, and their C10-desethyl analogues, J. Org. Chem. 75 (2010) 2333-2340.

[31] G. Bartoli, E. Marcantoni, L. Sambri, The CeCl3 center dot $\mathrm{nH}(2) \mathrm{O} / \mathrm{NaI}$ system in organic synthesis: an efficient water tolerant Lewis acid promoter, Synlett (2003) 2101-2116.

[32] N.D. Obushak, A.I. Lesyuk, Y.I. Gorak, V.S. Matiichuk, Mechanism of Meerwein arylation of furan derivatives, Russ. J. Org. Chem. 45 (2009) 1375-1381.

[33] M.G. Bell, M.J. Genin, P.A. Lander, L.S. Stelzer, R.A. Doti, F.J. Agejas-Chicharro, A.B. Bueno Melendo, P.R. Manninen, J.M. Ochoada, Q. Shen, A.M. Warshawsky, T. Ma, R.E. Stites, Preparation of 3-Phenylisoxazole Derivatives for Treatment of Dyslipidemia, Eli Lilly and Company, USA, 2007.

[34] M.C. Bagley, J.E. Dwyer, M.D.B. Molina, A.W. Rand, H.L. Rand, N.C.O. Tomkinson, Microwave-assisted synthesis of 3-aminobenzo[b]-thiophene scaffolds for the preparation of kinase inhibitors, Org. Biomol. Chem. 13 (2015) 6814-6824.

[35] M.J. Stocks, D.R. Cheshire, R. Reynolds, Efficient and regiospecific one-pot synthesis of substituted 1,2,4-triazoles, Org. Lett. 6 (2004) 2969-2971.

[36] A.A. Haddach, A. Kelleman, M.V. Deaton-Rewolinski, An efficient method for the N-debenzylation of aromatic heterocycles, Tetrahedron Lett. 43 (2002) 399-402.

[37] K. Zhang, P. Wang, L.N. Xuan, X.Y. Fu, F. Jing, S. Li, Y.M. Liu, B.O. Chen, Synthesis and antitumor activities of novel hybrid molecules containing 1,3,4-oxadiazole and 1,3,4-thiadiazole bearing Schiff base moiety, Bioorg. Med. Chem. Lett. 24 (2014) 5154-5156.

[38] S. Gemma, C. Camodeca, M. Brindisi, S. Brogi, G. Kukreja, S. Kunjir E. Gabellieri, L. Lucantoni, A. Habluetzel, D. Taramelli, N. Basilico, R. Gualdani, F. Tadini-Buoninsegni, G. Bartolommei, M.R. Moncelli, R.E. Martin, R.L. Summers, S. Lamponi, L. Savini, I. Fiorini, M. Valoti, E. Novellino, G. Campiani, S. Butini, Mimicking the intramolecular hydrogen bond: synthesis, biological evaluation, and molecular modeling of benzoxazines and quinazolines as potential antimalarial agents, J. Med. Chem. 55 (2012) $10387-10404$

[39] S. Gemma, C. Camodeca, S. Sanna Coccone, B.P. Joshi, M. Bernetti, V. Moretti, S. Brogi, M.C. Bonache de Marcos, L. Savini, D. Taramelli, N. Basilico, 
S. Parapini, M. Rottmann, R. Brun, S. Lamponi, S. Caccia, G. Guiso, R.L. Summers, R.E. Martin, S. Saponara, B. Gorelli, E. Novellino, G. Campiani, S. Butini, Optimization of 4-aminoquinoline/clotrimazole-based hybrid antimalarials: further structure-activity relationships, in vivo studies, and preliminary toxicity profiling, J. Med. Chem. 55 (2012) 6948-6967.

[40] M.W. Vos, W.J. Stone, K.M. Koolen, G.J. van Gemert, B. van Schaijk, D. Leroy, R.W. Sauerwein, T. Bousema, K.J. Dechering, A semi-automated luminescence based standard membrane feeding assay identifies novel small molecules that inhibit transmission of malaria parasites by mosquitoes, Sci. Rep. 5 (2015) 18704.

[41] N. Basilico, M. Migotto, D.P. Ilboudo, D. Taramelli, R. Stradi, E. Pini, Modified quaternary ammonium salts as potential antimalarial agents, Bioorg. Med. Chem. 23 (2015) 4681-4687.

[42] M. Brindisi, S. Butini, S. Franceschini, S. Brogi, F. Trotta, S. Ros, A. Cagnotto, M. Salmona, A. Casagni, M. Andreassi, S. Saponara, B. Gorelli, P. Weikop, J.D. Mikkelsen, J. Scheel-Kruger, K. Sandager-Nielsen, E. Novellino, G. Campiani, S. Gemma, Targeting dopamine D and serotonin 5-HT and 5-HT receptors for developing effective antipsychotics: synthesis, biological characterization, and behavioral studies, J. Med. Chem. 26 (2014) 9575-9597.

[43] E.N. Prystowsky, The effects of slow channel blockers and beta blockers on atrioventricular nodal conduction, J. Clin. Pharmacol. 28 (1988) 6-21.

[44] A. Lee, K. Lee, D. Kim, Using reverse docking for target identification and its applications for drug discovery, Expert Opin. Drug Disc. 11 (2016) 707-715.

[45] S. Butini, M. Brindisi, S. Brogi, S. Maramai, E. Guarino, A. Panico, A. Saxena, V. Chauhan, R. Colombo, L. Verga, E. De Lorenzi, M. Bartolini, V. Andrisano, E. Novellino, G. Campiani, S. Gemma, Multifunctional cholinesterase and amyloid beta fibrillization modulators. Synthesis and biological investigation, ACS Med. Chem. Lett. 4 (2013) 1178-1182.

[46] Glide. version 6.6, Schrödinger, LLC, New York, NY, 2015

[47] L. Zaccagnini, S. Brogi, M. Brindisi, S. Gemma, G. Chemi, G. Legname, G. Campiani, S. Butini, Identification of novel fluorescent probes preventing PrPSc replication in prion diseases, Eur. J. Med. Chem. 127 (2017) 859-873.

[48] C.C. Maquiaveli, J.F. Lucon, S. Brogi, G. Campiani, S. Gemma, P.C. Vieira, E.R. Silva, Verbascoside inhibits promastigote growth and arginase activity of Leishmania amazonensis, J. Nat. Prod. 79 (2016) 1459-1463.

[49] Prime. version 3.9, Schrödinger, LLC, New York, NY, 2015.

[50] M. Brindisi, S. Gemma, S. Kunjir, L. Di Cerbo, S. Brogi, S. Parapini, S. D'Alessandro, D. Taramelli, A. Habluetzel, S. Tapanelli, S. Lamponi, E. Novellino, G. Campiani, S. Butini, Synthetic spirocyclic endoperoxides: new antimalarial scaffolds, Medchemcomm 6 (2015) 357-362.

[51] S. Giovani, M. Penzo, S. Brogi, M. Brindisi, S. Gemma, E. Novellino, M.J. Blackman, G. Campiani, S. Butini, Rational design of the first difluorostatone-based PfSUB1 inhibitors, Bioorg. Med. Chem. Lett. 24 (2014)
$3582-3586$

52] S.G. Lee, W. Haakenson, J.P. McCarter, D.J. Williams, M.C. Hresko, J.M. Jez, Thermodynamic evaluation of ligand binding in the plant-like phosphoethanolamine methyltransferases of the parasitic nematode Haemonchus contortus, J. Biol. Chem. 286 (2011) 38060-38068.

[53] S.G. Lee, Y. Kim, T.D. Alpert, A. Nagata, J.M. Jez, Structure and reaction mechanism of phosphoethanolamine methyltransferase from the malaria parasite Plasmodium falciparum: an antiparasitic drug target, J. Biol. Chem. 287 (2012) 1426-1434.

[54] G. Pessi, G. Kociubinski, C.B. Mamoun, A pathway for phosphatidylcholine biosynthesis in Plasmodium falciparum involving phosphoethanolamine methylation, Proc. Natl. Acad. Sci. U. S. A. 101 (2004) 6206-6211.

[55] FAFDrugs4. http://fafdrugs3.mti.univ-paris-diderot.fr.

[56] D. Lagorce, O. Sperandio, J.B. Baell, M.A. Miteva, B.O. Villoutreix, FAF-Drugs3: a web server for compound property calculation and chemical library design, Nucleic Acids Res. 43 (2015) W200-W207.

[57] P.C. Burda, M.A. Roelli, M. Schaffner, S.M. Khan, C.J. Janse, V.T. Heussler A Plasmodium phospholipase is involved in disruption of the liver stage parasitophorous vacuole membrane, PLoS Pathog. 11 (2015) e1004760.

[58] M. Prado, N. Eickel, M. De Niz, A. Heitmann, C. Agop-Nersesian, R. Wacker J. Schmuckli-Maurer, R. Caldelari, C.J. Janse, S.M. Khan, J. May, C.G. Meyer, V.T. Heussler, Long-term live imaging reveals cytosolic immune responses of host hepatocytes against Plasmodium infection and parasite escape mechanisms, Autophagy 11 (2015) 1561-1579.

[59] S. Saponara, A. Ferrara, B. Gorelli, A. Shah, M. Kawase, N. Motohashi, J. Molnar, G. Sgaragli, F. Fusi, 3,5-dibenzoyl-4-(3-phenoxyphenyl)-1,4-dihydro-2,6dimethylpyridine (DP7): a new multidrug resistance inhibitor devoid of effects on Langendorff-perfused rat heart, Eur. J. Pharmacol. 563 (2007) 160-163.

[60] A. Ferrara, F. Fusi, B. Gorelli, G. Sgaragli, S. Saponara, Effects of freeze-dried red wine on cardiac function and ECG of the Langendorff-perfused rat heart, Can. J. Physiol. Pharmacol. 92 (2014) 171-174.

[61] J. Kmecova, J. Klimas, Heart rate correction of the QT duration in rats, Eur. J. Pharmacol. 641 (2010) 187-192.

[62] F. Fusi, F. Manetti, M. Durante, G. Sgaragli, S. Saponara, The vasodilator papaverine stimulates L-type $\mathrm{Ca}(2+)$ current in rat tail artery myocytes via a PKA-dependent mechanism, Vascul. Pharmacol. (Basel) 76 (2016) 53-61.

[63] P. Mugnai, M. Durante, G. Sgaragli, S. Saponara, G. Paliuri, S. Bova, F. Fusi, Ltype $\mathrm{Ca}(2+)$ channel current characteristics are preserved in rat tail artery myocytes after one-day storage, Acta Physiol. 211 (2014) 334-345.

[64] F. Fusi, G. Sgaragli, M. Ha le, N.M. Cuong, S. Saponara, Mechanism of osthole inhibition of vascular Ca(v)1.2 current, Eur. J. Pharmacol. 680 (2012) 22-27. 